CC Copyright 2017

Shean Han Soh 
Cyclic Loading Effects on Craniofacial Strain and Sutural Growth in Pigs

\author{
Shean Han Soh
}

\author{
A thesis \\ submitted in partial fulfillment of the \\ requirements for the degree of \\ Master of Science in Dentistry
}

University of Washington

2017

Committee:

Susan W. Herring

Katherine Rafferty

Bryan J. Venema

Zee (Zi-Jun) Liu

Program Authorized to Offer Degree:

Orthodontics 


\title{
University of Washington
}

\begin{abstract}
Cyclic Loading Effects on Craniofacial Strain and Sutural Growth in Pigs
\end{abstract}

Shean Han Soh

Chair of the Supervisory Committee:

Professor Susan W. Herring

Orthodontics and Oral Health Sciences

Background: Current craniofacial growth modification devices utilize static forces to modulate sutural growth. Although effective, the application of continuous static forces over several months is not efficient. Evidence on the effects of these orthopedic forces on distant parts of the skull is also lacking.

Purpose: 1 . To develop a loading system capable of reliably delivering cyclic loads to the nasofrontal suture (NFS), 2. To explore strain transmission resulting from cyclic loading of the NFS both ex vivo and in vivo and 3. To characterize the effects of cyclic loading on sutural growth.

Methods: Tensile loads cycling at $2.5 \mathrm{~Hz}$ were applied to one NFS of abattoir pig heads $(\mathrm{n}=6)$ instrumented with strain gages. Similar loading was applied to 3-month old live pigs (Sus scrofa, $\mathrm{n}=4$ and 1 sham) 30 minutes/day for 5 days. Strains were recorded on day 5. Quantitative computerized histomorphometric analysis was performed to compare suture widths and mineral apposition rate (MAR) with controls. 
Results: The loading system proved capable of producing a consistent load output and, strains of desired frequency, magnitude and polarity at the loaded NFS. Ex vivo, only the loaded NFS showed significant tensile strain $(+898 \mu \varepsilon)$ while the non-loaded NFS experienced smaller tensile strain $(+660 \mu \varepsilon)$. Internasal sutures experienced strain magnitudes $<200 \mu \varepsilon$ of varying polarity. Generally small $(<100 \mu \varepsilon)$ tensile and compressive strains were registered at the interfrontal and coronal sutures respectively. Nasal and frontal bone principal strains were also low $(<100 \mu \varepsilon)$. In vivo, live pigs showed a much higher NFS strain $(+1543 \mu \varepsilon)$ and notable coronal suture strain ($764 \mu \varepsilon)$. Preliminary evidence indicates cyclic loading increased MAR $(33 \mu \mathrm{m} /$ day in $\mathrm{n}=2$ loaded vs $11 \mu \mathrm{m} /$ day in $\mathrm{n}=5$ control $)$ and suture width $(355 \mu \mathrm{m}$ vs $184 \mu \mathrm{m})$ of the targeted NFS, suggesting increased suture growth.

Conclusions: Daily spurts of cyclic load increased strain transmission in the skull, perhaps by loosening the sutures. The regime likely has a positive effect on suture growth and may be therapeutically useful. 


\section{Table of Contents}

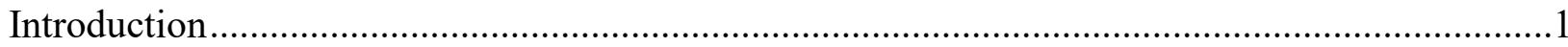

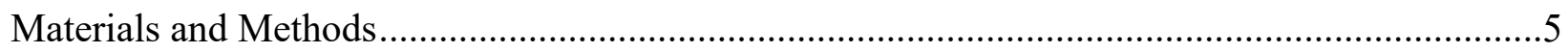

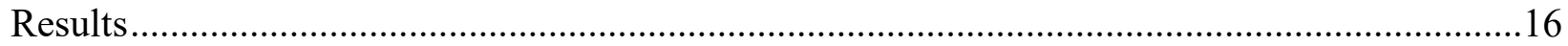

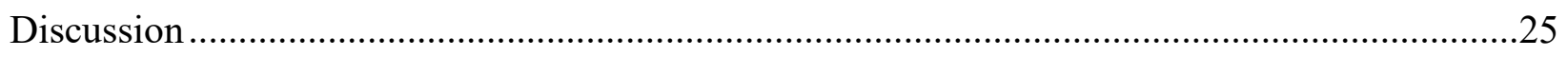

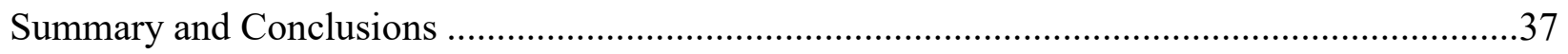

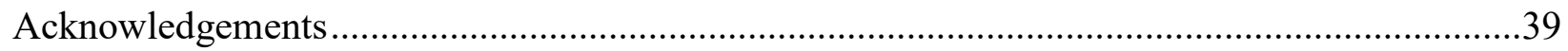

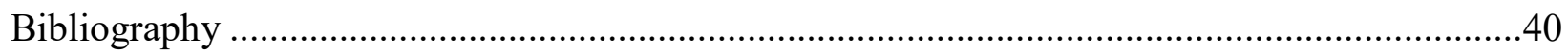

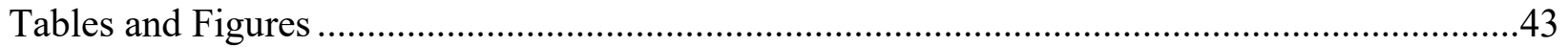




\section{$\underline{\text { Introduction }}$}

Cranial sutures must be patent to allow cranial bones to lengthen by intramembranous bone apposition (Opperman 2000). Unfortunately, in multiple syndromes and craniofacial deformities, there is early fusion of these cranial and facial sutures. Underdevelopment of certain facial structures due to early sutural fusion can lead to severe deformities with impairment in feeding, respiration and esthetics. Mechanical modulation of sutural growth is hence important in craniofacial orthopedics as a less invasive treatment modality. However, current growth modification devices in dentofacial orthopedics only utilize static forces to modulate sutural growth (Kopher and Mao 2003). Unfortunately, although static forces are shown to be effective, the application of continuous mechanical forces over several months is not time-efficient, hence sustained static mechanical forces are not the optimal stimulus for sutural growth (Mao 2002).

\section{$\underline{\text { In vivo Studies on Static or Quasi-Static Strains }}$}

The effect of static or quasi-static loading on sutural growth is well established. Static compressive loads via high-pull headgears in prepubertal Macaca mulatta monkeys prevented or redirected the normal downward and forward displacement of the upper facial bones and the maxillary dental arches (Meldrum 1975). On the contrary, static tensile forces via reverse-pull headgears in Macaca nemestrina monkeys produced anterior maxillary displacement with compensatory bone deposition and resorption at the sutural margins (Jackson et al., 1979). Expansion appliances applying static tensile loads on endosseous implants in the midface of rabbits increased mineral apposition and bone formation rates at the sutural surfaces (Parr et al., 1997). Maxillary distraction osteogenesis in rats, through static tensile forces, also led to greater nasomaxillary growth and forward displacement with new bone formation (Sasaki et al., 2002). 
In humans, although application of static forces via distraction osteogenesis has successfully restored function and esthetics (Capote-Morenzo et al., 2013) in patients with craniofacial deformities, some published studies have reported early (Al-Daghreer et al., 2008) and late (Marchac and Arnaud 2012) relapse.

\section{$\underline{\text { In vivo Studies on Cyclic Strains }}$}

In recent years, there has been a shift in the published literature towards investigation of the effects of cyclic loading on sutural growth. In 2 parallel studies, cyclic forces were applied to the rabbit's premaxillomaxillary suture (PMS) and nasofrontal suture (NFS) via indirect loading through the maxillary incisors. It was concluded that cyclic loading induced greater sutural width and more osteogenesis than static loading (Kopher and Mao 2003). It was also suggested that cyclic strain, regardless of its polarity (compressive or tensile), increased sutural widths and sutural cell densities (Peptan et al., 2008). A separate study on cyclic compressive forces applied to the maxillae of 17-, 23-, and 32-day old rats also showed an increase in sutural widths and sutural cell densities of the PMS and NFS (Vij and Mao 2006).

The results of these earlier experiments suggest that cyclic forces may be more effective than static forces in stimulating sutural growth. Unfortunately, the small animal models (rat and rabbit) used in these in vivo studies may not be good mimics of the skeletal biology of larger mammals such as humans.

A problem with both static and cyclic loading studies to date is the absence of information on transmission of applied forces through the skull. Such forces could potentially affect the growth 
of other parts of the skull and neighboring sutures. Thus, the effects of suture loading on global strain distribution and growth of the entire craniofacial region remain unknown.

Given the limitations of current published literature, this pilot study develops a pig model to investigate how cyclic loading of the nasofrontal suture (NFS) affects strain distribution and growth at multiple sutures in the midface and cranium. The pig (Sus scrofa domesticus) was chosen as it has an adult skull size comparable with that of a human and has similar patterns of embryology and ossification (reviewed by Courtemanche et al., 1992). Pigs also resemble humans more than any other non-primate animal because of their bunodont, low-cusped dentition, omnivorous diet and vertical occlusal orientation and stroke (Ciochon et al., 1997). In addition, physiological suture and bone strains, masticatory activity, sutural morphology and growth (Rafferty and Herring 1999) are uniquely well known for this species (Herring \& Teng 2000, Sun et al., 2004), thus providing a basis for comparison. This species also undergoes rapid and significant skull growth over a short time span. The period of most rapid longitudinal growth of the pigs' snouts has occurred by 180 days of age (reviewed by Watzek et al., 1982), making it a scientifically justifiable option for short-duration studies on growth. The nasofrontal suture (NFS) was chosen because it links the nasal complex to the cranium (Popowics and Herring 2007) and, mineralizing at $20 \mu \mathrm{m} /$ day (Rafferty and Herring 1999), it has a major contribution to midfacial length in normal minipigs. It has been shown to be affected in syndromic craniosynostosis, both human and murine (Purushothaman et al., 2011). Importantly, the NFS is also affected in certain breeds of pigs with midfacial hypoplasia. Successful stimulation of the growth of normal pig sutures would imply that the technique could be applied on hypoplastic 
animals to explore if abnormal sutures can be rescued. These data may have eventual therapeutic implications in craniofacial orthopedics.

Hence the aims of this pilot study are:

1. To test and validate a custom-engineered cyclic loading system using pig heads by:

a. Corroborating the ability of the device to deliver loads accurately according to programmed specifications

b. Identifying skull attachments of optimal dimensions and physical properties for retention and reliable load transmission

c. Characterizing the effects of direct cyclic loading of the NFS on strains at multiple sutures and bones in the midface and cranium

2. To employ cyclic tension on live animals in order:

a. To characterize the effects of in vivo unilateral cyclic loading of the NFS on strains at multiple sutures in the midface and cranium

b. To elicit the in vivo effects of cyclic loading on sutural widths and mineral apposition rate (MAR) of multiple craniofacial sutures in young live domestic pigs. This study tests the hypotheses that cyclic loading will widen the sutures and increase their mineral apposition rate compared to sham controls. 


\section{Materials and Methods}

\section{Development and Testing of the Loading System}

Loading was applied by a custom-engineered loading device based on a voice coil (Figures 1A1C), approximately $420 \mathrm{~g}$ in weight and $14 \mathrm{~cm}$ (when fully extended) $\mathrm{x} 4 \mathrm{~cm} \times 6.3 \mathrm{~cm}$ in dimensions. The device was positioned superior to the nasofrontal suture along the mid-sagittal axis of the skull. Two vertically extended plates were fitted with holes and screws that engaged the loading attachments on the skull. The horizontal distance between the plates was adjustable to maintain alignment with the loading attachments. To accommodate a wider range of interattachment distances, extra screw-holes were incorporated in one of the plates. To mitigate overheating of the loading device, which reduced load output, wet gauze was placed on the voice coil and a fan was used throughout the loading session.

To calibrate the loading device, weights were increasingly added to an attachment on the loading device up to a total mass of $6.85 \mathrm{Kg}$. The weights were then removed in the reverse order. This process was performed three times, giving six different sets of voltage values (waveform data) corresponding to the effect of adding or removing each weight. The mean of the 6 voltage values corresponding to the addition/removal of each weight was calculated and a graph comparing load $(\mathrm{Kg})$ and voltage (V) was plotted. This gave a linear graph (Figure 2) with a high correlation value of $\mathrm{R}^{2}=0.9999$. This equation was used for converting output voltage into load in kilograms.

The nasofrontal suture (NFS) was targeted for unilateral loading. The strain at this suture during mastication is compressive, averaging about $-1600 \mu \varepsilon$ (Rafferty and Herring, 1999). To provide 
sufficient contrast with physiological strain, the imposed cyclic strain was tensile, with a planned magnitude of $800-1000 \mu \varepsilon$. The intent of the applied loading was to provide a mechanical signal strong enough to provide a growth stimulus without causing structural damage. The criteria for successful performance were production of sine-wave tensile strain of 2-3 Hz frequency and a magnitude of at least $800 \mu \varepsilon$ at the targeted NFS. The criteria also included no disengagement of the loading device nor breakage, dislodgement or movement of the loading attachments, and no indication of impingement on or damage to neighboring structures, such as fractures in the surrounding bone. These post-loading changes were assessed using visual and tactile means. The loading attachments and device were modified until they performed to satisfaction.

Procedures to develop the protocol were carried out on one skull and four pig heads of varying age and provenance (Table 1). Pilot holes were made before the screws were placed. Initially, one stainless steel screw on each side of the targeted NFS was used as the loading attachment (Figure 3A). However, these screws lacked adequate retention and were changed to stainless steel loading plates with a central loading post which engaged the loading device (Figures 3A, 3B). These plates, each supported by two stainless steel screws, were placed singly on each side of the targeted NFS. Extended loading (via five 30-minute loading sessions) of these plate attachments was performed on 2 pig heads (\#4 and \#10, Table 1) with concurrent recording of strain transmission through the skull in \#10, to evaluate attachment stability.

The skull and heads \#1-4 were instrumented with strain gages over both the loaded and the contralateral NFS. Single-element strain gages (EP-08-125BT-120, Micro-Measurements, Vishay Precision Group) had been previously coated with insulation (double M-Coat A followed 
by double M-Coat D, Micro-Measurements, Wendell, NC). The nasofrontal sutures were exposed bilaterally, and periosteum, if present, was removed. The sites were smoothed with sandpaper, dried with acetone and prepared using the Micro-Measurements BAK-200 Basic Application Kit before the strain gages were affixed to the gage sites with cyanoacrylate glue. Gages were placed perpendicular to and across the nasofrontal sutures (Figure 3A). The lead wires from the strain gages were connected to the strain conditioner/amplifiers (Model 2110, Measurements Group, Instruments Division, Raleigh, NC), which were connected to a computer for data acquisition. Strain information was collected at intervals throughout the loading session and digitized using the BIOPAC MP150 system and Acqknowledge 3.9 software (BIOPAC Systems, Inc.). Analysis of strain data was accomplished by transferring waveform data in voltage (from the Acqknowledge software) into Microsoft Excel where they were converted to microstrain. Magnitude of the strain was obtained by subtracting baseline values from the peak values, while frequency of the strain was calculated by number of peaks per second. These measurements showed whether the NFS had been strained as planned (+800 to $+1000 \mu \varepsilon$ amplitude and 2-3 Hz frequency).

The dry skull (\#0, Table 1) produced a strain magnitude of only $+108 \mu \varepsilon$ at the loaded NFS, which was far below the target of $+800 \mu \varepsilon$. Therefore, instrumenting dry skulls was considered unrepresentative of in vivo response and was abandoned. However preliminary loading on the dry skull was helpful in indicating that the loading device should not contact the skull, nor should it be too distant, to avoid friction and torqueing of the attachments respectively. In addition, the loading device should be oriented parallel to the mid-sagittal plane (perpendicular 
to the NFS) to produce the highest strains at the NFS. However, the direction of the voice coil (anterior vs posterior) had no significant bearing on the magnitude of strain recorded.

Wet heads \#1-4 were used to establish the power level necessary to achieve the targeted strain (800 tensile $\mu \varepsilon, 2-3 \mathrm{~Hz}$ ) at the NFS. These yielded varied strain magnitudes (range 187-2161 $\mu \varepsilon$, average $1009 \mu \varepsilon$, Table 1), but all showed approximate sine wave patterns matching the load output frequency (usually $2.5 \mathrm{~Hz}$ ), and all showed increased strain as power amplitude was raised from setting 1 to setting 10 on the loading device. However, most specimens showed strain levels plateauing at settings 6-7 (Figure 4). Therefore, amplitude was set at 6 for subsequent trials.

Ex vivo Study of Strain Transmission through the Skull

Pig heads \#5-10 were from freshly slaughtered pigs (Kapowsin Meats Inc., an abattoir in Graham, WA), and were used to study the transmission of strain through the skull. Sex was unknown, and age was estimated at approximately 6 months.

One 2-screw plate attachment was placed on each side of the right NFS. The anatomical variation in the dorsal surface of the cranium was important in determining the precise location of the loading attachments as irregularities in the surface had to be avoided for maximum stability of the attachments and parallelism of the posts was necessary to engage the loading device. Strain gages were prepared and placed on the NFS bilaterally as before. Additional single-element strain gages were placed on the left and right coronal sutures, the internasal suture (INS) and the interfrontal suture (IFS). Further two three-element $45^{\circ}$ stacked rosette gages 
(WA-13-060WR-120, Micro-Measurements, Vishay Precision Group) were placed, one on the nasal bone and another on the frontal bone (Figure 5), with the middle element perpendicular to the mid-sagittal plane (Figure 6). The nasal rosette gage was placed anterior-lateral to the nasal loading attachment and the frontal rosette gage was placed posterior-lateral to the frontal loading attachment. Recording was conducted for 30 minutes. Pig head \#10 was subjected to extended loading (five 30-min sessions) to verify that the apparatus would not fail under fatigue conditions. Averages of 20 waveforms were used to determine the mean load output and strains for the beginning, middle, and final minutes of the session. In cases where there was a lag between the waveforms of the strain and load output, the true peaks and baselines of the strain waveforms were used for strain analysis.

For successful recordings, strains from each element of the rosette gages were used to calculate magnitude and orientation of tensile (maximum) and compressive (minimum) principal strains on the bones according to the manufacturer's instructions (Micro-Measurements, Vishay Precision Group). By convention, tensile strains were expressed as positive values and compressive strains as negative values. Descriptive statistics were calculated.

\section{In vivo Study of the Bone and Suture Response to Cyclic Loading of the Nasofrontal Suture}

As a pilot study to assess whether the protocol could be carried out on live animals and whether it would stimulate sutural growth, surgical implantation of loading attachments was carried out on five (four male, one female) Landrace mixed breed pigs (Sus scrofa) approximately 3 months old (Progressive Swine Farms, Woodinville, WA). All experimental procedures were approved by the University of Washington Institutional Animal Care and Use Committee. Animals (Table 
2) were acclimated for approximately 1 week after arriving at the facility to ensure that they were rested and healthy prior to surgery.

Pigs 1 and 2 received the same type of skull attachments as had been used in the ex vivo pig head study (Figure 3B) but because these became loose, the design was changed for Pigs 3-5. The new design (Figure 7) featured a custom titanium plate with 4 flanges, each stabilized by 2 stainless steel cortex self-tapping $2 \mathrm{~mm}$ screws (SYNTHES Vet). The titanium plate could be contoured to the natural curvature of the bone while the longer titanium central post facilitated engagement of the loading device in the presence of peri-implant swelling. The post was made wider to compensate for the increased flexibility of titanium and the loading device was modified accordingly to accommodate the posts. In trials using dry skulls from the ex vivo study, the modified attachments produced load output comparable to the original attachments, with no signs of damage to the bones.

Surgery was carried out under aseptic conditions. Food was restricted (no water restriction) 6-8 hours prior to the surgery. Anesthesia was induced with a cocktail consisting of midazolam (5 $\mathrm{mg} / \mathrm{ml})$, xylazine $(100 \mathrm{mg} / \mathrm{ml})$, and butorphanol $(10 \mathrm{mg} / \mathrm{ml})$ delivered intramuscularly and maintained with isoflurane inhalation. Prior to making the incisions in Pigs 3-5, a local anesthetic block of bupivacaine (1-2 $\mathrm{mg} / \mathrm{Kg})$ and/or lidocaine $(1-4 \mathrm{mg} / \mathrm{Kg})$ was administered subcutaneously at the incision sites to minimize local irritation. The skin of the forehead and dorsal snout was shaved and cleaned. Two separate arcuate incisions were made unilaterally on the right frontal and nasal bones. The NFS was not exposed. Flaps were raised with the periosteum left intact. Pilot holes for the screws were made and the loading attachments were 
placed. The incisions were closed with interrupted sutures so that the loading posts projected from the skin. To reduce the risk of peri-implant infection, releasing incisions were made in Pigs 3-5 where the loading posts protruded from the skin and then sutured close, to facilitate tighter primary closure of the surgical sites around the posts. The closed incisions were treated with betadine and left uncovered in Pigs 1-2, but in Pigs 3-5, a Tegaderm bandage was placed over the incisions (with the posts protruding through the bandage). In Pig 5, an antibiotic gel, ClinzGard NS (clindamycin hydrochloride 1\%), was also injected over the loading attachments and screws, and Lidocaine and Marcaine were applied on edges of the closed incisions. Betadine, Tegaderm and ClinzGard NS were later reapplied as needed.

Lateral headfilms were taken immediately post-surgery to document the position of the loading attachments. An antibiotic (ceftiofur, Excede formulation, $5 \mathrm{mg} / \mathrm{Kg}$ ) was delivered $\mathrm{IM}$ on the day of the surgery and again 4-7 days later if indicated. Carprofen and buprenorphine were administered and a fentanyl patch placed on the day of the surgery. Carprofen was continued for 5 days post-surgery (twice per day). The animals were monitored post-surgically for signs of lethargy, averse behavior, loss of appetite and infection/irritation of the surgical sites. In the presence of infection, additional medications were administered upon recommendation by the veterinary staff.

After 1 week of healing, cyclic loading sessions began. Pig 2 had loose attachments and was considered a sham control. Daily for 5 consecutive days, the pigs were anesthetized as described previously, placed in a prone position, and the custom-engineered loading device was engaged to the loading attachments. Loading was conducted for approximately 30 minutes per day, at $2.5 \mathrm{~Hz}$ 
and an amplitude setting of 6 . In the sham control (Pig 2), the loading device was engaged but no loads were applied. Upon recovery from anesthesia, the pigs were returned to their pens.

Fluorochrome labels of mineral apposition were administered IV on days 1 (calcein, SIGMA; $12.5 \mathrm{mg} / \mathrm{Kg}$ in sterile saline) and 3 (alizarin complexone, SIGMA; $12.5 \mathrm{mg} / \mathrm{Kg}$ in sterile saline) of loading. Solutions were filtered (with $0.22 \mu \mathrm{m}$ Millex Syringe-driven Filter Unit) prior to IV administration.

The mechanical environment resulting from loading was assessed via strain gages on the final $\left(5^{\text {th }}\right)$ day of loading. The pigs were anesthetized as usual. Soft tissue incisions were made and periosteal flaps elevated to expose the nasofrontal, internasal, interfrontal and coronal sutures. Bleeding tissues were cauterized as needed. The strain gage sites were prepared and strain gages were affixed as in the ex vivo study. No strain gages were placed on the unloaded sham control. Because bone strain levels recorded in the ex vivo experiments had been very low, nasal and frontal bone rosette gages were not placed in Pigs 1 or 3. However, as large right coronal suture strains were recorded in Pig 3, stacked rosette gages were placed on the parietal bone of Pig 4 (Figure 8A) and frontal bone of Pig 5 (anterior-lateral to the IFS gage). We were unable to place the rosette gage on the frontal bone in Pig 4 due to the lack of space.

Load output and strain data were collected as for the ex vivo study, at a sampling rate of $500 \mathrm{~Hz}$ at the initial, middle and final stages of the 30-minute loading sessions. Data were measured by a single investigator (S.H.S.) and expressed as mean \pm standard deviation. 
After collection of strain data during the final loading session, the animals were injected with heparin intravenously (IV) and euthanized with IV pentobarbital (Beuthanasia-D Special [390 mg pentobarbital sodium and $50 \mathrm{mg}$ phenytoin sodium per ml], Schering-Plough Animal Health). This was followed by perfusion through the ascending aorta with approximately 4 liters of saline followed by approximately 4 liters of $20 \%$ glyoxal fixative (Prefer Concentrate, Anatech Ltd., diluted with reagent alcohol and deionized water). Final lateral x-rays were taken to assess the positions of the loading attachments.

\section{$\underline{\text { Histological analysis }}$}

Each instrumented suture was removed en bloc from Pigs 1-5 (Table 2) with at least approximately $5 \mathrm{~mm}$ of surrounding tissue and separated into 2 blocks, one to remain undecalcified (plastic-embedded) for assessment of sutural width and mineral apposition, and one decalcified and paraffin-embedded for future immunohistochemistry (Figure 8B). Sutural tissues were stored in $70 \%$ ethanol.

In addition to the experimental pigs (Pigs 1-5), one randomly chosen nasofrontal suture was removed from each of four additional pigs (Pigs 6-9, histological controls, Table 2) of comparable breed mix. These animals had been used in an unrelated study involving tooth mobility and periodontal disease and had received bone labels on a slightly different schedule than Pigs 1-5 (Table 2). Pigs 6-8 were 1-2 months older than Pigs 1-5 and Pig 9.

The undecalcified samples were immersed in a mixture of $4 \%$ formaldehyde, $1 \%$ glutaraldehyde in $0.1 \mathrm{M}$ sodium cacodylate buffer $(\mathrm{pH} 7.4$, prepared from $0.2 \mathrm{M}$ sodium cacodylate buffer, 
Electron Microscopy Sciences, Hatfield, PA). This was followed by thorough washing (thrice) in $0.2 \mathrm{M}$ sodium cacodylate buffer, dehydration in a graded ethanol series $(70 \%, 90 \%, 100 \%)$, and infiltration with 3 changes of 100\% Micro-bed resin (Electron Microscopy Sciences, Hatfield, PA). Finally, the samples were infiltrated with fresh resin overnight. The samples then underwent a curing process in a thermal oven set at $35-36^{\circ} \mathrm{C}$.

After curing (approximately 21 days), the samples were sectioned perpendicular to the sutures at $50 \mu \mathrm{m}$ intervals using a saw microtome (Leica SP1600). Sections were mounted on slides with Cytoseal 60 (catalogue no. 8310-4, Richard-Allan Scientific, Thermo Fisher Scientific Inc) as mounting medium.

1-3 sections were selected per suture on the basis of clarity and completeness. These sections were examined under epifluorescent illumination (Nikon Eclipse E400; Nikon Y-FL, Japan) for measurement of the average sutural width and mineral apposition at the bone fronts. As calcein fluoresces green and alizarin complexone fluoresces red, the same microscopic field was separately captured under green and red fluorescent light using a digital camera (SPOT RT3 2Mp Slider, Diagnostic Instruments, Inc, Sterling Heights, MI) under similar magnification. The two images were then merged to give image files with double fluorescent labels via the MetaVue software. A series of overlapping images of parts of the sutures was digitally captured and constructed into a montage of the entire suture in Adobe Photoshop (Figure 9A). Histomorphometric analysis was performed with MetaMorph software and linear calibrations were used for all images. Calculation of suture width was accomplished by tracing the sutural margins and dividing the area between them over the average length of the two sutural margins 
(Figures 9B, 10B). Calculation of mineral apposition rate (MAR) was accomplished by tracing the area between the calcein and alizarin bone fronts and dividing it by the average suture length (Figures 9C, 10C). This was done separately on each side of the suture. The measurement was divided by the number of days between labels (2) to give MAR in $\mu \mathrm{m} /$ day. MAR values from the two sides of a suture were averaged to give the mean MAR. In samples in which a continuously patent suture space from the ectocranial to the endocranial surface could not be visualized (due to incompleteness or folding of the section, or possibly due to partial fusion of the suture), only parts of the suture which could be identified with certainty were included in the measurements. Data were expressed as mean \pm standard deviation. Selection of slides and measurements were all made by a single investigator (B.L.), who was blinded to the treatment (loading or sham) and suture identity. Intra-examiner reliability was determined by re-measurement of 5 randomly selected samples by the same examiner. 


\section{$\underline{\text { Results }}$}

\section{$\underline{\text { Ex vivo Study on Transmission of Strain in Pig Heads (\#5-10) }}$}

Throughout the 30-minute loading sessions and even with extended loading in head \#10, the 2screw loading attachments remained intact and stable with no visible fracture of the skull bones nor disengagement of the loading device. On average, the loading device produced a consistent load output of $1.55 \mathrm{Kg}$ with a small standard deviation of $0.1 \mathrm{Kg}$. However, except for \#10, within each 30-minute session the load output dropped from a high in the first minute $(1.71 \pm$ $0.03 \mathrm{Kg})$ to a low in the last minute $(1.50 \pm 0.09 \mathrm{Kg})$. The reduction between the $1^{\text {st }}$ and $15^{\text {th }} \min$ was always greater than the reduction between the $15^{\text {th }}$ and $30^{\text {th }}$ min (Table 3 ). Similarly, although bone and suture strains were relatively stable in orientation, they tended to reduce in magnitude during the session. This was particularly true for the loaded NFS which showed an average reduction of $230 \mu \varepsilon$ as load decreased. Notably, however, the extended loading (5 sessions separated by breaks of 0-35 minutes) of \#10 (Table 4) indicated that a break of 15 minutes was sufficient to return load output and NFS strain to original or even higher levels.

Quantitative results of loading are displayed in Tables 3-5. Figure 11 provides a visual overview of the strains in each skull while Figure 12 gives a diagrammatic summary of the mean strains observed across pig heads \#5-10. Strains of approximately $2.5 \mathrm{~Hz}$ frequency, usually synchronous with the power output, were consistently registered at most working gage locations. However, strain levels were quite different at the various locations.

Predictably, the highest level of strain was seen in the loaded right nasofrontal suture. Average tensile strain magnitudes were $+898 \pm 233 \mu \varepsilon$, ranging from +600 to $+1490 \mu \varepsilon$. The contralateral 
(left) nasofrontal suture also showed substantial, but less tensile strain, averaging $+660 \pm 205 \mu \varepsilon$ and ranging from +440 to $+1230 \mu \varepsilon$ (Table 3 ). The outlying high value, from head $\# 9$, was also unusual in that the loaded and the contralateral nasofrontal sutures had comparable magnitudes. In the other specimens, contralateral NFS strain ranged from 54\%-90\% of loaded NFS strain (calculated from Table 5).

In contrast to the induced tensile strain at the nasofrontal sutures, the coronal sutures experienced compressive strain, but magnitudes were very low, averaging $-47 \pm 30 \mu \varepsilon$ on the loaded (right) side (range 0 to $-90 \mu \varepsilon$, Table 3 ) and $-17 \pm 16 \mu \varepsilon$ on the contralateral (left) side (range +6 to -45 $\mu \varepsilon$, Table 3).

The two mid-sagittal sutures, internasal and interfrontal, were much less consistent among specimens. The internasal suture showed tensile and compressive strains in an equal number of pig heads (Table 5, Figure 11). Strains ranged from -210 to $+230 \mu \varepsilon$ (Table 3). The largest compressive strain was seen in $\# 9$, the same specimen that showed anomalous equality of strain in the loaded and contralateral nasofrontal sutures. The largest tensile strain was seen in \#7, which also showed relatively high contralateral NFS strain ( $90 \%$ of the loaded side). The interfrontal suture was in tension during loading, with a single exception $(\# 10,-85 \mu \varepsilon)$. The tensile strain was very low in all the remaining 5 specimens except for the anomalous head $\# 9$, in which the interfrontal suture reported $+213 \mu \varepsilon$ strain.

The 3-element rosette gages on the nasal and frontal bones were less successful than the sutural gages. Recordings from all three elements (allowing calculation of principal strain magnitude 
and orientation) were only achieved for 3 nasal bones (heads \#6, 9, 10) and 2 frontal bones (heads \#6 and 10). Principal strains were calculated for these 5 rosette recordings (the nasal bone recordings for $\# 10$ are from the $4^{\text {th }}$ loading session because the gages were not working in the $1^{\text {st }}$ session). For the remaining rosette gages, only one or two of the elements reliably reported strain. Values from the working channels of failed rosettes are shown as thin arrows in Figure 11; their orientation corresponds to the orientation of the gage element, not the orientation of principal strain, which is unknown.

In both the nasal and the frontal bones, strain magnitudes were low, with absolute values for principal strain ranging from 15 to $96 \mu \varepsilon$ (Table 3) and shear strain (sum of maximum and minimum strain) ranging from 49 to $140 \mu \varepsilon$ (Table 3).

For the nasal bone, both head \#6 and head \#10 demonstrated a tensile axis that ran antero-medial to postero-lateral, at angles $64^{\circ}$ and $57^{\circ}$ to the sagittal axis respectively (Figure 11). The three heads with incomplete rosette data showed similarities with this strain pattern in the working elements. Pig head \#9, however, was again anomalous in having the nasal bone strain with the tensile axis oriented at $128^{\circ}$ to the sagittal plane, antero-lateral to postero-medial. All three specimens showed a predominance of tension, with maximum principal strain exceeding the absolute value of minimum principal strain by $1.5-2 \mathrm{x}$.

The two specimens with complete frontal bone rosette data $(\# 6,10)$ gave similar results. Maximum principal (tensile) strain was roughly perpendicular to the sagittal axis but angled slightly postero-medially $\left(94^{\circ}\right.$ and $111^{\circ}$ respectively) (Figure 11$)$. The minimum (compressive) 
principal strain was approximately twice the magnitude of the tensile principal strain in both cases. Partial rosette data from the other heads showed similarities with this pattern, with the possible exception of \#8. Head \#8 had only one working element, which recorded very low compressive strain perpendicular to the sagittal plane. Thus, its difference from the other specimens is most likely an artifact resulting from poor gage attachment.

In summary, the results of the ex vivo study showed that the NFS was loaded as planned in strong tension and that the contralateral NFS experienced somewhat lesser tensile strain. The coronal sutures were slightly compressed, whereas the interfrontal suture typically evinced low levels of tension. The internasal suture showed strain that varied individually both in magnitude and in polarity. The frontal bone showed a strain pattern generally consistent with sagittal compression, whereas nasal bone showed an off-axis pattern in which tension predominated.

\section{In vivo Study of the Effect of Cyclic Loading on the Skull}

The pigs did not appear inconvenienced by the loading attachments and feeding behavior continued to be enthusiastic. However, the nasal implant in particular was in a position to be bumped as a consequence of normal investigative rooting by the animals. As explained under Methods, loosening of the 2-screw plate stainless steel loading attachments in Pigs 1 and 2 was accompanied by infection of the surgical sites and peri-implant swelling made engagement of loading posts difficult. No attempt was made to load Pig 2, which was considered a sham. Pig 1 did receive some loading initially, but by day 5 , the attachments were too loose to enable strain to be recorded. It is therefore unknown to what extent Pig 1 underwent cyclic loading. The 8screw plate titanium loading attachments for Pigs 3-5 were far more stable, although the nasal 
attachment in Pig 4 was loose, especially by day 5 (although still permitting loading and strain recording). Both Pigs 4 and 5 had angled nasal attachments and one screw hole of the nasal loading plate was not over bone in Pig 4.

There were several indications of normal growth in the in vivo sample, including thickening of the frontal bone periosteum around the attachments in Pigs 1 and 2 and periosteal apposition in Pigs 3-5. Between the survival and terminal surgeries, the inter-post distances increased approximately by $3 \mathrm{~mm}$ in Pig 3 and $4 \mathrm{~mm}$ in Pigs 4-5, indicative of sutural stretching or, more likely, growth, because the suture itself was not visibly open.

In Pig 1, the initial load output from days 1 to 4 , ranging from $0.4-1.1 \mathrm{Kg}$, was clearly lower than the load in the ex vivo study $(1.55 \pm 0.10 \mathrm{Kg})$ and declined precipitously over the course of each loading session (Table 6). The recorded load output on day 5 more closely approximated the load output in the ex vivo study, because raising the skin flaps enabled the loading device to engage the posts better. Nevertheless, despite the similar load output, sutural strains were negligible (Table 7), presumably because of the looseness of the attachments. As loading was not conducted for Pig 2, no strain data were collected.

In Pigs 3-5, the mean load output $(1.65 \mathrm{Kg})$ closely approximated the ex vivo study. Pig 4 had a relatively low mean load output $(1.30 \mathrm{Kg})$ due to the loose nasal attachment, while a distinctly larger load output was recorded in Pig $5(2.14 \mathrm{Kg})$. As in the ex vivo study, there was a mild tendency for load output and strain magnitude to reduce throughout the loading session, especially at the bilateral NFS and the ipsilateral coronal suture. The largest reduction in NFS 
strain took place between the initial and middle stages of loading, similar to ex vivo findings. Strain polarity remained consistent during sessions.

The strains recorded for Pigs 3-5 on day 5 of loading are displayed in Tables 7-8. All locations showed cyclic strains of approximately $2.5 \mathrm{~Hz}$ corresponding with the sine-wave pattern of the load.

Tensile strain magnitudes at the loaded NFS averaged $+1543 \pm 636 \mu \varepsilon$. Even with the loose nasal attachment in Pig 4, the mean loaded NFS strain exceeded the minimum target of $+800 \mu \varepsilon$, and Pigs 3 and 5 had values greater than +1500 and $+2100 \mu \varepsilon$ respectively. Notably, in Pig 5, only the first minute was recordable, because a gradual increase in baseline strain (i.e., suture stretching) brought the strain gage beyond its range. On the contralateral side, NFS strains averaged $+814 \pm 353 \mu \varepsilon$, or about $53 \%$ of the loaded NFS strain magnitude. Pigs 3 and 5 had contralateral strain magnitudes above $800 \mu \varepsilon$ throughout the entire loading session, whereas Pig 4 ranged from +290 to $+610 \mu \varepsilon$, presumably due to the loose nasal attachment.

The coronal suture on the loaded right side showed unexpectedly large compressive strain, averaging $-764 \pm 386 \mu \varepsilon$. Even the low value of $-338 \mu \varepsilon$ in Pig 4 (Table 8) greatly exceeded the range of 0 to $-80 \mu \varepsilon$ seen in the ex vivo heads (Table 5), yielding a statistically significant difference between in vivo and ex vivo $(\mathrm{p}=0.0238$, Mann-Whitney $\mathrm{U}$ test $)$. However, strain at the contralateral coronal suture was remarkable only for its inconsistency, with tensile strain observed in Pigs 3 and 4 ( +54 and $+113 \mu \varepsilon$ respectively) and compressive strain in Pig 5 (-265 $\mu \varepsilon)$. The magnitude of the strains recorded in vivo (144 $\pm 108 \mu \varepsilon$ if polarity is ignored) was 
distinctly higher $(\mathrm{p}=0.0119$, Mann-Whitney $\mathrm{U}$ test $)$ than the mean strain recorded ex vivo $(17 \pm$ $16 \mu \varepsilon)$. Although a lower load output was recorded in Pig 4, the magnitude of the contralateral coronal strain was higher in Pig 4 than Pig 3. Examination of the waveform of Pig 3 revealed noise during the initial stages of recording, suggesting a compromised gage, and the gage failed during the session, so the low strains were probably artefactual.

As in the ex vivo study, the internasal suture strains showed individual variation in magnitude and inconsistent polarity. Pigs 4 and 5 registered tensile strain while Pig 3 registered compressive strain. Only Pig 5 showed strain magnitude $(+251 \mu \varepsilon)$ outside of the ex vivo range $(-192$ to $+190 \mu \varepsilon)$.

Interfrontal suture strains were uniformly tensile, as were most in the ex vivo study. Although strain magnitudes were generally higher than in the ex vivo heads, both samples were variable and the difference was not statistically significant $(\mathrm{p}=0.0952$, Mann-Whitney $U$ test $)$. However, the relatively low values in Pigs 4 and $5(+115$ and $+109 \mu \varepsilon$ respectively) were probably underestimates, Pig 4 because of the loose attachment and Pig 5 because the waveform was strongly truncated due to a malfunction.

The rosette gage recordings from cranial bones were unsuccessful. The rosette gage on the parietal bone in Pig 4 yielded no data, and that on the frontal bone of Pig 5 had only two working elements, so principal strains could not be calculated. The strains observed from these two elements were generally consistent with those seen in the ex vivo study (compare Figure 13 with Figure 11). 


\section{$\underline{\text { Histological analysis }}$}

Suture widths and MAR data available to date are shown in Table 9. Double-labelled sutures of Pig 3 under epifluorescent illumination are shown in Figure 14. Intra-examiner error was low for both suture width (1.64\%) and MAR (5.35\%) measurements. It should be noted that only Pigs 3 and 4 were verified to be loaded. Pig 1 had stable loading attachments on day 1 of loading but not thereafter. Although recorded strains in Pig 1 were negligible on day 5, the possibility of measurable strains on day 1 of loading affecting growth cannot be excluded. Pig 2 was a sham with loose attachments.

While only a few specimens are yet available, Table 9 suggests that the width of the sutural space varies depending on the suture, with the nasofrontal suture and interfrontal suture being typically wider than the internasal and coronal sutures. Most notably, the widths of the loaded NFS in Pigs 3 and 4 (327 and $383 \mu$ m respectively) were strikingly larger than in the other specimens (184 $\pm 27 \mu \mathrm{m}$, average of bilateral NFS in Pig 2 plus histological controls, $\mathrm{n}=6)$. However, the contralateral NFS was much less affected (237 $\mu \mathrm{m}$ in Pig 3 and $305 \mu \mathrm{m}$ in Pig 4). The coronal suture widths on the loaded right side of Pigs 3 and 4 (147 and $168 \mu \mathrm{m})$ were marginally greater than those of Pigs 1 and $2(103$ and $139 \mu \mathrm{m})$, but again no effect was seen on the contralateral (left) coronal sutures.

Mineralization rate (MAR) appeared associated with loading in the right NFS, with the lowest values (8-15 $\mu \mathrm{m} /$ day) in Pig 2 and the histological controls, an intermediate value in Pig 1 (26 $\mu \mathrm{m} /$ day) and higher values in Pigs 3 and 4 (34 and $31 \mu \mathrm{m} /$ day). Again, however, the unloaded left NFS was closer to control values (22, 19, and $12 \mu \mathrm{m}$ /day in Pigs 1,3 and 4 respectively). 
MAR of the coronal sutures did not differ between sides or among Pigs 1-4 (range 3-11 $\mu \mathrm{m} /$ day). MAR of the internasal and interfrontal sutures were only available for the loaded pigs (8 and 13$14 \mu \mathrm{m} /$ day respectively).

\section{Association of sutural strain and histology}

Potential associations between strain, width and MAR within the experimental group (Pigs 3 and 4 only) were evaluated with scatter plots both collectively (Figure 15) and individually (Figures 16 and 17). Within each pig, sutural width and especially MAR were both strongly associated with tensile strain magnitude with the relationship well described by second-order polynomial functions. Suture width vs strain yielded $\mathrm{R}^{2}=0.72-0.89$, MAR vs strain yielded $\mathrm{R}^{2}=0.92-0.99$, and suture width vs MAR yielded $\mathrm{R}^{2}=0.96-0.99$. When data were evaluated collectively, individual variation was a confounding factor, and the strength of the correlations was reduced $\left(\mathrm{R}^{2}=0.51,0.85\right.$ and 0.73 respectively). The shapes of the second-order polynomial relationships suggested that compressive strain was not a determinant of sutural width or MAR, and that the positive correlations were associated with tensile strain magnitude. 


\section{$\underline{\text { Discussion }}$}

\section{$\underline{\text { Technical Considerations and Limitations }}$}

For the ex vivo study, a thorough overview of the transmission of the strain through the skull was hampered by missing data and individual biological and experimental variation. Nevertheless, the ex vivo sample size was adequate to achieve the objectives of this part of the study, which were to evaluate the loading system, loading parameters and distribution of sutural strain in the skull. However, small sample size for the in vivo study, particularly for histology, limits the conclusions that can be drawn about the effects of cyclic strain on sutural growth.

The loading device was highly reliable except for the declining power output with time, which appeared to be a function of overheating. However, the reductions in power and strain were relatively minor, and the extended loading in head \#10 showed that a rest period as short as 15 minutes was sufficient to restore the original values.

Placement of the attachments on the skull was made difficult by the fact that the NFS is strongly beveled in some animals. Low strains would result from impingement of the suture by a screw. Firm attachment was also important. The fact that placing 2-screw loading attachments on head \#4 increased strain by about $500 \mu \varepsilon$ (\#4a vs \#4b, Table 1) affirms that single screws provided less than ideal anchorage for loading. Failure of a screw to make secure contact with the bone in Pig 4 probably also attenuated strain. The nasal loading attachments became loose more frequently than those of the frontal, presumably because the thinner nasal bone offered less mechanical retention. The frontal bone was possibly growing faster (higher apposition rate) than 
the nasal bone, as evident from the higher frequency of periosteal thickening around the attachments in the frontal bone.

There are several inherent limitations in the strain gage data. Poor adhesion to the irregular, damp skull surface and/or insulation faults probably attenuated some recordings and certainly contributed to gage failures. The three-element stacked rosettes used on bone were particularly problematic. These gages are thicker, stiffer and less conformable to the surface than the singleelement strain gages used on sutures. Furthermore, even well attached gages that report good data only give partial information about the local mechanical environment. Gages on the outer surface of the skull cannot distinguish planar strain from bending and torsion, deformations that probably occurred because the loading device was about $1 \mathrm{~cm}$ distant from the skull. Even within the plane of the bone surface, the single-element gages placed across the sutures cannot distinguish between shear and axial strain and do not assess principal strains. Shearing undoubtedly occurred in the midline sutures as the right nasal and frontal bones were pushed apart, and would have exaggerated tensile strains and underestimated compressive strains. Moreover, although we strove to place the sutural gages perpendicular to the suture line, the sutures themselves are three-dimensional, curvilinear, beveled and interdigitated, making a standard placement impossible. The placement of two gages on the NFS of head \#3 showed slightly higher strains at the medial gage, probably because it was better aligned with the torqueing load. However, using three-element rosette gages rather than single-element gages was not considered feasible because each element would have crossed the suture in a different orientation, in addition to artificially stiffening the sutures and having a greater failure rate. Furthermore, single-element recording rendered the present study comparable to previous work 
on masticatory strains in these sutures (Rafferty and Herring 1999, Herring and Teng 2000), which was performed using the same technique.

An unexpected technical problem arose with the very high strains observed in the in vivo pigs at the loaded right NFS. The high strains presumably led to stretching of the suture and an inability to balance the gages at later stages of loading in Pigs 3 and 5. This stretching of the suture could have been a result of the 5-day loading regime but was more likely an immediate short-term effect of the tensile strain. This was evident from strains returning to recording range in Pig 3, with 30 minutes of rest post-loading. NFS strain was therefore slightly overestimated as the decline in strain magnitude over time could not be fully accounted for. A similar problem occurred with the loaded-side coronal suture gage in Pig 5. These findings, coupled with the increased suture width, suggest that high applied strains could possibly have loosened these sutures. Contrary to previous studies which used suture width as a surrogate for growth (Kopher and Mao 2003, Vij and Mao 2006), suture width could possibly indicate only stretching rather than actual growth rate.

A final limitation is that the in vivo experimental pigs were younger than the ex vivo heads and 3 of the 4 histological controls. Age is a likely determinant of strain under cyclic loading as well as of sutural morphology. Of all the specimens and subjects examined in this study, the smallest NFS strains were seen in the oldest (and only full grown) specimen (head \#2, Table 1). Sutures become increasingly interdigitated with age (Miura et al., 2009) and may hence respond less to a given load. It is even conceivable that fusion of the suture had begun in this animal. For the histological results, it is not clear whether the 1-2 month discrepancy between the histological 
controls (Pigs 6-8) and the remainder of the sample would have affected sutural growth rate. Pigs of this age grow at a constant or increasing rate (Mount and Ingram 1971), so the older animals would not be expected to have more slowly growing sutures unless fusion had begun. Fusion, however, is unlikely in this age group and was not verified histologically in any specimen.

\section{$\underline{\text { Pig Heads \#5-10 and Specific Aim } 1}$}

Using 2-screw plates, and with a sample of pigs of similar age and provenance, the loading apparatus consistently produced sine-wave tensile strains at $2.5 \mathrm{~Hz}$ at the loaded NFS, with an average magnitude of approximately $+900 \mu \varepsilon$, well over the target minimum of $+800 \mu \varepsilon$. Some specimens fell short of the target during the 30-minute loading session, but the loaded NFS strain was always over $+600 \mu \varepsilon$, a striking contrast to the natural compressive strain of mastication ($1583 \pm 506 \mu \varepsilon$, Rafferty and Herring 1999). For that reason, the protocol was deemed likely sufficient to provide a growth stimulus. These ex vivo data confirm that Specific Aims 1a (to corroborate the ability of the device to deliver loads accurately according to programmed specifications) and $1 \mathrm{~b}$ (to identify skull attachments of optimal dimensions and physical properties for retention and reliable load transmission) were accomplished.

Specific Aim 1c, to characterize strain elsewhere in the skull, involved placement of additional gages over adjacent bones (nasal and frontal) and sutures (contralateral NFS, coronal, interfrontal and internasal sutures). 
Sutures at closer proximity to the site of loading generally registered higher strains. In the ex vivo heads, mean recorded strains obtained corresponded with the following order of decreasing magnitude (absolute values): loaded NFS $>$ contralateral NFS $>$ internasal suture $\geq$ interfrontal suture $>$ loaded-side (right) coronal suture $>$ contralateral coronal suture $($ Table 5$)$. The reductions in magnitude over time of the right loaded sutures (NFS and coronal) were also larger than the left. Both trends correspond with published literature that strain is a local phenomenon, with proximity of the applied force being important (Herring and Teng 2000).

The unloaded contralateral side of the NFS was strongly affected by the applied cyclic loading, typically showing tensile strain of at least $50 \%$ of the magnitude observed in the loaded side and ranging from approximately +400 to $+1100 \mu \varepsilon$, a pattern differing strongly from the compressive strain observed during mastication (Rafferty and Herring 1999). Nevertheless, the differential between loaded and contralateral sides in strain magnitude implies a "wedging" effect, with nasal and frontal bones more separated on the right than the left, and therefore shearing forces at the internasal and interfrontal sutures.

Coronal suture strains on the cyclically loaded side were predictably compressive because of the axial loading forces that "pushed" the frontal bone towards the parietal bone. This contrasts with coronal suture strains during mastication, which are both compressive and tensile, with the latter predominating at magnitudes over $+350 \mu \varepsilon$ (Herring and Teng 2000). Coronal suture strain magnitude in the ex vivo heads was small, never exceeding $-100 \mu \varepsilon$, leading us to predict that no growth change should be expected at this location. 
The midline sutures, interfrontal and internasal, were individually variable in their response to loading. This probably reflects the dual tendency of the loading device to shear paired bones at the midline and to wedge them apart in a more rotary movement. The shearing effect, with the right nasal bone moving anteriorly with respect to the left and the right frontal bone moving posteriorly with respect to the left, would be expected to result in tensile strain. Tensile strain was, in fact, recorded at 5/6 interfrontal sutures and 3/6 internasal sutures. The wedging effect would have tended to rotate the right nasal and frontal bones around their gravitational centers, with either compressive or tensile strain observed depending on the location of the strain gage with respect to the bone's center of rotation. In addition to these intentional strains, the loading device might have inadvertently pulled one or both bones in a dorsal or ventral direction, which would have produced compression or tension, respectively. The actual strains observed were presumably the sum of all these displacements. Physiological strains at these sutures are typically much larger than those observed in the present study, with the interfrontal suture showing tension of $+1036 \mu \varepsilon$ (Rafferty and Herring 1999) and the internasal showing compression at $-440 \mu \varepsilon$ (Rafferty and Herring 1999). Therefore, cyclic loading was not considered likely to have growth effects at these sutures.

One final point of interest about the midline sutures was seen in the head subjected to extended loading (\#10, Table 4). During the first two 30-minute sessions, the internasal suture of this head was consistently slightly compressed, but subsequently it was tensed during the first minute, then returning to compression. This change suggests that the repetitive loading had altered the suture in some fashion, perhaps slightly disarticulating it. Bazargani et al. (2013) reported that rapid 
maxillary expansion disarticulated sutures beyond the site of loading (i.e., other than the targeted intermaxillary suture).

Bones are much stiffer than sutures (Herring and Teng 2000), resulting in lower strains for any given applied load. Thus, the lower strain magnitudes in the nasal and frontal bones (Table 5) were expected and are similar to those reported for mastication (Sun et al., 2004, Herring and Teng 2000, Rafferty et al., 2003). However, the strain patterns in our study differed from those produced by mastication. For the frontal bone, Herring and Teng (2000) found an alternating orientation of approximately $+45^{\circ}$ or $-45^{\circ}$ from the sagittal axis with the tensile axis directed toward the origin of the dominant masseter and similar magnitudes of tension and compression. This was interpreted as a twisting of the cranium due to muscle force. On the contrary, the tensile axis induced by cyclic loading was approximately perpendicular to the sagittal plane, and compressive strains were approximately twice larger than the tensile strains. This pattern suggests an almost axial compression of the frontal bone. As for the nasal bone, during mastication compression was the dominant strain pattern, and the compressive axis was approximately orthogonal to the sagittal plane (Rafferty et al., 2003). In our study, however, nasal principal strains were starkly different. Cyclic loading produced dominant tensile principal strain and the compressive axis was almost parallel with the sagittal plane. Despite the differences in strain pattern in the bones, however, the low strains in these bones during both mastication and cyclic loading make it unlikely that these mechanical forces are strong determinants of bone growth.

\section{Pigs 1-5 and Specific Aim 2}


Specific Aim 2a focused on whether cyclic loading of the right NFS in vivo produced similar strains and strain transmission through the skull to those observed in the ex vivo heads. Several but not all findings showed similarity between the two samples. The similarities included comparable power output with decreasing trends for power and strain over the course of the session as well as strong tensile strain at both the loaded and the contralateral NFS (45-61\% of loaded NFS values). In addition, coronal suture strain was compressive on the loaded side, interfrontal strain was tensile, and internasal strain polarity was inconsistent.

However, there were also striking differences between the in vivo and ex vivo results. Strain magnitudes across the sutures were higher in vivo than ex vivo except for the internasal suture, at which magnitude was comparable (Figure 18). Higher in vivo strains could be attributed to several factors. Firstly, the live pigs were younger (3-4 vs approximately 6 months). Their sutures might have been more flexible, thinner, less interdigitated, or less fused. Secondly, the 8screw plate loading attachments used in Pigs 3-5 were more stable than the 2-screw plate loading attachments used in the ex vivo study, and hence likely allowed for more reliable transmission of forces from the loading device to the sutures. Thirdly, live tissues could potentially be less stiff due to the presence of unaltered extracellular matrices and cells and a blood supply. Finally, Pigs 3-5 all underwent extended loading over 5 days, during which sutures could have been loosened or could have been remodeled in a way which modified their deformability.

In addition to this global increase in strain magnitude, in vivo results for the coronal sutures were quite different from those expected based on the ex vivo heads. On the loaded right side, compressive strain magnitude was more than an order of magnitude greater in the in vivo than in 
the ex vivo sample (-764 vs $-47 \mu \varepsilon$, Table 8$)$, a difference much greater than that seen in the nasofrontal suture $(+1543$ vs $+898 \mu \varepsilon)$. It is conceivable that coronal sutures of the ex vivo heads were partially fused. In addition, the larger loading attachments in the smaller skulls resulted in the posterior edge of the frontal attachment being placed in close proximity to the ipsilateral coronal suture in the live pigs. This close proximity of the point of force application, in addition to the younger and exercised sutures, likely led to the disproportionate increase in strain in the loaded-side coronal suture.

The contralateral coronal suture also exhibited unexpected results. Only one subject (Pig 5, Table 8) experienced compressive strain; the other two subjects reported tensile strain, a finding that was not observed ex vivo. Interestingly, in these subjects (Pigs 3 and 4) there was a short lag between the load output and the contralateral coronal suture strain waveforms, suggesting a complex movement at the suture, perhaps a differential rotation of bones. It is also conceivable that the polarity of contralateral coronal suture strain was related to the strain on the loaded side. Pig 5, which showed the most compression at the loaded coronal suture, also showed compression on the contralateral side.

\section{Suture Growth and Relation to Cyclic Loading}

The values for MAR are generally consistent with previous work, and confirm that the nasofrontal suture is a relatively fast growing location in 3-month old pigs (Rafferty and Herring 1999). Width of the interfrontal suture $(251 \mu \mathrm{m}$, Table 9) is comparable to that reported elsewhere (205 $\mu \mathrm{m}$, Sun et al. 2004), but that of the nasofrontal suture (157-236 $\mu \mathrm{m}$ in controls 
and the sham, Table 9) is less than that measured by Popowics and Herring (2007) (256-342 $\mu \mathrm{m})$.

The effect of cyclic loading on suture histology was evaluated by comparing the loaded Pigs 3-4 with the histology controls and the sham (Pig 2), a necessarily speculative exercise because of the small loaded sample. This comparison suggests that the loaded NFS did show loading effects, at least compared to the contralateral NFS. Sutural width in Pigs 3 and 4 were respectively $90 \mu \mathrm{m}$ and $78 \mu \mathrm{m}$ greater on the right than the left NFS. While this finding could simply represent stretch rather than growth, there was also a comparable difference in MAR, with the loaded sides adding mineral at more than double the rate of the unloaded sides ( 33 vs 15 $\mu \mathrm{m} /$ day). Thus, unilateral cyclic loading of the NFS may have increased suture width and mineral apposition rate at the targeted suture.

Effects of cyclic loading on the contralateral NFS are less clear. Although widths (237 and 305 $\mu \mathrm{m}$ ) and MARs (19 and $12 \mu \mathrm{m} /$ day) of Pigs 3 and 4 were greater than those of the Pigs 6-9 (173 $\mu \mathrm{m}$ and $9 \mu \mathrm{m} /$ day), they also had comparable NFS widths and MARs as Pigs 1 and 2 (178-236 $\mu \mathrm{m}, 15-26 \mu \mathrm{m} /$ day), so this might have simply been an age effect. There is also no suggestion in Table 9 that the coronal sutures of Pigs 3 and 4 differed from those of Pigs 1 and 2 in either width or MAR. Data are still lacking for the midline sutures.

Retrospectively, the ex vivo predictions of growth in relation to strain patterns were relatively accurate. As predicted, growth changes at midline sutures and the left coronal suture were absent because of the low strains at these locations whereas the applied tensile strain at the loaded 
nasofrontal suture, which differed starkly from the compressive functional strain that the suture typically undergoes, apparently resulted in increased suture width and MAR. The strongly tensed contralateral nasofrontal suture was also expected to show growth effects, but if these occurred, they were too moderate to be demonstrated. The high compressive strain at the right coronal suture might also have been expected to have an effect, but none was seen. Conceivably, compressive strain may not be as osteogenic as tensile strain, even under cyclic delivery conditions. Alternatively, polarity might not be a factor, but initial magnitudes of the contralateral NFS and right coronal suture strain might have been low, with the sutures only loosening enough to yield high strain measurements on day 5. However, this explanation is unlikely because the ex vivo sample showed high contralateral NFS strain even in the first loading session. Finally, it is possible that strain magnitudes at the contralateral NFS and the loaded-side coronal suture, although high, might not have reached some threshold necessary to trigger growth changes.

The notion of a threshold magnitude was discussed by Mao et al. (2003), who reported a bone strain threshold of approximately $500 \mu \varepsilon$ for inducing sutural osteogenesis in rabbits. Given that our study utilizes pigs which are significantly larger, the threshold magnitude is plausibly higher. Similarly, Henderson et al. (2004) described strain magnitudes of 20-400 $\mu \varepsilon$ as being too small to influence osteoblast biology in the cranial sutures of humans.

In the present study, it is clear that suture width cannot be taken as a surrogate for sutural growth because the tensed suture stretches during loading. Nevertheless, the targeted right nasofrontal suture showed positive correlations between suture width, MAR and tensile strain magnitude. 
Such a correlation between loading and apposition rate corresponds with Frost's "mechanostat" theory (Frost 1996). The strong positive correlation between MAR and suture width in the loaded pigs does suggest that wider sutures are more active in mineral apposition. This corresponds with previously published literature which reported an increase in suture width corresponding with an increase in suture cell density and osteoblast-occupied sutural bone surface in rats (Vij and Mao 2006) and rabbits (Peptan et al., 2008). Kopher and Mao (2003) also concluded an increase in suture width was accompanied by an increased number of suture cells and increased sutural osteogenesis. 


\section{Summary and Conclusions}

Although previous studies have investigated the effects of cyclic loading, the small animal models (rats and rabbits) may not accurately represent the skeletal biology of humans.

Moreover, the transmission of cyclic strains through the skull and their effects on growth of the skull remain unknown. Hence our study had set out to investigate the effects of cyclic loading on strain transmission through the craniofacial skeleton and their impact on sutural growth using a pig model, which closely mimics the skeletal biology of humans. Moreover, unlike previously published studies which used a computerized servohydraulic system (MTS machine) attached to the maxillary incisors, our study utilized a less bulky, user-friendly, custom-engineered loading device capable of delivering cyclic loads directly to the craniofacial skeleton. This provides for a device with outcomes which may be more easily translatable into future therapeutic uses.

We validated the new device by applying it unilaterally to the nasofrontal suture of pigs. Using the same frequency but a reversed polarity from the physiological strain of mastication, we characterized the transmission of the load across the skull surface and performed a pilot study to determine whether the protocol could affect sutural growth rate.

The strong tensile strain at the targeted suture was diminished but still apparent on the contralateral side of the nasofrontal suture. Sutures on the dorsal midline showed individual effects due to shearing, rotation, and bending at the sutures. The coronal sutures were typically compressed as the loading pushed one frontal bone posteriorly. Strains were much larger in the in vivo sample than in heads loaded ex vivo, perhaps because of younger age or loosening of the sutures by repetitive loading. 
Preliminary evidence suggested that direct cyclical loading of sutures had positive effects on suture width and mineral apposition rate, but only of the targeted suture. The observed mean increase in MAR of $18 \mu \mathrm{m} /$ day at the loaded NFS would translate to a clinically significant MAR of $6.6 \mathrm{~mm} /$ year. Short spurts of cyclic loading may be a more time-efficient yet viable growth modification treatment modality for patients with craniofacial syndromes and/or dentofacial deformities.

With these results, future work will focus on attempting to rescue hypoplastic sutures in midfacial hypoplastic pigs using cyclic loading and will also investigate the underlying mechanism for the sutural response to direct cyclic loading. These results would have potential implications in devising innovative orthodontic or craniofacial orthopedic appliances. 


\section{Acknowledgements}

I would like to thank the following for their invaluable contributions: my committee members (Susan W. Herring, Katherine Rafferty, Bryan J. Venema, Zee (Zi-Jun) Liu) and Siddharth Vora

for their advice and support, especially Susan Herring (my mentor) and Katherine Rafferty who were closely involved in the development, execution and/or inscription stages of the project; Benjamin LaCourse for his work on the histological measurements; Atriya Salamati for contributing the histological controls (NFS); Michael C. Baldwin and Joshua Alumbaugh for their assistance with the experiments; Robert Lee for his assistance with statistical analysis.

I would also like to thank the following for sponsoring the project: University of Washington Orthodontic Alumni Association, Dr. Douglass L. Morell Dentistry Research Fund, Public Health Service (PHS) award 1R21 DE024814. 


\section{Bibliography}

1. Al-Daghreer S, Flores-Mir C, El-Bialy T. 2008 Sep. Long-term stability after craniofacial distraction osteogenesis. J Oral Maxillofac Surg. 66(9):1812-9.

2. Bazargani F, Feldmann I, Bondemark L. 2013 Nov. Three-dimensional analysis of effects of rapid maxillary expansion on facial sutures and bones. Angle Orthod. 83(6):1074-82.

3. Capote-Moreno AL, Naval-Gías L, Muñoz-Guerra MF, Rodríguez-Campo FJ. 2013 Apr. Zygomatic distraction osteogenesis for correction of midfacial support after hemimaxillectomy: experience and technical considerations. J Oral Maxillofac Surg. 71(4):e189-97.

4. Ciochon RL, Nisbett RA, Corruccini RS. 1997 Apr-Jun. Dietary consistency and craniofacial development related to masticatory function in minipigs. J Craniofac Genet Dev Biol. 17(2):96-102.

5. Courtemanche DJ, Mutimer KL, Holmes AD, Levant BA, Clement JG. 1992 Jun. Experimental calvarial growth disturbance by micro-plate and screw fixation. Aust N Z J Surg. 62(6):482-8.

6. Frost HM. 1996 Feb. Perspectives: a proposed general model of the "mechanostat" (suggestions from a new skeletal-biologic paradigm). Anat Rec. 244(2):139-47.

7. Henderson JH, Longaker MT, Carter DR. 2004 Feb. Sutural bone deposition rate and strain magnitude during cranial development. Bone. 34(2):271-80.

8. Herring SW, Mucci RJ. 1991 Mar. In vivo strain in cranial sutures: the zygomatic arch. J Morphol. 207(3):225-39.

9. Herring SW, Teng S. 2000 Aug. Strain in the braincase and its sutures during function. Am J Phys Anthropol. 112(4):575-93.

10. Jackson GW, Kokich VG, Shapiro PA. 1979 Mar. Experimental and postexperimental response to anteriorly directed extraoral force in young Macaca nemestrina. Am J Orthod. 75(3):318-33.

11. Kopher RA, Mao JJ. 2003 Mar. Suture growth modulated by the oscillatory component of micromechanical strain. J Bone Miner Res. 18(3):521-8.

12. Mao JJ. 2002 Dec. Mechanobiology of craniofacial sutures. J Dent Res. 81(12):810-6.

13. Mao JJ, Wang X, Mooney MP, Kopher RA, Nudera JA. 2003 Jan. Strain induced osteogenesis of the craniofacial suture upon controlled delivery of low-frequency cyclic forces. Front Biosci. 8:a10-7. 
14. Marchac A, Arnaud E. 2012 Jan. Cranium and midface distraction osteogenesis: current practices, controversies, and future applications. J Craniofac Surg. 23(1):235-8.

15. Meldrum RJ. 1975 Apr. Alterations in the upper facial growth of Macaca mulatta resulting from high-pull headgear. Am J Orthod. 67(4):393-411.

16. Miura T, Perlyn CA, Kinboshi M, Ogihara N, Kobayashi-Miura M, Morriss-Kay GM, Shiota K. 2009 Dec. Mechanism of skull suture maintenance and interdigitation. J Anat. 215(6):64255.

17. Mount, L. E. (Laurence Edward), Ingram, D. L. (Douglas Leslie). 1971. The pig as a laboratory animal. London; New York: Academic Press.

18. Opperman LA. 2000 Dec. Cranial sutures as intramembranous bone growth sites. Dev Dyn. 219(4):472-85.

19. Parr JA, Garetto LP, Wohlford ME, Arbuckle GR, Roberts WE. 1997. Sutural expansion using rigidly integrated endosseous implants: an experimental study in rabbits. Angle Orthod. 67(4):283-90.

20. Peptan AI, Lopez A, Kopher RA, Mao JJ. 2008 Feb. Responses of intramembranous bone and sutures upon in vivo cyclic tensile and compressive loading. Bone. 42(2):432-8.

21. Popowics TE, Herring SW. 2007. Load transmission in the nasofrontal suture of the pig, Sus scrofa. J Biomech. 40(4):837-44.

22. Purushothaman R, Cox TC, Maga AM, Cunningham ML. 2011 Jul. Facial suture synostosis of newborn Fgfr1(P250R/+) and Fgfr2(S252W/+) mouse models of Pfeiffer and Apert syndromes. Birth Defects Res A Clin Mol Teratol. 91(7):603-9.

23. Rafferty KL, Herring SW. 1999 Nov. Craniofacial sutures: morphology, growth, and in vivo masticatory strains. J Morphol. 242(2):167-79.

24. Rafferty KL, Herring SW, Marshall CD. 2003 Jul. Biomechanics of the rostrum and the role of facial sutures. J Morphol. 257(1):33-44.

25. Sasaki A, Sugiyama H, Tanaka E, Sugiyama M. 2002 Jun. Effects of sutural distraction osteogenesis applied to rat maxillary complex on craniofacial growth. J Oral Maxillofac Surg. 60(6):667-75.

26. Sun Z, Lee E, Herring SW. 2004 Feb. Cranial sutures and bones: growth and fusion in relation to masticatory strain. Anat Rec A Discov Mol Cell Evol Biol. 276(2):150-61.

27. Vij K, Mao JJ. 2006 May. Geometry and cell density of rat craniofacial sutures during early postnatal development and upon in vivo cyclic loading. Bone. 38(5):722-30. 
28. Watzek G, Grundschober F, Plenk H Jr, Eschberger J. 1982 May. Experimental investigations into the clinical significance of bone growth at viscerocranial sutures. J Maxillofac Surg. 10(2):61-79. 


\section{$\underline{\text { Tables and Figures }}$}

Table 1: Summary of specimen source, loading attachment type, strain gages placed and NFS strains (mean \pm standard deviation [number of loading cycles measured]) in the ex vivo specimens

\begin{tabular}{|c|c|c|c|c|c|}
\hline No. & Specimen source & $\begin{array}{l}\text { Loading } \\
\text { attachment type }\end{array}$ & $\begin{array}{l}\text { Strain gages } \\
\text { placed }\end{array}$ & $\begin{array}{l}\text { Loaded NFS } \\
\text { strain at } \\
\text { amplitude } 6(\mu \varepsilon)\end{array}$ & $\begin{array}{l}\text { Contralateral NFS } \\
\text { strain at amplitude } \\
6(\mu \varepsilon)\end{array}$ \\
\hline 0 & $\begin{array}{l}\text { Dry skull, estimated } 3 \mathrm{mths} \text { old, } \\
\text { unknown source. }\end{array}$ & \multirow{6}{*}{$\begin{array}{l}\text { Stainless steel } \\
\text { screws: } 9.5 \mathrm{~mm} \\
\text { length, } 1.4 \mathrm{~mm} \\
\text { diameter }\end{array}$} & $\begin{array}{l}\text { Single-element: } \\
\text { bilateral NFS }\end{array}$ & $108 \pm 3[10]$ & $29 \pm 2[10]$ \\
\hline 1 & $\begin{array}{l}5.5 \mathrm{mth} \text { old, male minipig, Hanford } \\
\text { breed, soft tissue intact, perfused } \\
\text { with fixative. }\end{array}$ & & $\begin{array}{l}\text { Single-element: } \\
\text { bilateral NFS }\end{array}$ & $2161 \pm 4[10]$ & $307 \pm 1[10]$ \\
\hline 2 & $\begin{array}{l}\text { Dentally mature, at least } 2 \text { year old, } \\
\text { female minipig, Gottingen breed, } \\
\text { soft tissue intact. }\end{array}$ & & $\begin{array}{l}\text { Single-element: } \\
\text { bilateral NFS }\end{array}$ & $187 \pm 14[5]$ & $-9 \pm 2[5]$ \\
\hline $3 a$ & \multirow{2}{*}{$\begin{array}{l}\text { Slaughterhouse pig, estimated } 6 \mathrm{mths} \\
\text { old, unknown sex, previously } \\
\text { frozen. }\end{array}$} & & $\begin{array}{l}\text { Single-element: } \\
\text { bilateral NFS }+ \\
\text { lateral loaded NFS }\end{array}$ & $\begin{array}{l}318 \pm 5[5] \\
\text { Lateral gage: } \\
289 \pm 5[5]\end{array}$ & $491 \pm 7[5]$ \\
\hline $3 b$ & & & $\begin{array}{l}\text { Single-element: } \\
\text { bilateral NFS }+ \\
\text { lateral non-loaded } \\
\text { NFS }\end{array}$ & $241 \pm 3[20]$ & $\begin{array}{l}162 \pm 2[20] \\
\text { Lateral gage: } \\
128 \pm 1[20]\end{array}$ \\
\hline $4 a$ & $\begin{array}{l}\text { Slaughterhouse pig, estimated } 6 \mathrm{mths} \\
\text { old, unknown sex, previously } \\
\text { frozen. }\end{array}$ & & $\begin{array}{l}\text { Single-element: } \\
\text { bilateral NFS }\end{array}$ & $1369 \pm 19[5]$ & $764 \pm 14[5]$ \\
\hline $4 \mathrm{~b}$ & $\begin{array}{l}\text { Changed to } 2 \text {-screw loading } \\
\text { attachments. } \\
\text { Extended loading to five } 30 \mathrm{~min} \\
\text { sessions. }\end{array}$ & $\begin{array}{l}\text { Stainless steel plate, } \\
\text { stabilized by } 2 \\
\text { screws. Nasal bone: } \\
\text { machine screws } \\
\text { (1.4mm diameter } \mathrm{x} \\
6.4 \mathrm{~mm} \text { length). }\end{array}$ & $\begin{array}{l}\text { Single-element: } \\
\text { bilateral NFS }\end{array}$ & $1856 \pm 7[3]$ & $836 \pm 2[3]$ \\
\hline
\end{tabular}




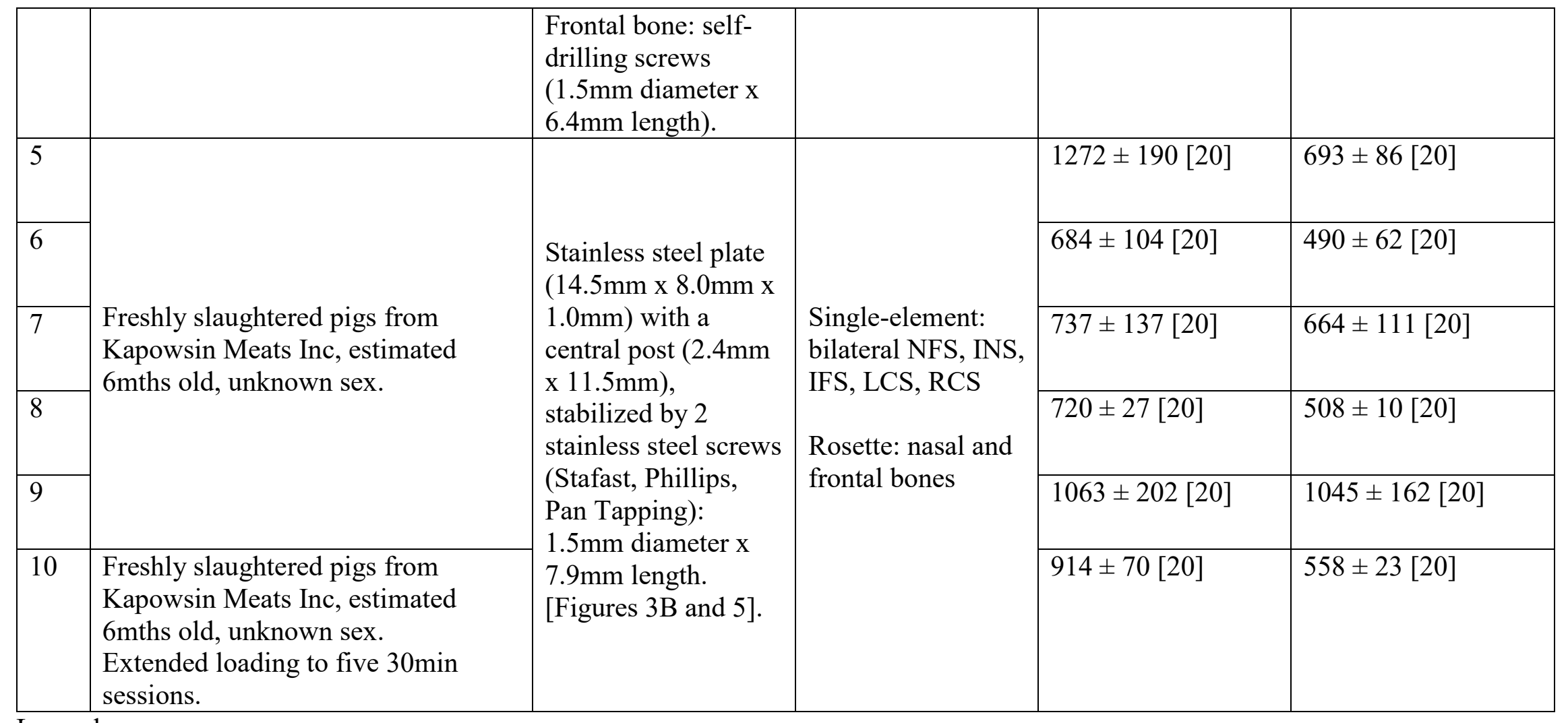

Legend:

NFS: nasofrontal suture, INS: internasal suture, IFS: interfrontal suture, LCS: left coronal suture, RCS: right coronal suture 
Table 2: Summary of characteristics of all in vivo subjects and treatment rendered

\begin{tabular}{|c|c|c|c|c|c|c|c|c|}
\hline Pigs & Breed & Sex & $\begin{array}{l}\text { Weight } \\
\text { (Kg) }\end{array}$ & Treatment & $\begin{array}{l}\text { Loading attachments } \\
\text { placed }\end{array}$ & $\begin{array}{l}\text { Type and } \\
\text { Timing } \\
\text { (number of } \\
\text { days before } \\
\text { death) of labels } \\
\text { injected }\end{array}$ & $\begin{array}{l}\text { Strain } \\
\text { analysis }\end{array}$ & $\begin{array}{l}\text { Histological } \\
\text { analysis }\end{array}$ \\
\hline 1 & \multirow{4}{*}{$\begin{array}{l}\text { Landrace } \\
\text { mixed } \\
\text { breed } \\
\text { (approx. } \\
1.5 \\
\text { weeks } \\
\text { older } \\
\text { than Pig } \\
9 \text { on day } \\
\text { of } \\
\text { terminal } \\
\text { surgery) }\end{array}$} & Male & 20.5 & $\begin{array}{l}\text { Loading } \\
\text { (loose } \\
\text { attachments) }\end{array}$ & \multirow{2}{*}{$\begin{array}{l}\text { Stainless steel plate } \\
(14.5 \mathrm{~mm} \times 8.0 \mathrm{~mm} \times \\
1.0 \mathrm{~mm}) \text { with a central } \\
\text { stainless steel post } \\
(2.4 \mathrm{~mm} \text { diameter } \mathrm{x} \\
11.5 \mathrm{~mm}) \text {, stabilized by } 2 \\
\text { stainless steel screws } \\
\text { (Stafast, Phillips, Pan } \\
\text { Tapping): } 1.5 \mathrm{~mm} \\
\text { diameter } \times 7.9 \mathrm{~mm} \\
\text { length }\end{array}$} & \multirow{4}{*}{$\begin{array}{l}\text { Calcein (4 days) } \\
\text { Alizarin } \\
\text { complexone } \\
\text { ( } 2 \text { days) }\end{array}$} & $\begin{array}{l}\text { LNFS, } \\
\text { RNFS, INS, } \\
\text { IFS, LCS, } \\
\text { RCS } \\
\text { (single- } \\
\text { element } \\
\text { gages) }\end{array}$ & $\begin{array}{l}\text { LNFS, } \\
\text { RNFS, LCS, } \\
\text { RCS }\end{array}$ \\
\hline 2 & & Male & 21 & $\begin{array}{l}\text { Sham control } \\
\text { (loose } \\
\text { attachments) }\end{array}$ & & & none & $\begin{array}{l}\text { LNFS, } \\
\text { RNFS, LCS, } \\
\text { RCS }\end{array}$ \\
\hline 3 & & Male & 20 & Loading & $\begin{array}{l}\text { Titanium plate }(28.5 \mathrm{~mm} \\
\text { x } 16 \mathrm{~mm} \text { x } 1-1.5 \mathrm{~mm}) \\
\text { with a central titanium } \\
\text { post }(4 \mathrm{~mm} \text { diameter } \mathrm{x} \\
15 \mathrm{~mm}), \text { stabilized by } 8 \\
\text { stainless steel cortex } \\
\text { self-tapping screws } \\
\text { (SYNTHES Vet): } \\
\text { 2.0mm diameter x 6- } \\
8 \mathrm{~mm} \text { length }\end{array}$ & & $\begin{array}{l}\text { Similar to } \\
\text { Pig } 1\end{array}$ & $\begin{array}{l}\text { LNFS, } \\
\text { RNFS, INS, } \\
\text { IFS, LCS, } \\
\text { RCS }\end{array}$ \\
\hline 4 & & Female & 18.6 & Loading & $\begin{array}{l}\text { Similar to Pig } 3 \text { but only } \\
7 \text { screws were used for } \\
\text { the nasal attachment } \\
\text { (antero-lateral screw }\end{array}$ & & $\begin{array}{l}\text { Similar to } \\
\text { Pig } 1 \& \\
\text { parietal } \\
\text { bone }\end{array}$ & $\begin{array}{l}\text { LNFS, } \\
\text { RNFS, INS, } \\
\text { IFS, LCS, } \\
\text { RCS }\end{array}$ \\
\hline
\end{tabular}




\begin{tabular}{|c|c|c|c|c|c|c|c|c|}
\hline & & & & & $\begin{array}{l}\text { hole was not overlying } \\
\text { bone). One of the screws } \\
\text { used was wider and } \\
\text { shorter than the } \\
\text { SYNTHES Vet screws } \\
\text { due to an enlarged pilot } \\
\text { hole. }\end{array}$ & & $\begin{array}{l}\text { (rosette } \\
\text { gage) }\end{array}$ & \\
\hline 5 & & Male & 20.9 & Loading & Similar to Pig 3 & & $\begin{array}{l}\text { Similar to } \\
\text { Pig } 1 \& \\
\text { frontal bone } \\
\text { (rosette } \\
\text { gage) }\end{array}$ & $\begin{array}{l}\text { LNFS, } \\
\text { RNFS, INS, } \\
\text { IFS, LCS, } \\
\text { RCS }\end{array}$ \\
\hline 6 & \multirow[b]{3}{*}{$\begin{array}{l}\text { Landrace } \\
\text { mixed } \\
\text { breed } \\
\text { (approx. } \\
7 \text { weeks } \\
\text { older } \\
\text { than Pig } \\
9 \text { on day } \\
\text { of } \\
\text { terminal } \\
\text { surgery) }\end{array}$} & Female & 34.0 & \multirow{4}{*}{$\begin{array}{l}\text { Histology } \\
\text { controls }\end{array}$} & None & \multirow{4}{*}{$\begin{array}{l}\text { Calcein and } \\
\text { Alizarin, } \\
\text { injected } 5 \text { days } \\
\text { apart }\end{array}$} & N/A & RNFS \\
\hline 7 & & Female & 30.8 & & None & & $\mathrm{N} / \mathrm{A}$ & LNFS \\
\hline 8 & & Female & 32.2 & & None & & $\mathrm{N} / \mathrm{A}$ & LNFS \\
\hline 9 & $\begin{array}{l}\text { Landrace } \\
\text { mixed } \\
\text { breed } \\
\end{array}$ & Female & 22.2 & & None & & $\mathrm{N} / \mathrm{A}$ & $\begin{array}{l}\text { RNFS (only } \\
\text { suture } \\
\text { width) }\end{array}$ \\
\hline
\end{tabular}

Legend:

LNFS: left nasofrontal suture, RNFS: right nasofrontal suture 
Table 3: Load output and strains during the first 30 minutes of loading in pig heads $\# 5-10$

\begin{tabular}{|c|c|c|c|c|c|c|c|c|c|c|c|c|c|c|c|c|}
\hline \multirow[b]{3}{*}{ Pig Head No. } & \multirow[b]{3}{*}{$\begin{array}{l}\text { Stage of 30-minute } \\
\text { Loading Session }\end{array}$} & \multicolumn{4}{|c|}{ Nasal Bone } & \multicolumn{4}{|c|}{ Frontal Bone } & \multirow[b]{3}{*}{$\begin{array}{l}\text { Load Output } \\
\text { (Kg) }\end{array}$} & \multicolumn{6}{|c|}{ Sutures } \\
\hline & & \multicolumn{3}{|c|}{ Principal Strain $(\mu \varepsilon)$} & \multirow{2}{*}{$\begin{array}{l}\text { Maximum } \\
\text { Principal } \\
\text { Strain Angle } \\
\text { (degrees) }\end{array}$} & \multicolumn{3}{|c|}{ Principal Strain $(\mu \varepsilon)$} & \multirow{2}{*}{$\begin{array}{l}\text { Maximum } \\
\text { Principal } \\
\text { Strain Angle } \\
\text { (degrees) }\end{array}$} & & \multicolumn{6}{|c|}{ Strain $(\mu \varepsilon)$} \\
\hline & & Maximum & Minimum & Shear & & Maximum & Minimum & Shear & & & \begin{tabular}{|c|} 
Loaded \\
Nasofrontal \\
Suture
\end{tabular} & \begin{tabular}{|c|}
$\begin{array}{c}\text { Contralateral } \\
\text { Nasofrontal } \\
\text { Suture }\end{array}$ \\
\end{tabular} & \begin{tabular}{|c} 
Internasal \\
Suture
\end{tabular} & \begin{tabular}{|c|} 
Loaded-side \\
Coronal \\
Suture \\
\end{tabular} & \begin{tabular}{|c|}
$\begin{array}{c}\text { Contralateral } \\
\text { Coronal } \\
\text { Suture }\end{array}$ \\
\end{tabular} & $\begin{array}{c}\text { Interfrontal } \\
\text { Suture }\end{array}$ \\
\hline \multirow{5}{*}{ Pig Head 5} & Initial & \multirow{5}{*}{\multicolumn{4}{|c|}{ Indeterminate: no data for elements $1 \& 2$}} & \multirow{5}{*}{\multicolumn{4}{|c|}{ Indeterminate: no data for elements $1 \& 3$}} & 1.71 & 1485 & 789 & 87 & -62 & -17 & 16 \\
\hline & Middle & & & & & & & & & 1.50 & 1212 & 666 & 80 & -52 & -15 & 15 \\
\hline & Final & & & & & & & & & 1.43 & 1118 & 624 & 74 & -49 & -15 & 15 \\
\hline & Mean & & & & & & & & & 1.54 & 1272 & 693 & 81 & -54 & -15 & 15 \\
\hline & \begin{tabular}{|l|} 
Standard Deviation \\
\end{tabular} & & & & & & & & & 0.15 & 190 & 86 & 7 & 7 & 1 & 1 \\
\hline \multirow{5}{*}{ Pig Head 6} & Initial & 16 & -41 & 57 & 65 & 44 & -96 & 140 & 94 & 167 & 803 & 561 & 23 & 0 & -9 & 114 \\
\hline & Middle & 15 & -35 & 50 & 63 & 36 & -80 & 117 & 94 & 1.48 & 640 & 464 & 28 & 0 & 0 & 72 \\
\hline & Final & 15 & -34 & 49 & 63 & 33 & -74 & 107 & 94 & 1.41 & 609 & 446 & 29 & 0 & 0 & 71 \\
\hline & Mean & 15 & -37 & 52 & 64 & 38 & -84 & 121 & 94 & 1.52 & 684 & 490 & 26 & 0 & -3 & 86 \\
\hline & \begin{tabular}{|l|} 
Standard Deviation \\
\end{tabular} & 1 & 3 & 4 & 1 & 6 & 11 & 17 & 0 & 0.14 & 104 & 62 & 3 & 0 & 5 & 25 \\
\hline \multirow{5}{*}{ Pig Head 7} & Initial & \multirow{5}{*}{\multicolumn{4}{|c|}{ Indeterminate: no data for element 1}} & \multirow{5}{*}{\multicolumn{4}{|c|}{ Indeterminate: no data for element 3}} & 1.72 & 894 & 792 & 232 & -31 & -16 & 61 \\
\hline & Middle & & & & & & & & & 1.57 & 678 & 616 & 174 & -27 & -14 & 51 \\
\hline & Final & & & & & & & & & 1.50 & 639 & 585 & 164 & -27 & -14 & 49 \\
\hline & Mean & & & & & & & & & 1.60 & 737 & 664 & 190 & -28 & -15 & 53 \\
\hline & \begin{tabular}{|l|} 
Standard Deviation \\
\end{tabular} & & & & & & & & & 0.11 & 137 & 111 & 37 & 2 & 1 & 6 \\
\hline & & \multirow{6}{*}{\multicolumn{4}{|c|}{ Indeterminate: no data for element 1}} & \multirow{6}{*}{\multicolumn{4}{|c|}{ Indeterminate: no data for elements $1 \& 3$}} & & & & & & & \\
\hline \multirow{5}{*}{ Pig Head 8} & Initial & & & & & & & & & 1.70 & 751 & 519 & -106 & -48 & -45 & 19 \\
\hline & Middle & & & & & & & & & 1.62 & 710 & 505 & -100 & -46 & -43 & 21 \\
\hline & Final & & & & & & & & & 1.61 & 699 & 501 & -95 & -47 & -44 & 20 \\
\hline & Mean & & & & & & & & & 1.64 & 720 & 508 & -100 & -47 & -44 & 20 \\
\hline & \begin{tabular}{|l|} 
Standard Deviation \\
\end{tabular} & & & & & & & & & 0.05 & 27 & 10 & 6 & 1 & 1 & 1 \\
\hline & & & & & & & & & & & & & & & & \\
\hline \multirow{5}{*}{ Pig Head 9} & Initial & 48 & -36 & 84 & 126 & \multirow{5}{*}{\multicolumn{4}{|c|}{ Indeterminate: no data for element 2}} & 1.75 & 1292 & 1228 & -211 & -88 & 6 & 234 \\
\hline & Middle & 46 & -33 & 79 & 129 & & & & & 1.60 & 983 & 986 & -186 & -79 & 0 & 207 \\
\hline & Final & 43 & -34 & 77 & 128 & & & & & 1.57 & 913 & 920 & -178 & -73 & -6 & 199 \\
\hline & Mean & 46 & -34 & 80 & 128 & & & & & 1.64 & 1063 & 1045 & -192 & -80 & 0 & 213 \\
\hline & \begin{tabular}{|l|} 
Standard Deviation \\
\end{tabular} & 2 & 2 & 4 & 1 & & & & & 0.09 & 202 & 162 & 17 & 7 & 6 & 18 \\
\hline & Initial & & & & & 27 & -58 & 85 & 111 & 1.35 & 992 & 584 & -15 & -79 & -27 & -84 \\
\hline & Middle & & & & & 25 & -53 & 78 & 111 & 1.37 & 895 & 551 & -18 & -74 & -27 & -84 \\
\hline Pig Head 10 & Final & Indete & rminate: no & data for & ement 2 & 25 & -53 & 79 & 112 & 1.39 & 857 & 539 & -18 & -72 & -27 & -85 \\
\hline & Mean & & & & & 26 & -55 & 80 & 111 & 1.37 & 914 & 558 & -17 & -75 & -27 & -85 \\
\hline & Standard Deviation & & & & & 1 & 3 & 4 & 1 & 0.02 & 70 & 23 & 2 & 4 & 0 & 1 \\
\hline
\end{tabular}

Principal strain orientation of $0^{\circ}$ represents the sagittal axis. All orientations are given with the rosette gages placed on the right. Mean and standard deviation refer to mean and standard deviation calculated using the three stages (initial, middle, final) of the 30-minute loading session for that specimen. Values for each stage of loading were derived from averaging measurements from 20 cycles. 
Table 4: Load output and strains during extended loading (five 30-minute sessions) in pig head \#10

\begin{tabular}{|c|c|c|c|c|c|c|c|c|c|c|c|c|c|c|c|}
\hline & \multicolumn{4}{|c|}{ Nasal Bone } & \multicolumn{4}{|c|}{ Frontal Bone } & \multirow[b]{3}{*}{$\begin{array}{l}\text { Load Output } \\
\text { (Kg) }\end{array}$} & \multirow{2}{*}{\multicolumn{6}{|c|}{$\begin{array}{c}\text { Sutures } \\
\text { Strain }(\mu \varepsilon)\end{array}$}} \\
\hline & \multicolumn{3}{|c|}{ Principal Strain $(\mu \varepsilon)$} & \multirow{2}{*}{$\begin{array}{c}\text { Maximum } \\
\text { Principal } \\
\text { Strain Angle } \\
\text { (degrees) }\end{array}$} & \multicolumn{3}{|c|}{ Principal Strain $(\mu \varepsilon)$} & \multirow{2}{*}{\begin{tabular}{|c|} 
Maximum \\
Principal \\
Strain Angle \\
(degrees)
\end{tabular}} & & & & & & & \\
\hline & Maximum & Minimum & Shear & & Maximum & Minimum & Shear & & & \begin{tabular}{|c|} 
Loaded \\
Nasofrontal \\
Suture \\
\end{tabular} & \begin{tabular}{|c|}
$\begin{array}{c}\text { Contralateral } \\
\text { Nasofrontal } \\
\text { Suture }\end{array}$ \\
\end{tabular} & \begin{tabular}{|c|} 
Internasal \\
Suture
\end{tabular} & \begin{tabular}{c|} 
Loaded-side \\
Coronal \\
Suture \\
\end{tabular} & \begin{tabular}{|c|}
$\begin{array}{c}\text { Contralateral } \\
\text { Coronal } \\
\text { Suture }\end{array}$ \\
\end{tabular} & $\begin{array}{c}\text { Interfrontal } \\
\text { Suture }\end{array}$ \\
\hline \multicolumn{16}{|c|}{\begin{tabular}{|l|} 
Loading Session 1 \\
\end{tabular}} \\
\hline Initial & \multirow{3}{*}{\multicolumn{4}{|c|}{ Indeterminate: no data for element 2}} & 27 & -58 & 85 & 111 & 1.35 & 992 & 584 & -15 & -79 & -27 & -84 \\
\hline Middle & & & & & 25 & -53 & 78 & 111 & 1.37 & 895 & 551 & -18 & -74 & -27 & -84 \\
\hline Final & & & & & 25 & -53 & 79 & 112 & 1.39 & 857 & 539 & -18 & -72 & -27 & -85 \\
\hline \multicolumn{16}{|c|}{ Loading Session 2 (no break after first cycle) } \\
\hline Initial & \multirow{3}{*}{\multicolumn{4}{|c|}{ Indeterminate: no data for element 2}} & 24 & -51 & 75 & 111 & 1.21 & 732 & 474 & -11 & -53 & -26 & -67 \\
\hline Middle & & & & & 25 & -51 & 76 & 110 & 1.18 & 720 & 471 & -20 & -59 & -28 & -70 \\
\hline Final & & & & & 24 & -48 & 73 & 111 & 1.20 & 725 & 476 & -26 & -59 & -29 & -70 \\
\hline \multicolumn{16}{|c|}{ Loading Session 3 (after a 20-minute break and re-balancing) } \\
\hline Initial & \multirow{3}{*}{\multicolumn{4}{|c|}{ Indeterminate: no data for element 2}} & 26 & -57 & 83 & 112 & 1.65 & 1069 & 688 & 27 & -79 & -35 & -96 \\
\hline Middle & & & & & 25 & -53 & 78 & 113 & 1.45 & 869 & 579 & -16 & -69 & -33 & -89 \\
\hline Final & & & & & 26 & -53 & 79 & 112 & 1.41 & 853 & 569 & -16 & -68 & -33 & -88 \\
\hline \multicolumn{16}{|c|}{ 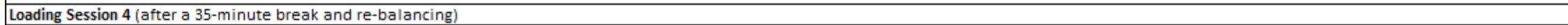 } \\
\hline Initial & 29 & -48 & 78 & 57 & 30 & -64 & 94 & 112 & 1.55 & 1124 & 690 & 16 & -78 & -40 & -73 \\
\hline Middle & 26 & -45 & 71 & 57 & 30 & -62 & 92 & 112 & 1.40 & 961 & 606 & -18 & -70 & -37 & -67 \\
\hline Final & 27 & -44 & 71 & 57 & 30 & -61 & 91 & 112 & 1.40 & 946 & 600 & -20 & -70 & -36 & -68 \\
\hline \multicolumn{16}{|c|}{ Loading Session 5 (after a 15-minute break and re-balancing) } \\
\hline Initial & \multirow{3}{*}{\multicolumn{4}{|c|}{ Indeterminate: no data for element 3}} & 25 & -71 & 95 & 105 & 1.70 & 1217 & 766 & 0 & -81 & -40 & -68 \\
\hline Middle & & & & & 29 & -78 & 107 & 104 & 1.53 & 978 & 639 & -24 & -76 & -38 & -67 \\
\hline Final & & & & & 28 & -76 & 104 & 104 & 1.50 & 939 & 638 & -27 & $\begin{array}{l}-73 \\
\end{array}$ & -38 & -67 \\
\hline
\end{tabular}

Principal strain orientation of $0^{\circ}$ represents the sagittal axis. All orientations are given with the rosette gages placed on the right.

Values for each stage of loading were derived from averaging measurements from 20 cycles. 
Table 5: Mean load output and strains during the first 30 minutes of loading in each specimen and of all specimens (pig heads \#5-10)

\begin{tabular}{|c|c|c|c|c|c|c|c|c|c|c|c|c|c|c|c|}
\hline \multirow[b]{3}{*}{ Pig Head No. } & \multicolumn{4}{|c|}{ Nasal Bone } & \multicolumn{4}{|c|}{ Frontal Bone } & \multirow[b]{3}{*}{$\begin{array}{l}\text { Load } \\
\text { Output } \\
\text { (Kg) }\end{array}$} & \multicolumn{6}{|c|}{ Sutures } \\
\hline & \multicolumn{3}{|c|}{ Principal Strain $(\mu \varepsilon)$} & \multirow{2}{*}{$\begin{array}{c}\text { Maximum } \\
\text { Principal } \\
\text { Strain Angle } \\
\text { (degrees) }\end{array}$} & \multicolumn{3}{|c|}{ Principal Strain $(\mu \varepsilon)$} & \multirow{2}{*}{$\begin{array}{l}\text { Maximum } \\
\text { Principal } \\
\text { Strain Angle } \\
\text { (degrees) }\end{array}$} & & \multicolumn{6}{|c|}{ Strain $(\mu \varepsilon)$} \\
\hline & Maximum & Minimum & Shear & & Maximum & Minimum & Shear & & & \begin{tabular}{|c|} 
Loaded \\
Nasofrontal \\
Suture \\
\end{tabular} & $\begin{array}{c}\text { Contralateral } \\
\text { Nasofrontal } \\
\text { Suture } \\
\end{array}$ & $\begin{array}{c}\text { Internasal } \\
\text { Suture }\end{array}$ & $\begin{array}{c}\text { Loaded-side } \\
\text { Coronal } \\
\text { Suture } \\
\end{array}$ & \begin{tabular}{|c|} 
Contralateral \\
Coronal \\
Suture \\
\end{tabular} & $\begin{array}{c}\text { Interfrontal } \\
\text { Suture }\end{array}$ \\
\hline Pig Head 5 & \multicolumn{4}{|c|}{ Indeterminate } & \multicolumn{4}{|c|}{ Indeterminate } & 1.55 & 1272 & 693 & 81 & -54 & -15 & 15 \\
\hline Pig Head 6 & 15 & -37 & 52 & 64 & 38 & -84 & 121 & 94 & 1.52 & 684 & 490 & 26 & 0 & -3 & 86 \\
\hline Pig Head 7 & \multicolumn{4}{|c|}{ Indeterminate } & \multicolumn{4}{|c|}{ Indeterminate } & 1.60 & 737 & 664 & 190 & -28 & -15 & 53 \\
\hline Pig Head 8 & \multicolumn{4}{|c|}{ Indeterminate } & \multicolumn{4}{|c|}{ Indeterminate } & 1.64 & 720 & 508 & -100 & -47 & -44 & 20 \\
\hline Pig Head 9 & 46 & -34 & 80 & 128 & \multicolumn{4}{|c|}{ Indeterminate } & 1.64 & 1063 & 1045 & -192 & -80 & 0 & 213 \\
\hline Pig Head 10 & 27 & -46 & 73 & 57 & 26 & -55 & 80 & 111 & 1.37 & 914 & 558 & -17 & -75 & -27 & -85 \\
\hline Mean & 29 & -39 & 68 & 83 & 32 & -69 & 101 & 103 & 1.55 & 898 & 660 & -2 & -47 & -17 & 50 \\
\hline Standard Deviation & 15 & 6 & 14 & 39 & 8 & 21 & 29 & 12 & 0.10 & 233 & 205 & 135 & 30 & 16 & 98 \\
\hline
\end{tabular}

Strain data from nasal bone of pig head $\# 10$ were obtained from the fourth 30 -minute loading session. Principal strain orientation of $0^{\circ}$ represents the sagittal axis. All orientations are given with the rosette gages placed on the right. Mean and standard deviation were calculated using the mean values of the first 30-minute loading sessions (Table 3 ) of all six pig heads. 
Table 6: Load output at initial, middle and final stages of all loading sessions in the in vivo experimental pigs

\begin{tabular}{|c|c|c|c|c|c|c|c|}
\hline \multirow[b]{2}{*}{ Pig No. } & \multirow{2}{*}{$\begin{array}{l}\text { Stage of } \\
\text { Loading }\end{array}$} & \multicolumn{6}{|c|}{ Load Output (Kg) } \\
\hline & & Day 1 & Day 2 & Day 3 & Day 4 & Day 5 & Days 1-5 \\
\hline \multirow{5}{*}{1} & Initial & 1.09 & 0.64 & 0.41 & 1.00 & 1.58 & \\
\hline & Middle & 0.67 & 0.44 & 0.18 & 0.25 & 1.47 & \\
\hline & Final & 0.58 & 0.35 & 0.19 & 0.24 & 1.43 & \\
\hline & Mean & 0.78 & 0.48 & 0.26 & 0.49 & 1.50 & 0.70 \\
\hline & $\begin{array}{l}\text { Standard } \\
\text { Deviation }\end{array}$ & 0.27 & 0.15 & 0.13 & 0.44 & 0.08 & 0.48 \\
\hline & & & & & & & \\
\hline \multirow{5}{*}{3} & Initial & 1.63 & 1.63 & 1.57 & 1.44 & 1.58 & \\
\hline & Middle & 1.62 & 1.62 & 1.50 & 1.40 & 1.48 & \\
\hline & Final & 1.58 & 1.57 & 1.45 & 1.35 & 1.44 & \\
\hline & Mean & 1.61 & 1.61 & 1.50 & 1.40 & 1.50 & 1.52 \\
\hline & $\begin{array}{l}\text { Standard } \\
\text { Deviation }\end{array}$ & 0.03 & 0.03 & 0.06 & 0.04 & 0.07 & 0.09 \\
\hline & & & & & & & \\
\hline \multirow{5}{*}{4} & Initial & 2.06 & 1.60 & 1.19 & 1.43 & 1.44 & \\
\hline & Middle & 1.79 & 1.46 & 0.86 & 1.04 & 0.99 & \\
\hline & Final & 1.76 & 1.39 & 0.88 & 0.73 & 0.81 & \\
\hline & Mean & 1.87 & 1.49 & 0.98 & 1.07 & 1.08 & 1.30 \\
\hline & $\begin{array}{l}\text { Standard } \\
\text { Deviation }\end{array}$ & 0.17 & 0.11 & 0.19 & 0.35 & 0.32 & 0.38 \\
\hline & & & & & & & \\
\hline \multirow{5}{*}{5} & Initial & 2.05 & 2.51 & 2.36 & 2.34 & 2.24 & \\
\hline & Middle & 2.04 & 2.16 & 2.07 & 2.02 & 2.06 & \\
\hline & Final & 2.05 & 2.06 & 2.09 & 1.97 & 2.02 & \\
\hline & Mean & 2.05 & 2.24 & 2.17 & 2.11 & 2.11 & 2.14 \\
\hline & $\begin{array}{l}\text { Standard } \\
\text { Deviation }\end{array}$ & 0.01 & 0.24 & 0.17 & 0.20 & 0.11 & 0.08 \\
\hline
\end{tabular}


Table 7: Load output, bone and suture strains recorded on day 5 of loading in the in vivo experimental pigs

\begin{tabular}{|c|c|c|c|c|c|c|c|c|c|c|c|c|}
\hline \multirow[b]{2}{*}{ Pig No. } & \multirow[b]{2}{*}{$\begin{array}{l}\text { Stage of } \\
\text { Loading }\end{array}$} & \multirow[b]{2}{*}{$\begin{array}{l}\text { Load } \\
\text { Output } \\
\text { (Kg) }\end{array}$} & \multirow{2}{*}{$\begin{array}{c}\text { Loaded } \\
\text { Nasofrontal } \\
\text { Suture } \\
\text { Strain }(\mu \varepsilon) \\
\end{array}$} & \multirow{2}{*}{$\begin{array}{c}\text { Contralateral } \\
\text { Nasofrontal } \\
\text { Suture Strain } \\
(\mu \varepsilon)\end{array}$} & \multirow{2}{*}{\begin{tabular}{|c|} 
Internasal \\
Suture \\
Strain \\
$(\mu \varepsilon)$ \\
\end{tabular}} & \multirow{2}{*}{\begin{tabular}{|c} 
Loaded-side \\
Coronal \\
Suture Strain \\
$(\mu \varepsilon)$
\end{tabular}} & \multirow[b]{2}{*}{\begin{tabular}{|c|} 
Contralateral \\
Coronal Suture \\
Strain $(\mu \varepsilon)$
\end{tabular}} & \multirow[b]{2}{*}{$\begin{array}{l}\text { Interfrontal } \\
\text { Suture } \\
\text { Strain }(\mu \varepsilon) \\
\end{array}$} & \multicolumn{2}{|c|}{ Parietal Bone } & \multicolumn{2}{|c|}{ Frontal Bone } \\
\hline & & & & & & & & & $\begin{array}{c}\text { Principal } \\
\text { Strains } \\
(\mu \varepsilon)\end{array}$ & $\begin{array}{c}\text { Maximum } \\
\text { Principal Strain } \\
\text { Angle (degrees) }\end{array}$ & $\begin{array}{c}\text { Rosette } \\
\text { Element } 2 \\
\text { Strain }(\mu \varepsilon) \\
\end{array}$ & $\begin{array}{c}\text { Rosette } \\
\text { Element } 3 \\
\text { Strain }(\mu \varepsilon) \\
\end{array}$ \\
\hline \multirow{5}{*}{1} & Initial & 1.58 & -2 & -2 & 0 & 0 & 0 & 0 & \multirow{5}{*}{\multicolumn{2}{|c|}{ N/A }} & \multirow{5}{*}{\multicolumn{2}{|c|}{$\mathrm{N} / \mathrm{A}$}} \\
\hline & Middle & 1.47 & -3 & -2 & 0 & 0 & 0 & 0 & & & & \\
\hline & Final & 1.43 & -2 & -2 & 0 & 0 & 0 & 0 & & & & \\
\hline & Mean & 1.50 & -2 & -2 & 0 & 0 & 0 & 0 & & & & \\
\hline & \begin{tabular}{|l|} 
Standard \\
Deviation
\end{tabular} & 0.08 & 0 & 0 & 0 & 0 & 0 & 0 & & & & \\
\hline \multirow{5}{*}{3} & Initial & 1.58 & 1666 & 1082 & -68 & -914 & 54 & 541 & \multirow{5}{*}{\multicolumn{2}{|c|}{$\mathrm{N} / \mathrm{A}$}} & \multirow{5}{*}{\multicolumn{2}{|c|}{$\mathrm{N} / \mathrm{A}$}} \\
\hline & Middle & 1.48 & 1376 & 875 & -80 & -854 & \multirow{2}{*}{$\mid \begin{array}{c}\text { No data - } \\
\text { compromised } \\
\text { gage }\end{array}$} & 457 & & & & \\
\hline & Final & 1.44 & \begin{tabular}{|c|} 
Channel \\
saturation \\
\end{tabular} & 839 & -94 & -819 & & 433 & & & & \\
\hline & Mean & 1.50 & 1521 & 932 & -81 & -863 & 54 & 477 & & & & \\
\hline & \begin{tabular}{|l|} 
Standard \\
Deviation \\
\end{tabular} & 0.07 & 205 & 131 & 13 & 48 & $\mathrm{~N} / \mathrm{A}$ & 57 & & & & \\
\hline & & & & & & & & & & & & \\
\hline \multirow{5}{*}{4} & Initial & 1.44 & 1211 & 605 & 29 & \multirow{2}{*}{\multicolumn{3}{|c|}{ No data - unsuccessful recording }} & \multirow{5}{*}{\multicolumn{2}{|c|}{ No data - failed gage }} & \multirow{5}{*}{\multicolumn{2}{|c|}{$\mathrm{N} / \mathrm{A}$}} \\
\hline & Middle & 0.99 & 807 & 354 & 20 & & & & & & & \\
\hline & Final & 0.81 & 734 & 292 & 18 & -338 & 113 & 115 & & & & \\
\hline & Mean & 1.08 & 917 & 417 & 22 & -338 & 113 & 115 & & & & \\
\hline & \begin{tabular}{|l|} 
Standard \\
Deviation \\
\end{tabular} & 0.32 & 257 & 166 & 6 & N/A & $\mathrm{N} / \mathrm{A}$ & $\mathrm{N} / \mathrm{A}$ & & & & \\
\hline & & & & & & & & & & & & \\
\hline \multirow{5}{*}{5} & Initial & 2.24 & 2189 & 1328 & 245 & -1257 & -283 & 153 & \multirow{5}{*}{\multicolumn{2}{|c|}{ N/A }} & \multicolumn{2}{|c|}{ No data } \\
\hline & Middle & 2.06 & \multirow[b]{2}{*}{$\begin{array}{l}\text { Channel } \\
\text { saturation }\end{array}$} & 1083 & 211 & -1102 & -260 & 87 & & & -11 & 53 \\
\hline & Final & 2.02 & & 866 & 297 & -914 & -253 & 85 & & & -10 & 48 \\
\hline & Mean & 2.11 & 2189 & 1092 & 251 & -1091 & -265 & 109 & & & -10 & 50 \\
\hline & \begin{tabular}{|l|} 
Standard \\
Deviation \\
\end{tabular} & 0.11 & $\mathrm{~N} / \mathrm{A}$ & 231 & 43 & 172 & 15 & 39 & & & 1 & 4 \\
\hline
\end{tabular}

Decline in magnitude of RNFS strains over time during loading in Pigs 3 and 5 could not be fully accounted for due to channel saturation at later stages of loading. RCS, LCS, IFS strains in Pig 4 were measured separately (15mins after actual loading session ended) as successful recording was initially not possible. IFS in Pig 5 exhibited an atypical, possibly truncated, waveform, leading to an underestimate of true strains. 
Table 8: Mean load output and strains in the in vivo experimental pigs, in comparison with data from the ex vivo study and published literature

\begin{tabular}{|c|c|c|c|c|c|c|c|c|}
\hline \multirow[b]{2}{*}{ Pig No. } & \multicolumn{2}{|c|}{ Load Output } & \multicolumn{6}{|c|}{ Mean Suture Strain $(\mu \varepsilon)$} \\
\hline & $\begin{array}{c}\text { Mean Over } 5 \\
\text { Days of } \\
\text { Loading }(\mathrm{Kg})\end{array}$ & $\begin{array}{c}\text { On Day of } \\
\text { Strain } \\
\text { Recording } \\
\text { (Kg) }\end{array}$ & \begin{tabular}{|c|} 
Loaded \\
Nasofrontal \\
Suture \\
\end{tabular} & $\begin{array}{c}\text { Contralateral } \\
\text { Nasofrontal } \\
\text { Suture }\end{array}$ & $\begin{array}{c}\text { Internasal } \\
\text { Suture }\end{array}$ & \begin{tabular}{|c} 
Loaded-side \\
Coronal \\
Suture
\end{tabular} & \begin{tabular}{|c|} 
Contralateral \\
Coronal \\
Suture
\end{tabular} & $\begin{array}{c}\text { Interfrontal } \\
\text { Suture }\end{array}$ \\
\hline Pig 1 & 0.70 & 1.50 & N/A & $\mathrm{N} / \mathrm{A}$ & $\mathrm{N} / \mathrm{A}$ & $\mathrm{N} / \mathrm{A}$ & $\mathrm{N} / \mathrm{A}$ & $\mathrm{N} / \mathrm{A}$ \\
\hline Pig 3 & 1.52 & 1.50 & 1521 & 932 & -81 & -863 & 54 & 477 \\
\hline Pig 4 & 1.30 & 1.08 & 917 & 417 & 22 & -338 & 113 & 115 \\
\hline Pig 5 & 2.14 & 2.11 & 2189 & 1092 & 251 & -1091 & -265 & 109 \\
\hline $\begin{array}{c}\text { Mean } \\
\text { (Pigs 3-5) }\end{array}$ & 1.65 & 1.56 & 1543 & 814 & 64 & -764 & -33 & 296 \\
\hline $\begin{array}{l}\text { Standard } \\
\text { Deviation } \\
\text { (Pigs 3-5) }\end{array}$ & 0.43 & 0.51 & 636 & 353 & 170 & 386 & 203 & 256 \\
\hline Ex Vivo Study & \multirow{2}{*}{ N/A } & 1.55 & 898 & 660 & 190 to -192 & -47 & -17 & 50 \\
\hline Published Data & & $\mathrm{N} / \mathrm{A}$ & \multicolumn{2}{|c|}{$-1583 \pm 506$} & $-440 \pm 238$ & \multicolumn{2}{|c|}{$369 \pm 212$ to $-156 \pm 68$} & $1036 \pm 400$ \\
\hline
\end{tabular}

IFS strains in Pig 5 were likely an underestimate and were excluded from calculation of the mean and standard deviation (SD) of the IFS strains. Published data on NFS, INS and IFS strains were from Rafferty and Herring 1999. Published data on RCS and LCS strains were from Herring and Teng 2000. 
Table 9: Mean suture width and mineral apposition rate (MAR) in the in vivo experimental and control pigs, in comparison with data from published literature

\begin{tabular}{|c|c|c|c|c|c|c|c|c|c|c|c|c|}
\hline \multicolumn{13}{|c|}{ Experimental Pigs } \\
\hline \multirow[b]{2}{*}{ Pig No. } & \multicolumn{2}{|c|}{\begin{tabular}{|c|} 
Loaded \\
Nasofrontal Suture
\end{tabular}} & \multicolumn{2}{|c|}{$\begin{array}{c}\text { Contralateral } \\
\text { Nasofrontal Suture }\end{array}$} & \multicolumn{2}{|c|}{ Internasal Suture } & \multicolumn{2}{|c|}{$\begin{array}{l}\text { Loaded-side } \\
\text { Coronal Suture }\end{array}$} & \multicolumn{2}{|c|}{$\begin{array}{l}\text { Contralateral } \\
\text { Coronal Suture }\end{array}$} & \multicolumn{2}{|c|}{ Interfrontal Suture } \\
\hline & \begin{tabular}{|c} 
Suture \\
Width \\
$(\mu \mathrm{m})$
\end{tabular} & $\begin{array}{c}\text { MAR } \\
(\mu \mathrm{m} / \text { day })\end{array}$ & $\begin{array}{c}\text { Suture } \\
\text { Width } \\
\text { ( } \mu \mathrm{m})\end{array}$ & $\begin{array}{c}\text { MAR } \\
(\mu \mathrm{m} / \mathrm{day})\end{array}$ & $\begin{array}{c}\text { Suture } \\
\text { Width } \\
\text { ( } \mu \mathrm{m})\end{array}$ & $\begin{array}{c}\text { MAR } \\
(\mu \mathrm{m} / \mathrm{day})\end{array}$ & $\begin{array}{c}\text { Suture } \\
\text { Width } \\
\text { ( } \mu \mathrm{m})\end{array}$ & $\begin{array}{c}\text { MAR } \\
(\mu \mathrm{m} / \text { day })\end{array}$ & $\begin{array}{c}\text { Suture } \\
\text { Width } \\
\text { ( } \mu \mathrm{m})\end{array}$ & $\begin{array}{c}\text { MAR } \\
(\mu \mathrm{m} / \text { day })\end{array}$ & $\begin{array}{c}\text { Suture } \\
\text { Width } \\
\text { ( } \mu \mathrm{m})\end{array}$ & $\begin{array}{c}\text { MAR } \\
(\mu \mathrm{m} / \text { day })\end{array}$ \\
\hline Pig 1 & 187 & 26 & 197 & 22 & - & - & [103] & [11] & - & [10] & - & - \\
\hline Pig 3 & 327 & 34 & 237 & 19 & 163 & 8 & [147] & [9] & 103 & 6 & 210 & 13 \\
\hline Pig 4 & 383 & 31 & 305 & 12 & [150] & [8] & 168 & 4 & 155 & 10 & [293] & [14] \\
\hline $\begin{array}{c}\text { Mean } \\
\text { (Pigs 3-4) }\end{array}$ & 355 & 33 & 271 & 15 & 157 & 8 & 157 & 7 & 129 & 8 & 251 & 14 \\
\hline $\begin{array}{l}\text { Standard } \\
\text { Deviation } \\
\text { (Pigs 3-4) }\end{array}$ & 39 & 2 & 48 & 5 & 9 & 0 & 15 & 3 & 37 & 3 & 59 & 0 \\
\hline \multicolumn{13}{|c|}{ Histological Controls } \\
\hline & \multicolumn{4}{|c|}{ Nasofrontal Suture } & \multicolumn{2}{|c|}{ Internasal Suture } & \multicolumn{4}{|c|}{ Coronal Suture } & \multicolumn{2}{|c|}{ Interfrontal Suture } \\
\hline Pig No. & $\begin{array}{c}\text { Suture } \\
\text { Width } \\
\text { ( } \mu \mathrm{m})\end{array}$ & $\begin{array}{c}\text { MAR } \\
(\mu \mathrm{m} / \text { day })\end{array}$ & $\begin{array}{c}\text { Suture } \\
\text { Width } \\
(\mu \mathrm{m})\end{array}$ & $\begin{array}{c}\text { MAR } \\
(\mu \mathrm{m} / \text { day })\end{array}$ & $\begin{array}{c}\text { Suture } \\
\text { Width } \\
\text { ( } \mu \mathrm{m})\end{array}$ & $\begin{array}{c}\text { MAR } \\
(\mu \mathrm{m} / \text { day })\end{array}$ & $\begin{array}{c}\text { Suture } \\
\text { Width } \\
(\mu \mathrm{m})\end{array}$ & $\begin{array}{c}\text { MAR } \\
(\mu \mathrm{m} / \text { day })\end{array}$ & $\begin{array}{c}\text { Suture } \\
\text { Width } \\
(\mu \mathrm{m})\end{array}$ & $\begin{array}{c}\text { MAR } \\
(\mu \mathrm{m} / \text { day })\end{array}$ & $\begin{array}{c}\text { Suture } \\
\text { Width } \\
(\mu \mathrm{m})\end{array}$ & $\begin{array}{c}\text { MAR } \\
(\mu \mathrm{m} / \text { day })\end{array}$ \\
\hline Pig 2 & 178 & 15 & 236 & 15 & - & - & [139] & [5] & [153] & [3] & - & - \\
\hline Pig 6 & 157 & 8 & - & - & - & - & - & - & - & - & - & - \\
\hline Pig 7 & - & - & 175 & 10 & - & - & - & - & - & - & - & - \\
\hline Pig 8 & - & - & 180 & 8 & - & - & - & - & - & - & - & - \\
\hline Pig 9 & 178 & - & - & - & - & - & - & - & - & - & - & - \\
\hline $\begin{array}{c}\text { Mean \& } \\
\text { Standard } \\
\text { Deviation } \\
\text { (Histological } \\
\text { Controls) } \\
\end{array}$ & $184 \pm 27$ & $11 \pm 4$ & $184 \pm 27$ & $11 \pm 4$ & - & - & [139] & [5] & [153] & [3] & - & - \\
\hline Published Data & & $19 \pm 7$ & & $19 \pm 7$ & & $6 \pm 2$ & & & & & & $9 \pm 2$ \\
\hline
\end{tabular}

Legend: Values in parentheses indicate data which were collected from sutures without a continuously patent suture space from the ectocranial to the endocranial surface. Published data were from Rafferty and Herring 1999. 
Figure 1A: Lateral view of the loading device

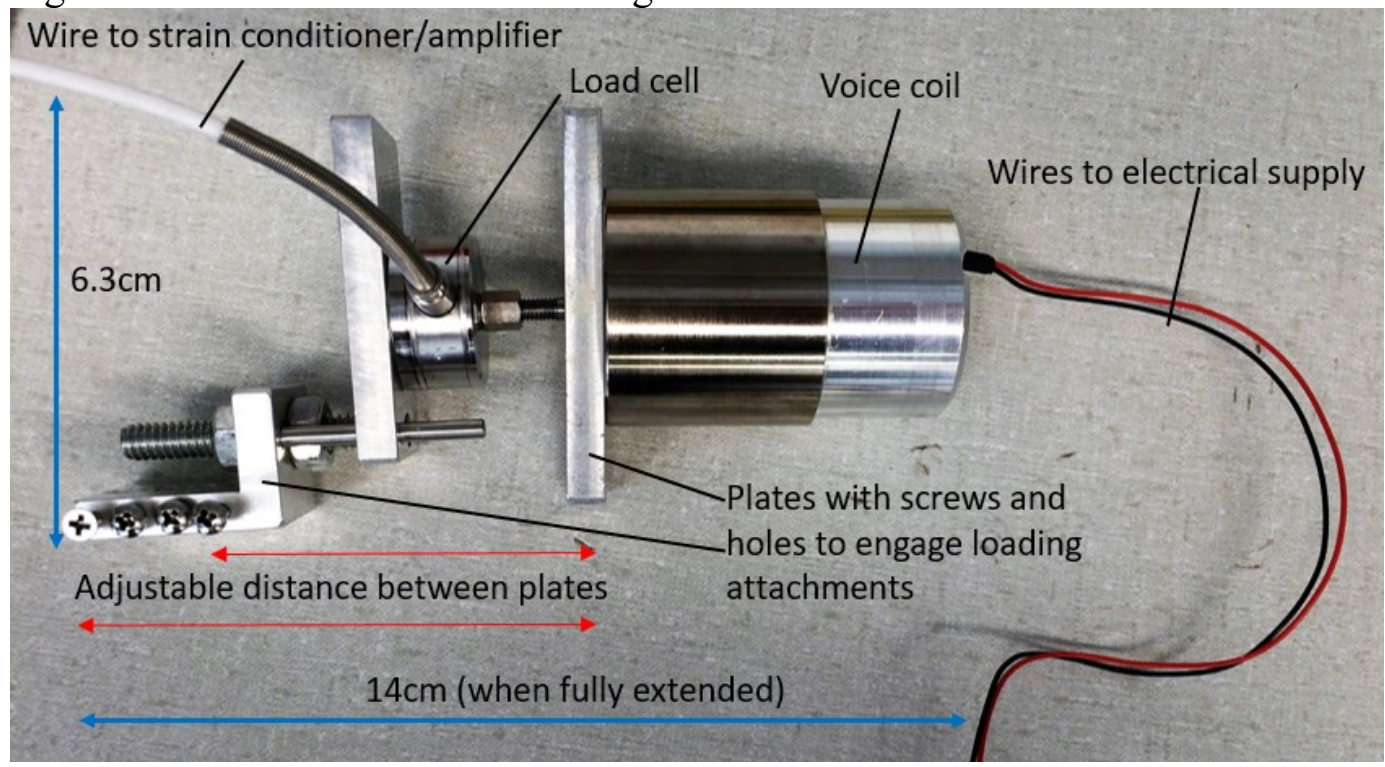

Figure 1B: Inferior view of the loading device

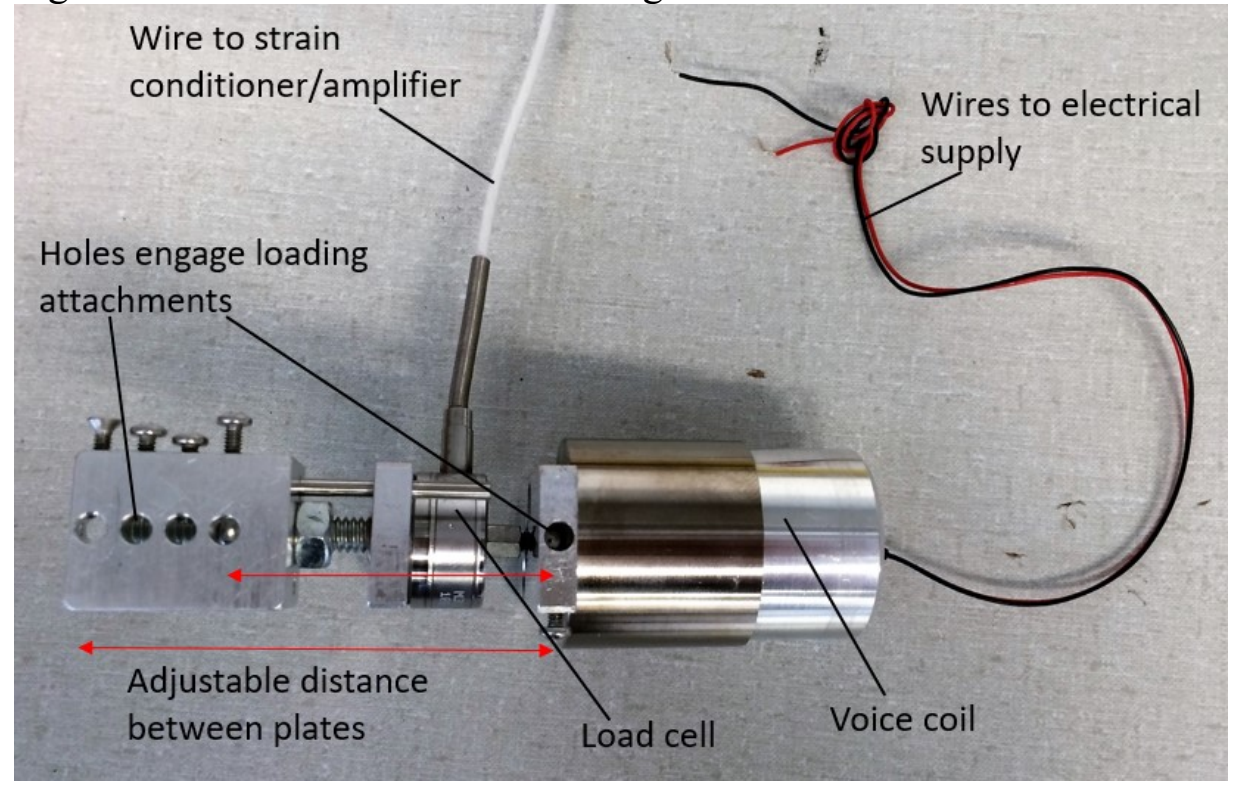


Figure 1C: Pictorial representation of the loading device engaging loading attachments on the skull (diagram not drawn to scale)

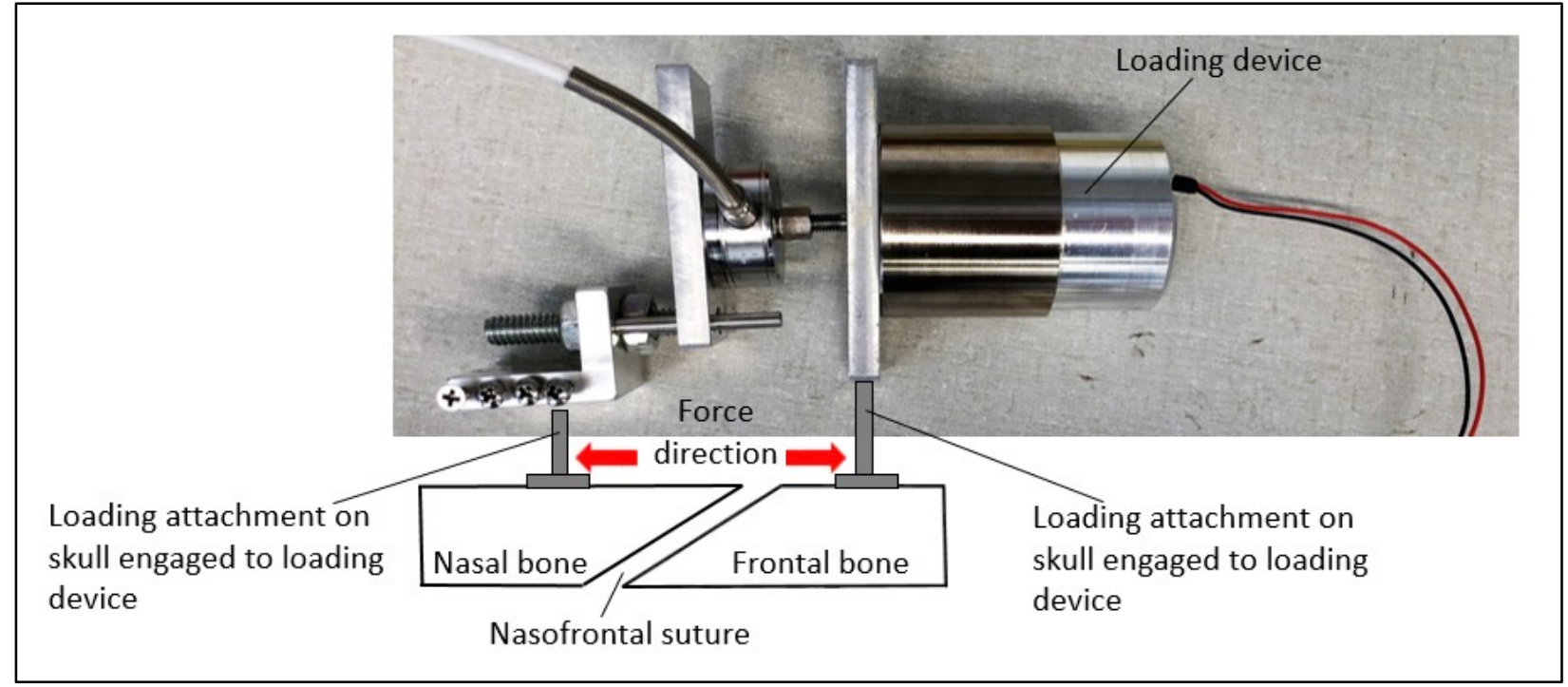

Figure 2: Graph of load (Kg) vs mean voltage (Volts) from calibration of loading device

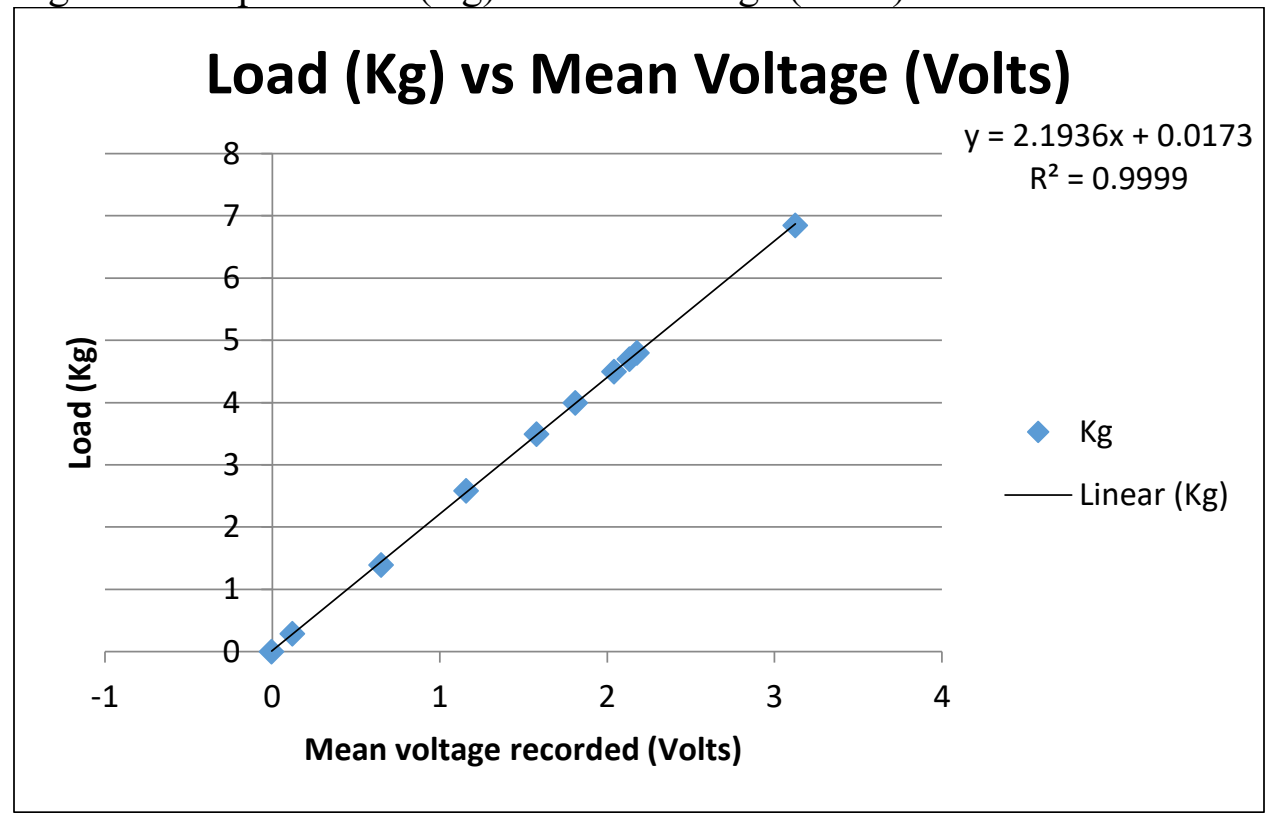


Figure 3A: Image showing orientation of single-screw and 2-screw plate loading attachments, and single-element strain gages on pig head \#4

Single stainless
steel screws,
used in heads
\#1-4


Figure 3B: Design of the 2-screw plate loading attachment

Stainless steel loading attachment
Weight $=0.94 \mathrm{~g}$


Figure 4: Graphs demonstrating strain changes with increasing load amplitude in pig heads \#1-4. The load was not ramped for pig head \#3b. The purpose of these investigations was to determine the load amplitude that gave the desired strains at the loaded NFS.

Pig head

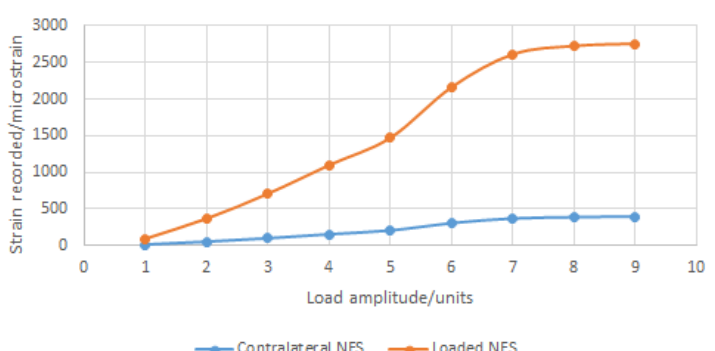

Pig head 3a

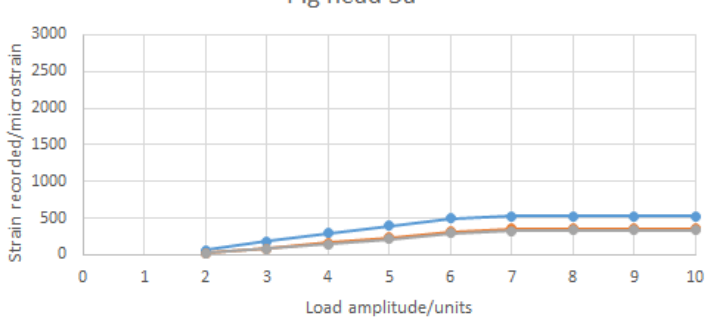

$\rightarrow$ Contralateral NFS- $\rightarrow$ Lateral loaded NFS.

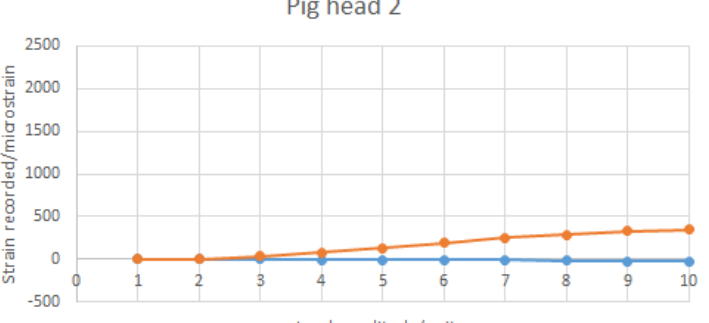

Load amplitude/units

$\rightarrow$ Contralateral NFS $\rightarrow$ - Loaded NFS

Pig head 4a

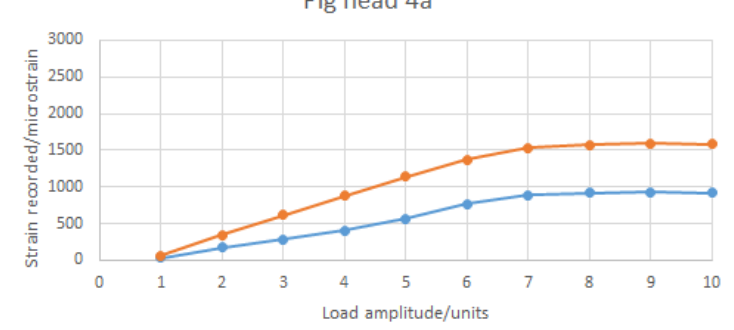

$\rightarrow-$ Contralateral NFS
Pig head $4 b$ (2-screw plate loading attachments)

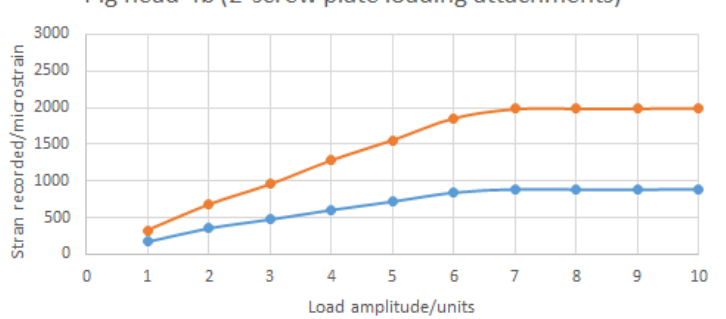

$\rightarrow$ Contralateral NFS 
Figure 5: Image showing location of single-element and three-element $45^{\circ}$ stacked rosette gages on pig head \#7

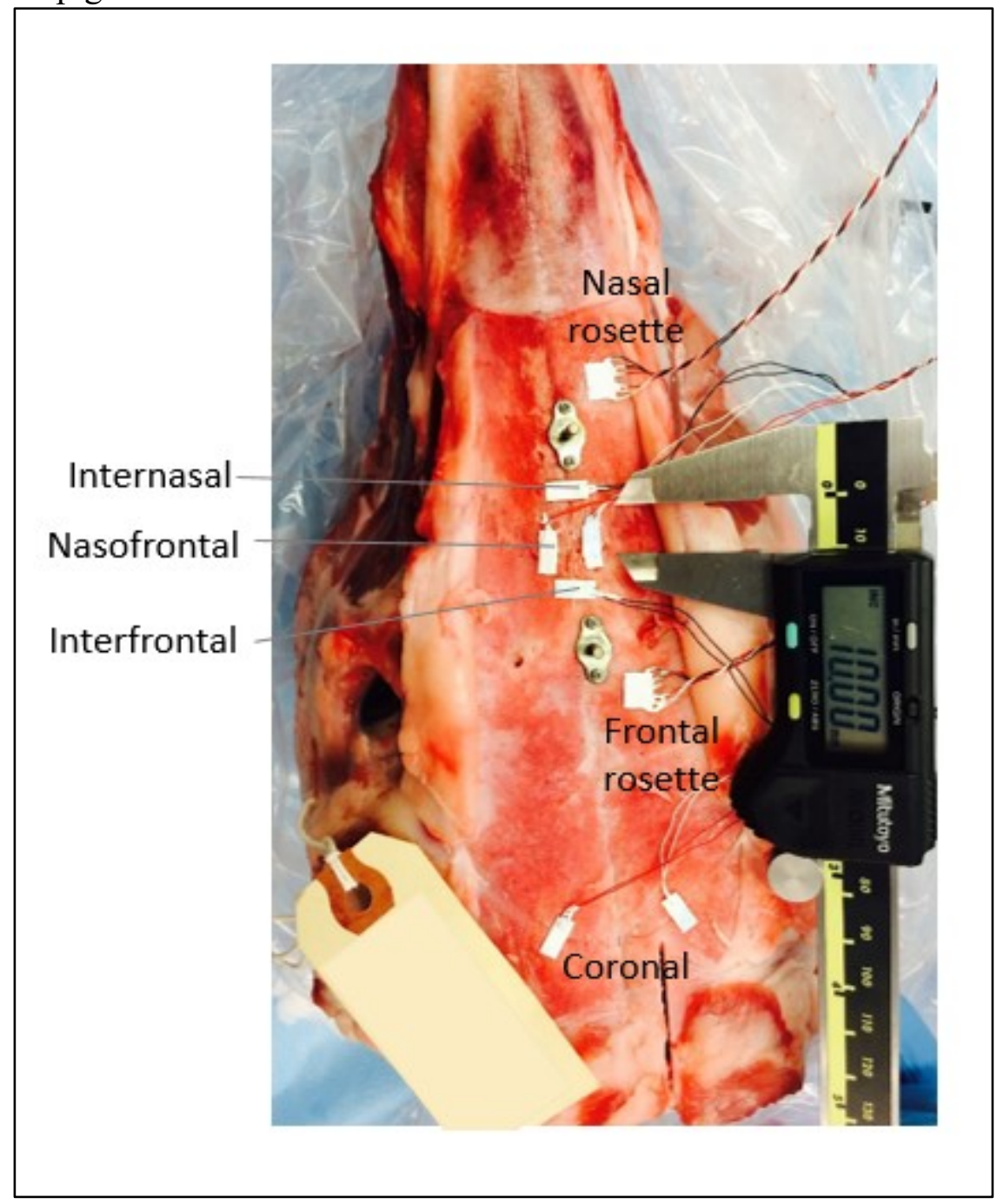


Figure 6: Orientation of rosette gages and their individual elements. Element 2 is oriented perpendicular to the sagittal axis, while elements 1 and 3 are oriented $45^{\circ}$ and $135^{\circ}$ counterclockwise from the sagittal axis respectively.

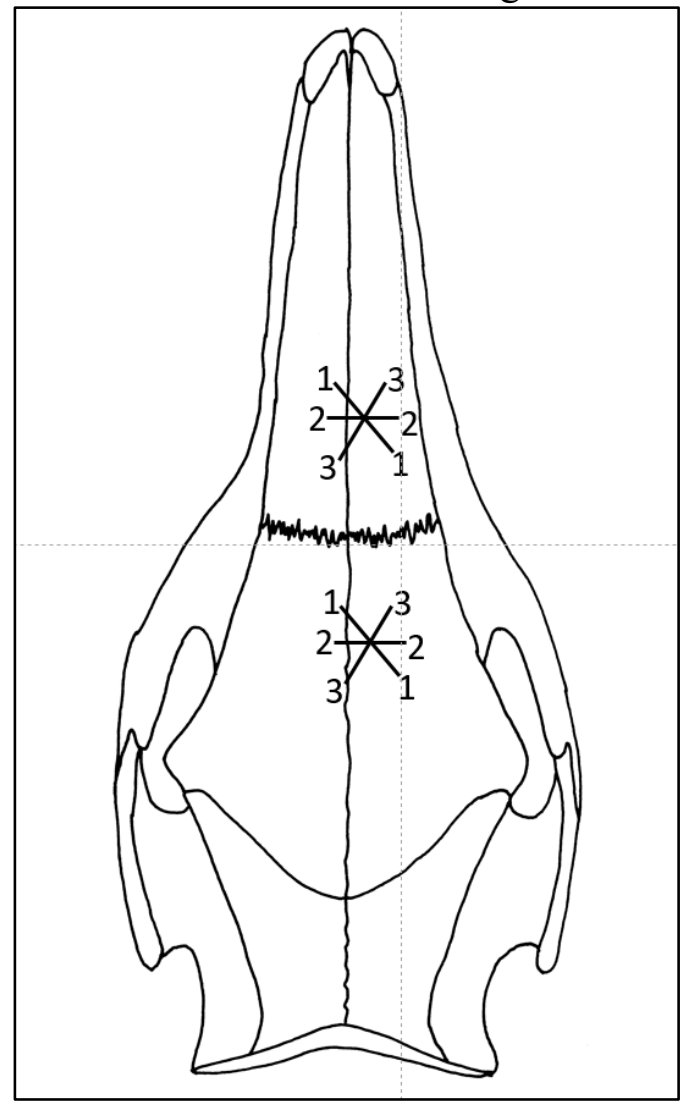


Figure 7: Design of the 8-screw plate titanium loading attachment

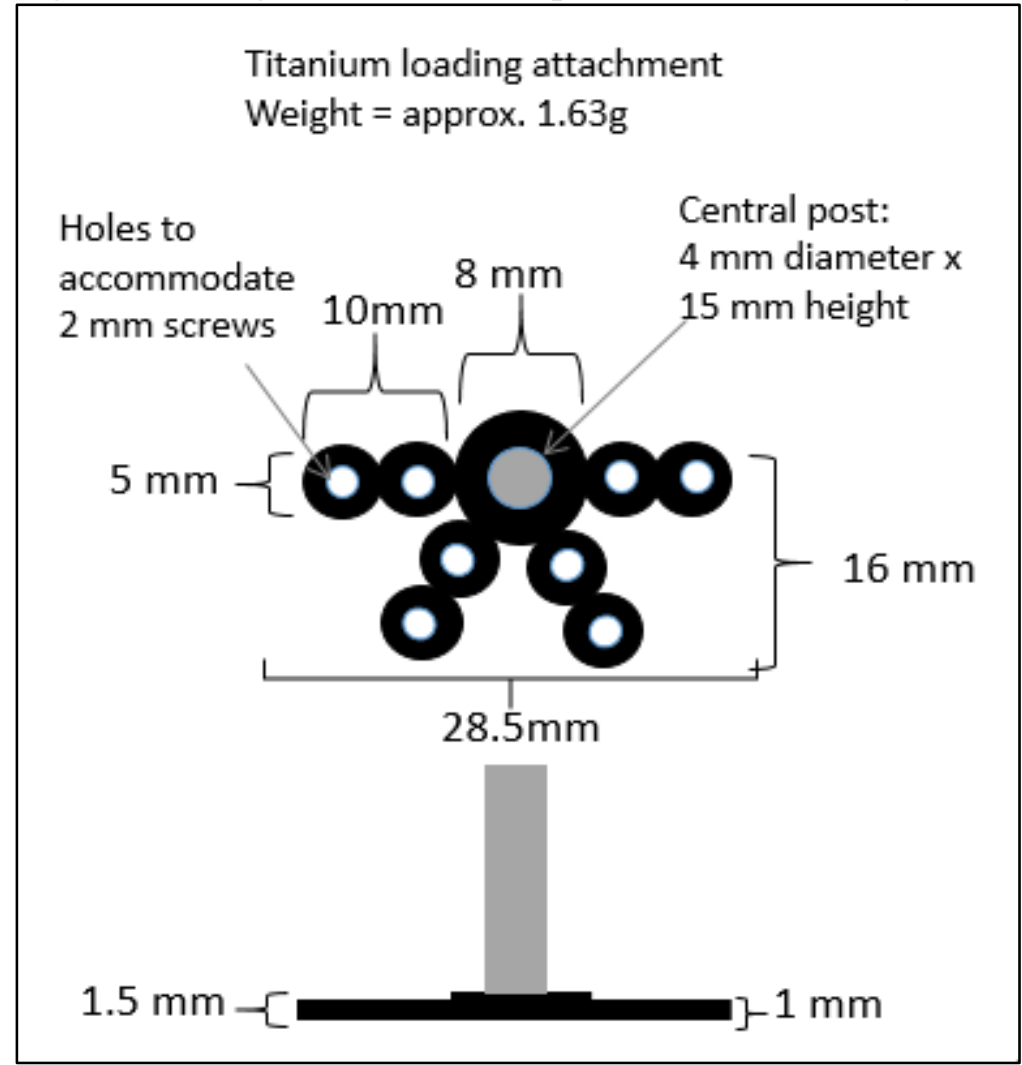


Figure 8A: Pictorial representation (not drawn to scale) of the 8-screw plate loading attachments, single-element strain gages (red rectangles), and parietal rosette strain gage (blue square) on Pig 4

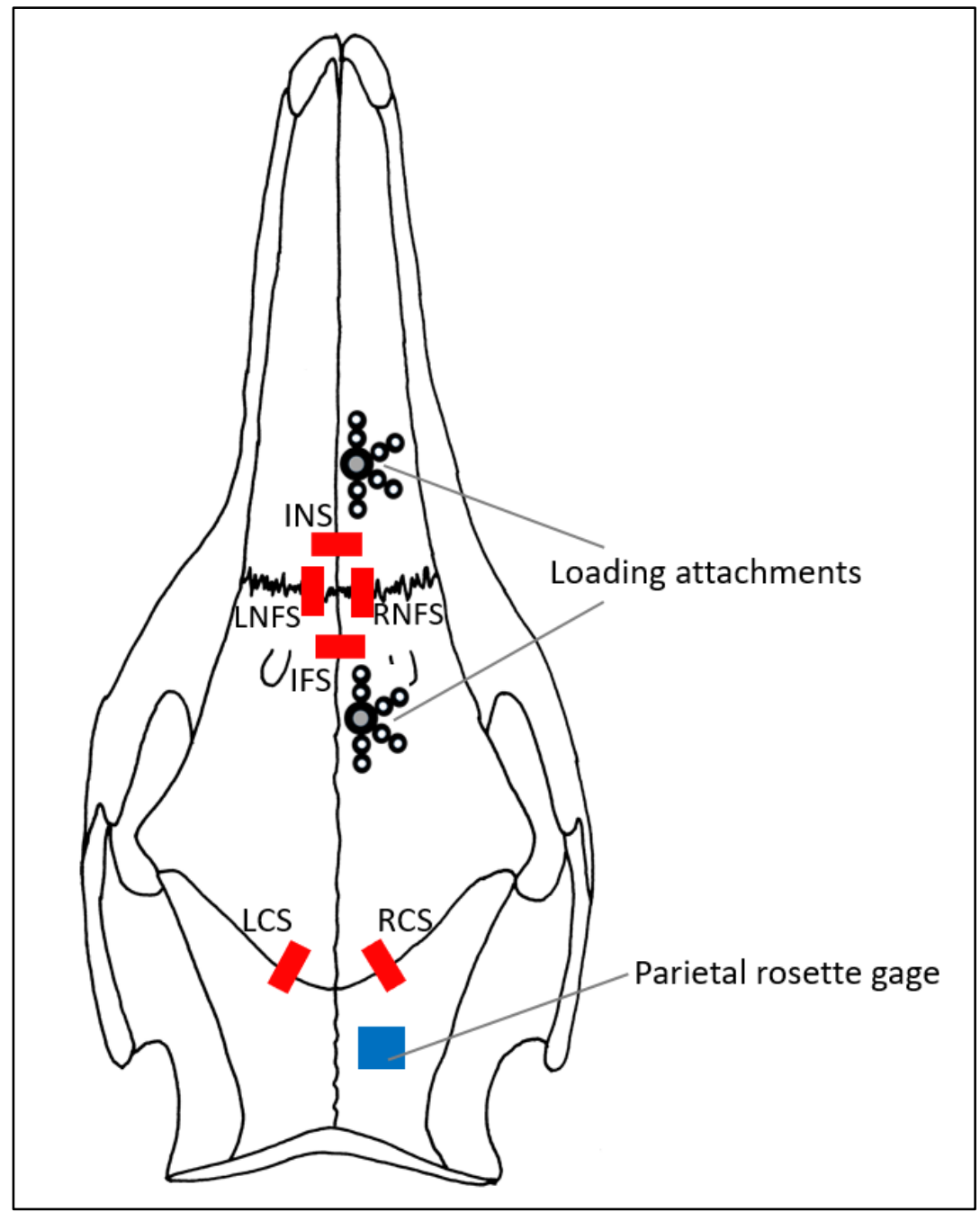


Figure 8B: Pictorial representation (not drawn to scale) of the approximate location of the sectioned samples. Medial sections (blue) were used for plastic-embedding and lateral sections (red) were used for paraffin-embedding in a follow-up study.

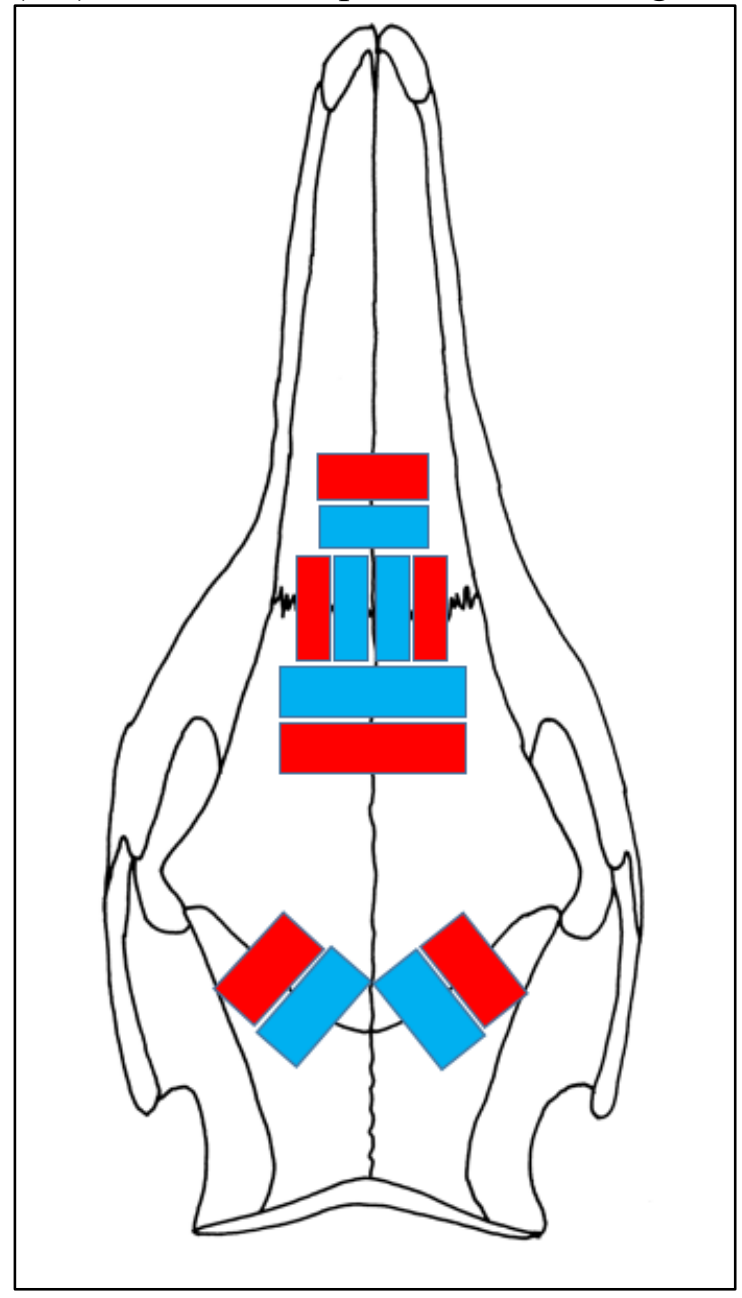


Figure 9: Entire interfrontal suture of Pig 3 under epifluorescent illumination, at 1x magnification. A: Double-labelled interfrontal suture. The first label was calcein (green) and the second label was alizarin complexone (red). B: Suture width highlighted in yellow. C: Newly mineralized bone on each side of the suture highlighted in magenta and blue. Scale bar $=993 \mu \mathrm{m}$.

A

B

C

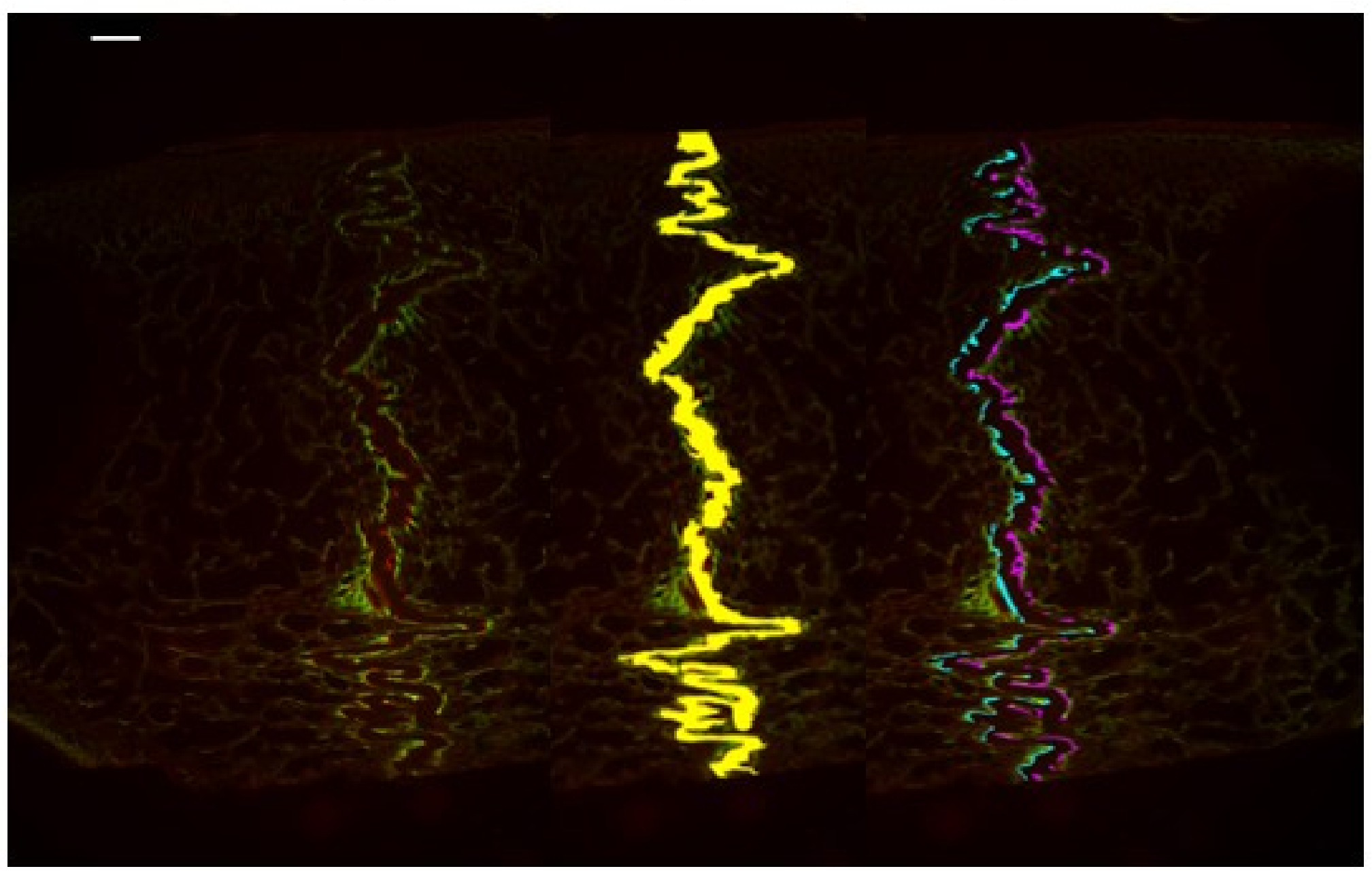


Figure 10: A segment of the interfrontal suture of Pig 3 under epifluorescent illumination, at $4 \mathrm{x}$ magnification. A: Double-labelled interfrontal suture. The first label was calcein (green) and the second label was alizarin complexone (red). B: Suture width highlighted in yellow. C: Newly mineralized bone on each side of the suture highlighted in magenta and blue. Scale bar $=974$ $\mu \mathrm{m}$.

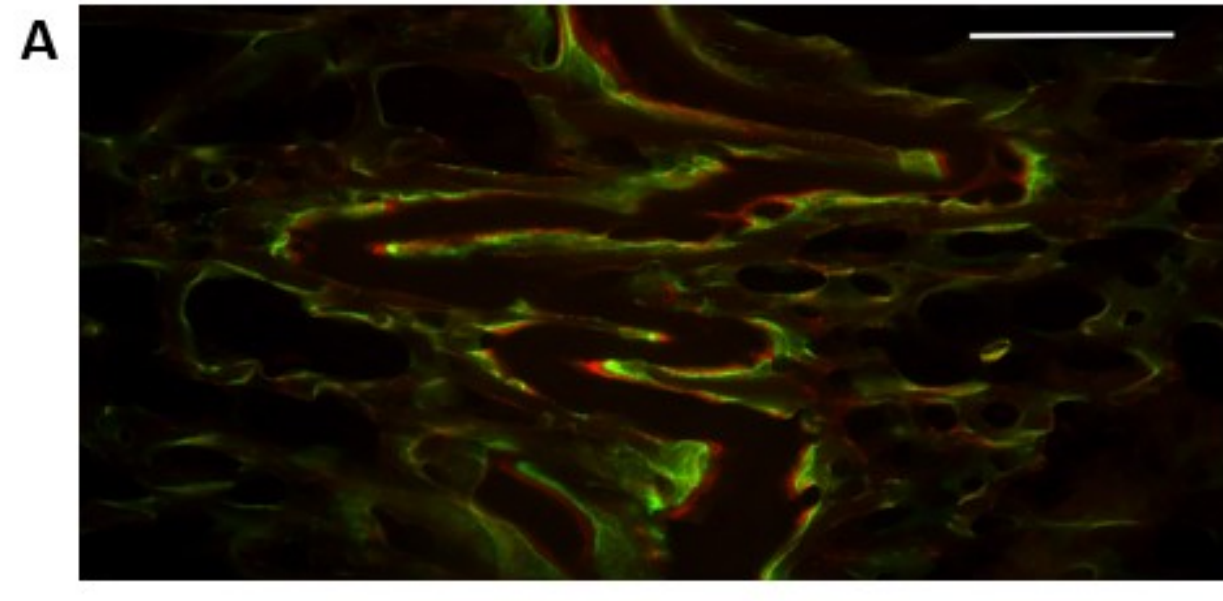

B

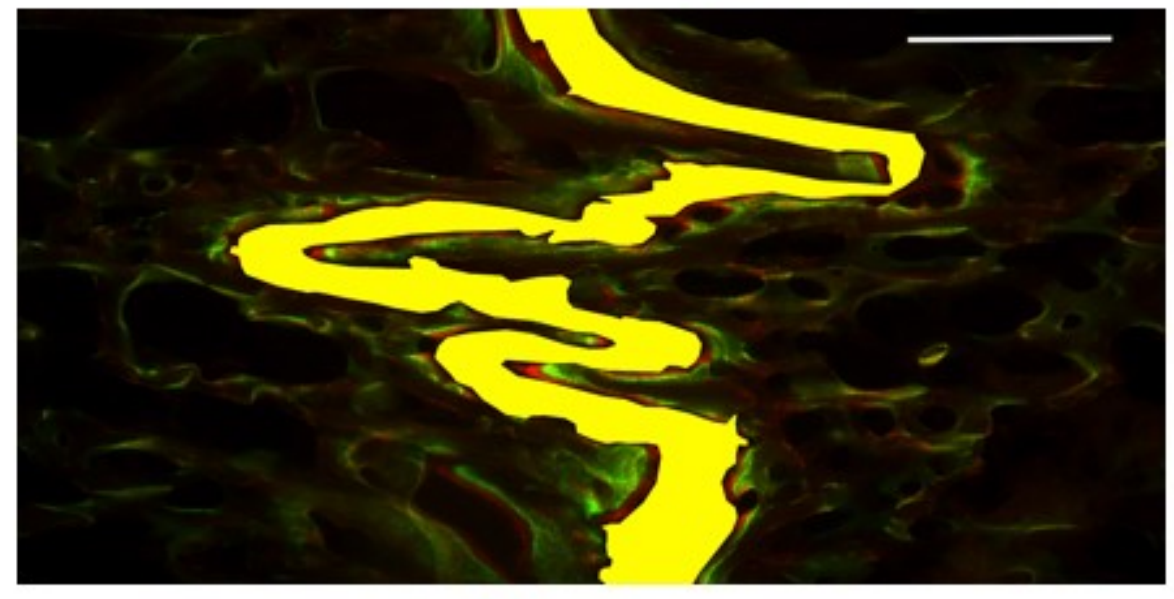

C

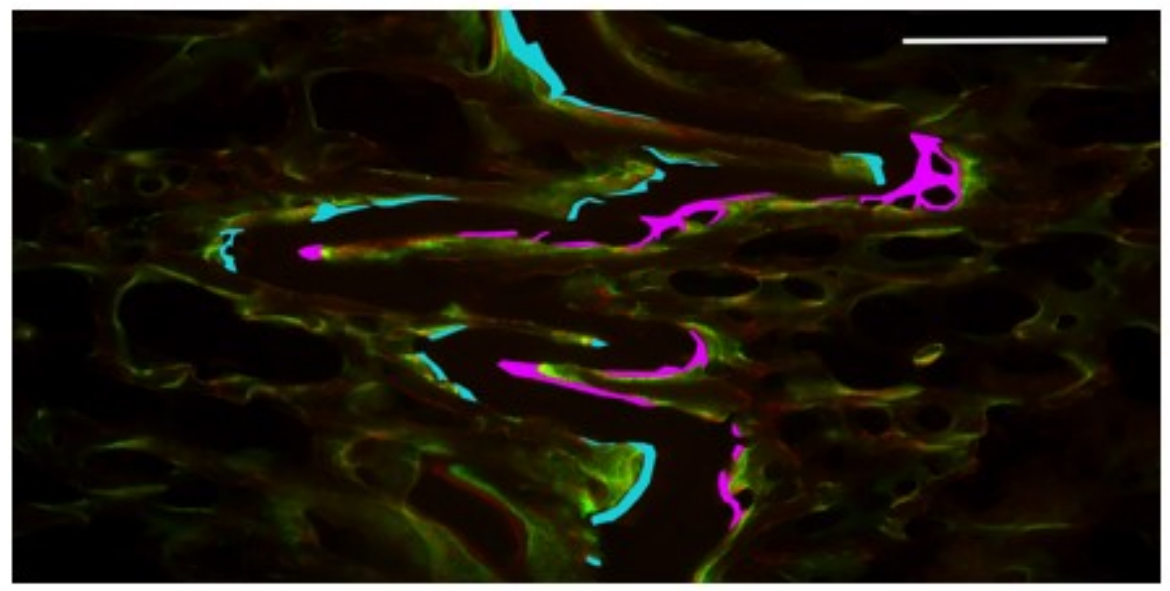


Figure 11: Strains on pig heads \#5-10
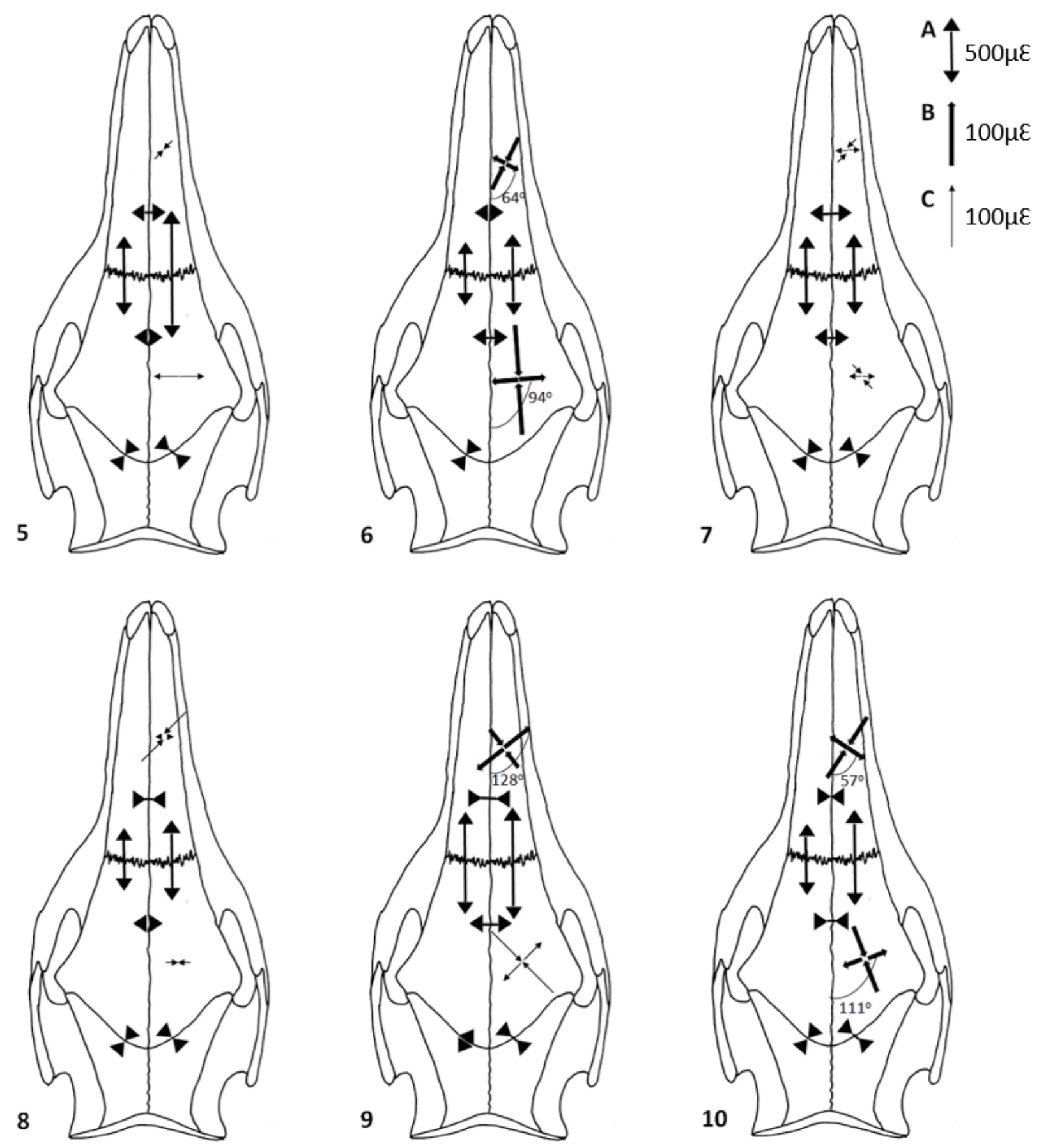

Tensile strains are indicated by divergent arrowheads and compressive strains by convergent arrowheads. Arrow A indicates strain data from the single-element strain gages; the linear bar represents $500 \mu \varepsilon$. Strain values were rounded off to the nearest $100 \mu \varepsilon$. Arrows B and C respectively indicate the rosette gage principal strains and strain data of the individual working elements when principal strains were indeterminate. The lengths of arrows B and $\mathrm{C}$ each represent $100 \mu \varepsilon$. Strain values were rounded off to the nearest $10 \mu \varepsilon$. The nasal bone principal strains of pig head \#10 were from the fourth 30-minute loading session. 
Figure 12: Overview of mean sutural strains and bone principal strain patterns across pig heads $\# 5-10$, excluding anomalous data (pig heads $\# 9$ and $\# 8$ for the nasal and frontal bone strains respectively)

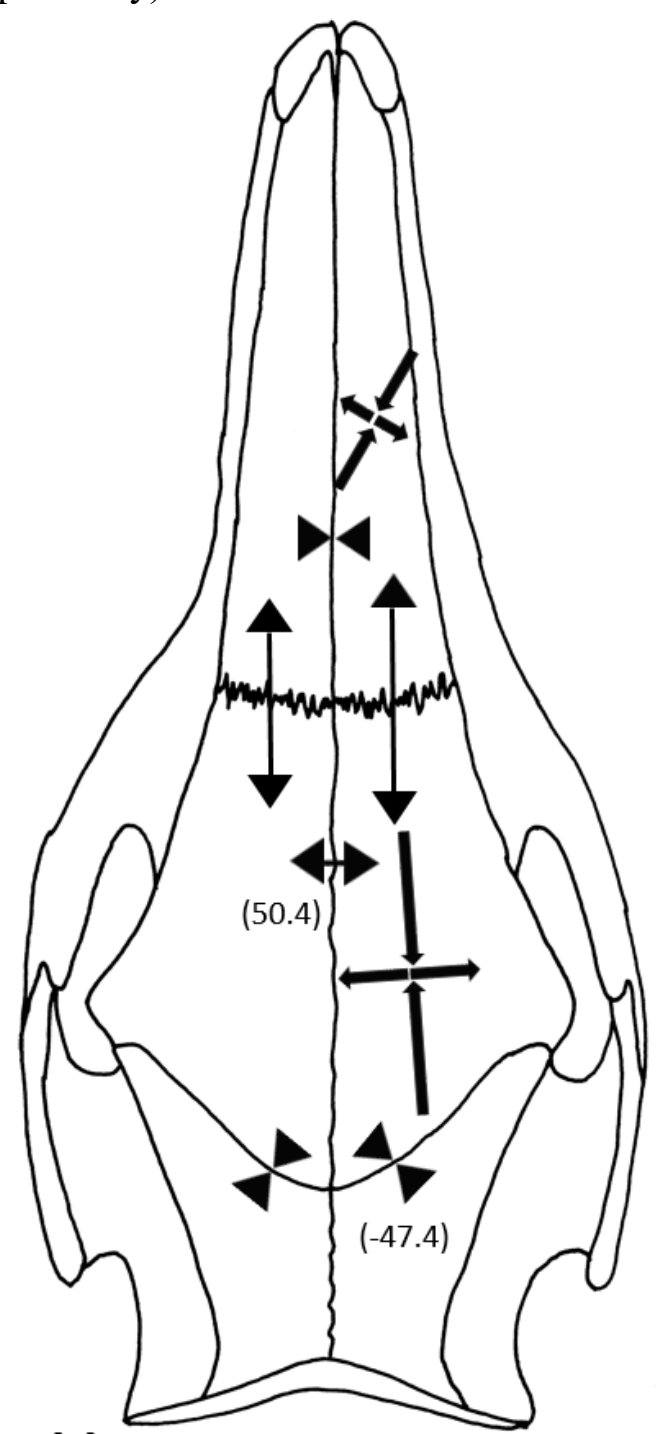

(I)

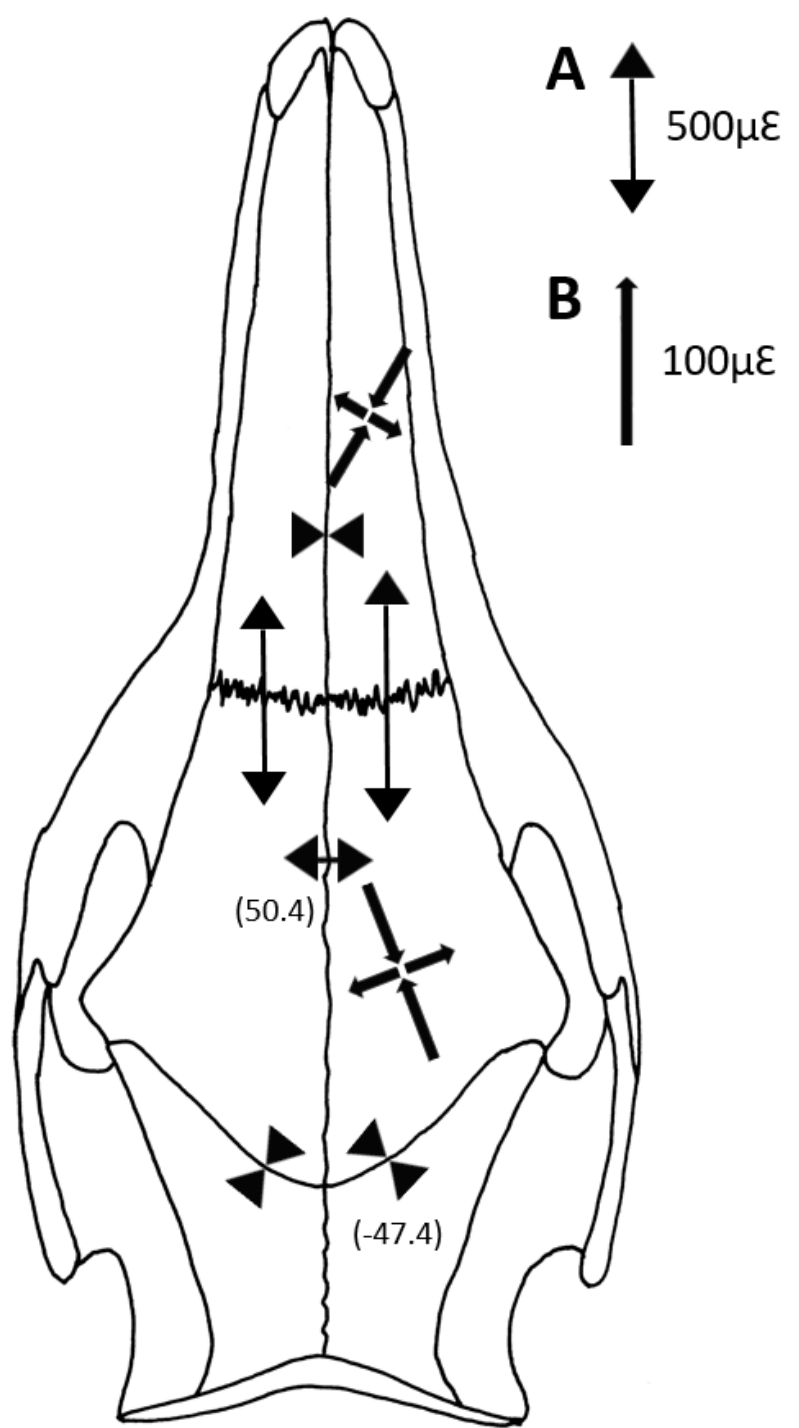

(II)

Tensile strains are indicated by divergent arrowheads and compressive strains by convergent arrowheads. Arrow A indicates strain data from the single-element strain gages; the linear bar represents $500 \mu \varepsilon$ and strain values were rounded off to the nearest $100 \mu \varepsilon$. Arrow B indicates the rosette gage principal strains; the length of arrow B represents $100 \mu \varepsilon$ and strain values were rounded off to the nearest $10 \mu \varepsilon$. Diagrams (I) and (II) illustrate two different general trends of principal strain orientation at the frontal bone. The frontal bone principal strains in (I) were from pig head \#6 and (II) from pig head \#10. The nasal bone principal strains in both diagrams were a mean of the nasal bone principal strains of pig heads \#6 and \#10, which showed minimal variation in principal strain orientation. Mean strain values (in $\mu \varepsilon$ ) for the interfrontal sutures and right coronal sutures are indicated in parentheses. 
Figure 13: Strains on Pigs 3-5
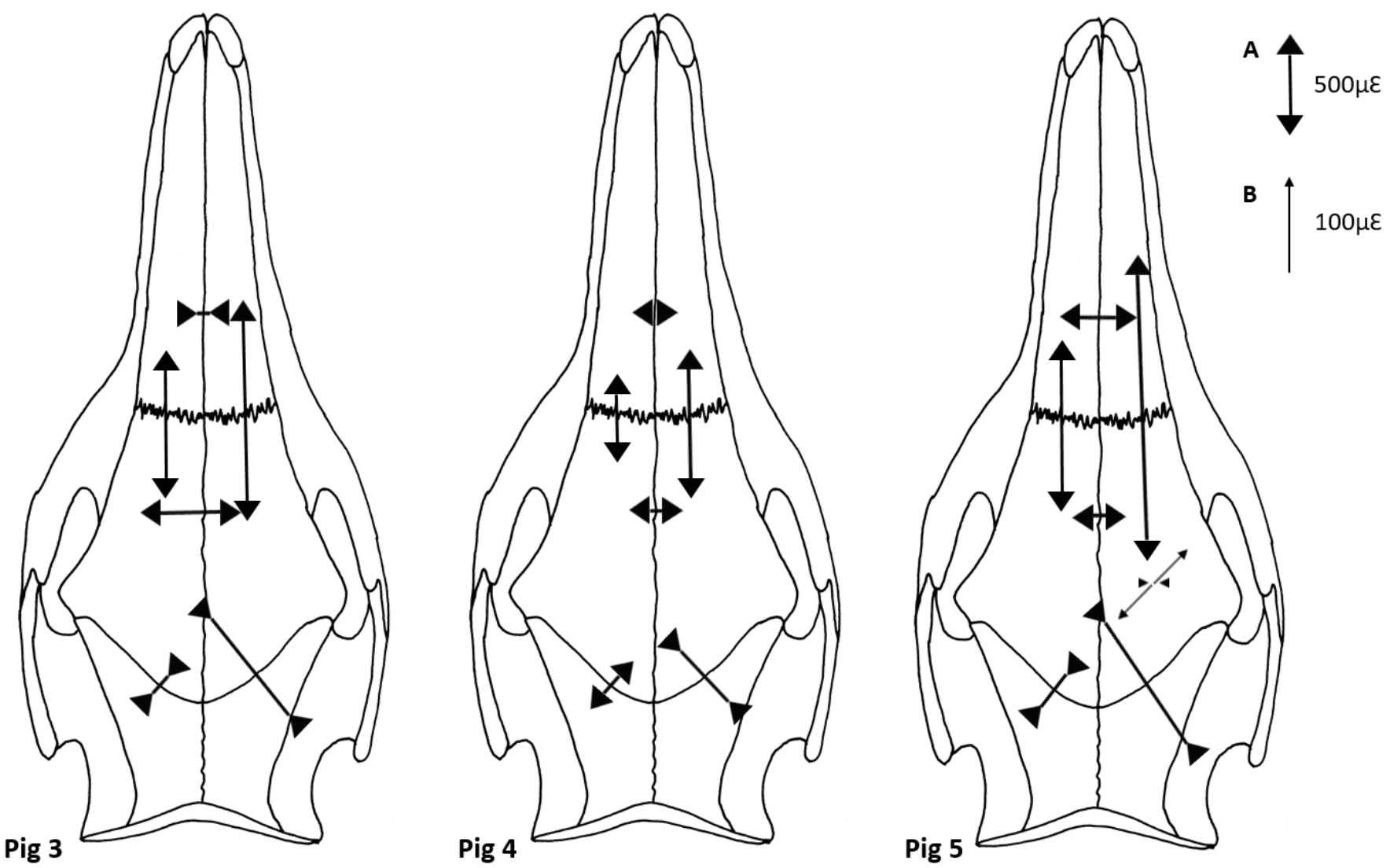

Tensile strains are indicated by divergent arrowheads and compressive strains by convergent arrowheads. Arrow A indicates strain data from the single-element strain gages; the linear bar represents $500 \mu \varepsilon$. Strain values were rounded off to the nearest $100 \mu \varepsilon$. Arrow B indicates strain data of the individual working elements when principal strains were indeterminate; the length of arrow B represents $100 \mu \varepsilon$. Strain values were rounded off to the nearest $10 \mu \varepsilon$. 
Figure 14: Double-labelled sutures of Pig 3 under epifluorescent illumination, at 1x magnification. The first label was calcein (green) and the second label was alizarin complexone (red). Scale bar $=993 \mu \varepsilon$. A: Right nasofrontal suture. B: Left nasofrontal suture. C: Right coronal suture. D: Left coronal suture. E: internasal suture. F: interfrontal suture.

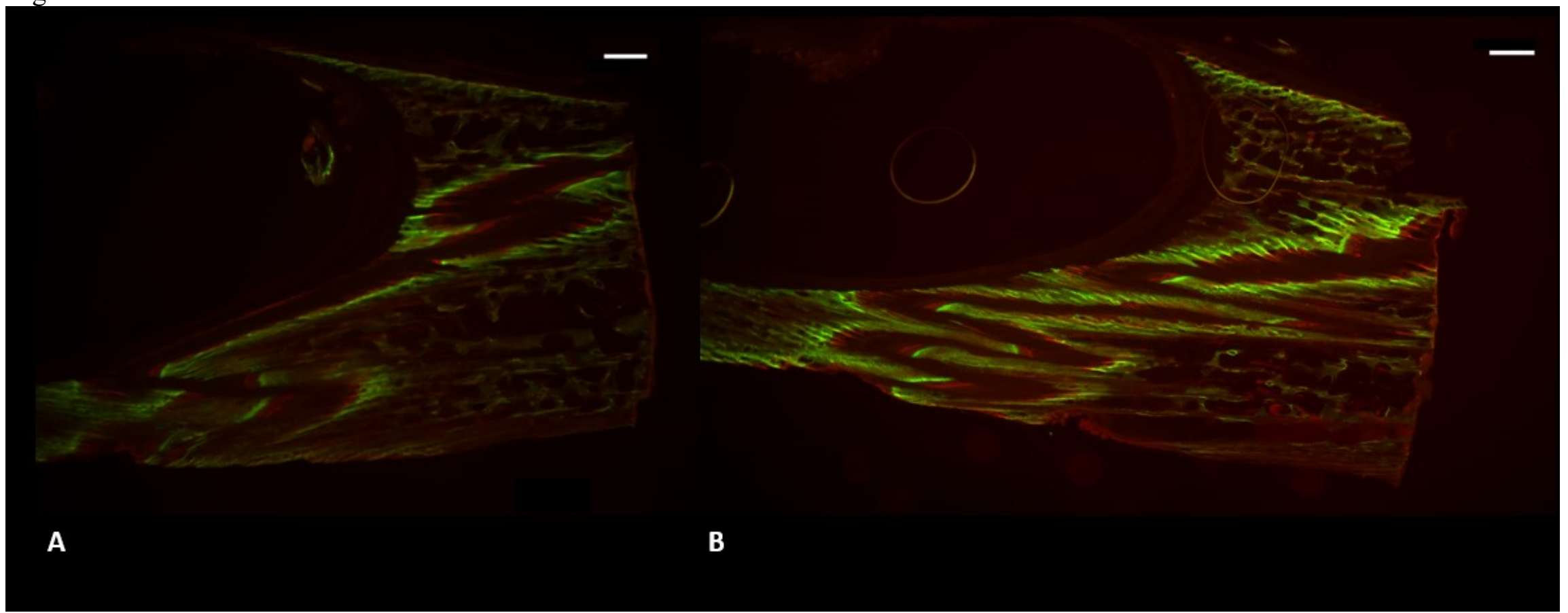




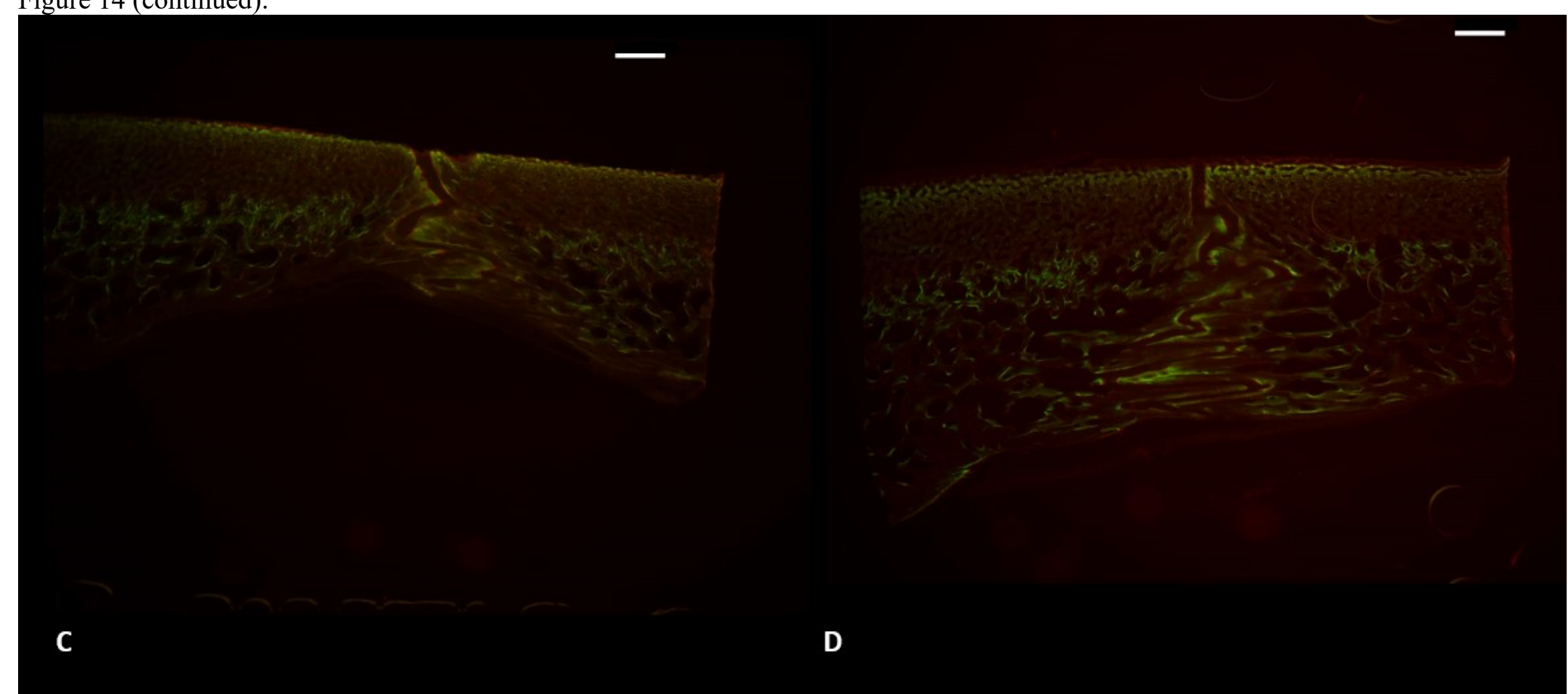




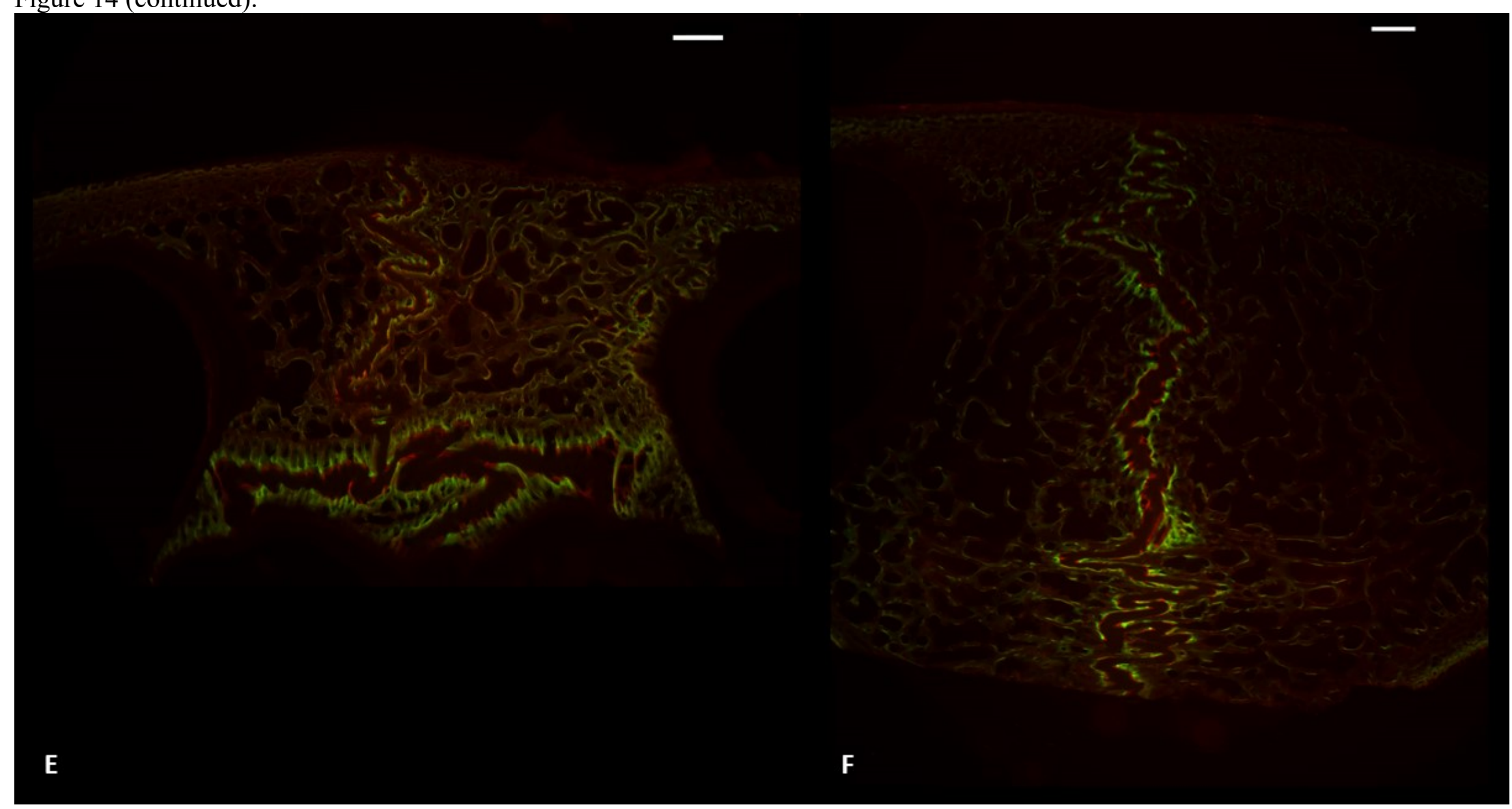


Figure 15: Graphs of A) suture width vs strain, B) MAR vs strain, C) MAR vs suture width, using data derived from Pigs 3 and 4

A)

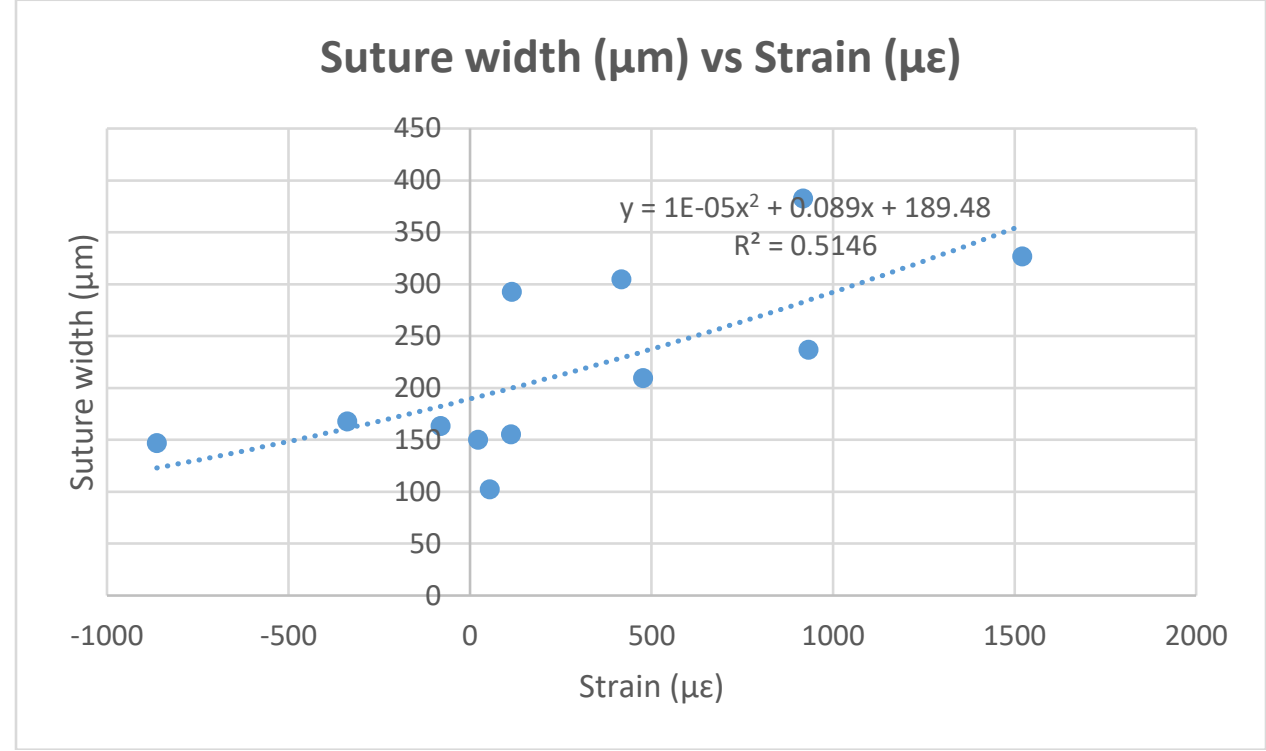

B)

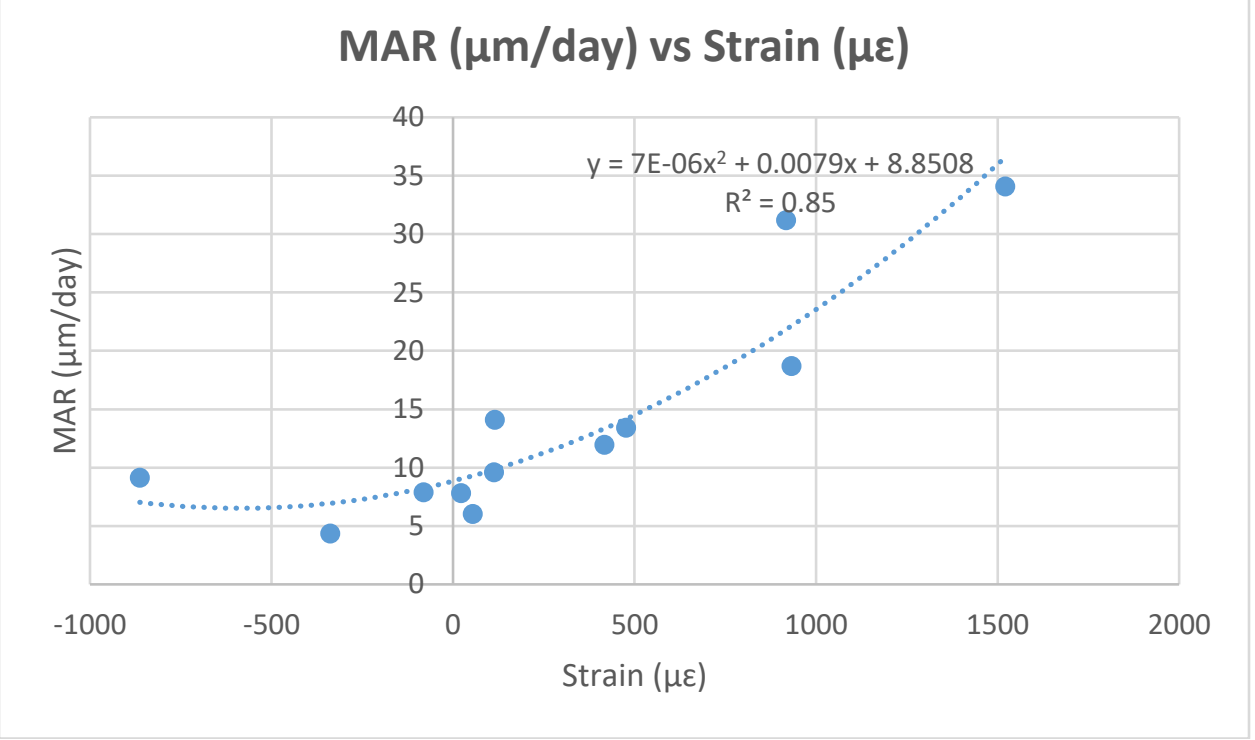


C)

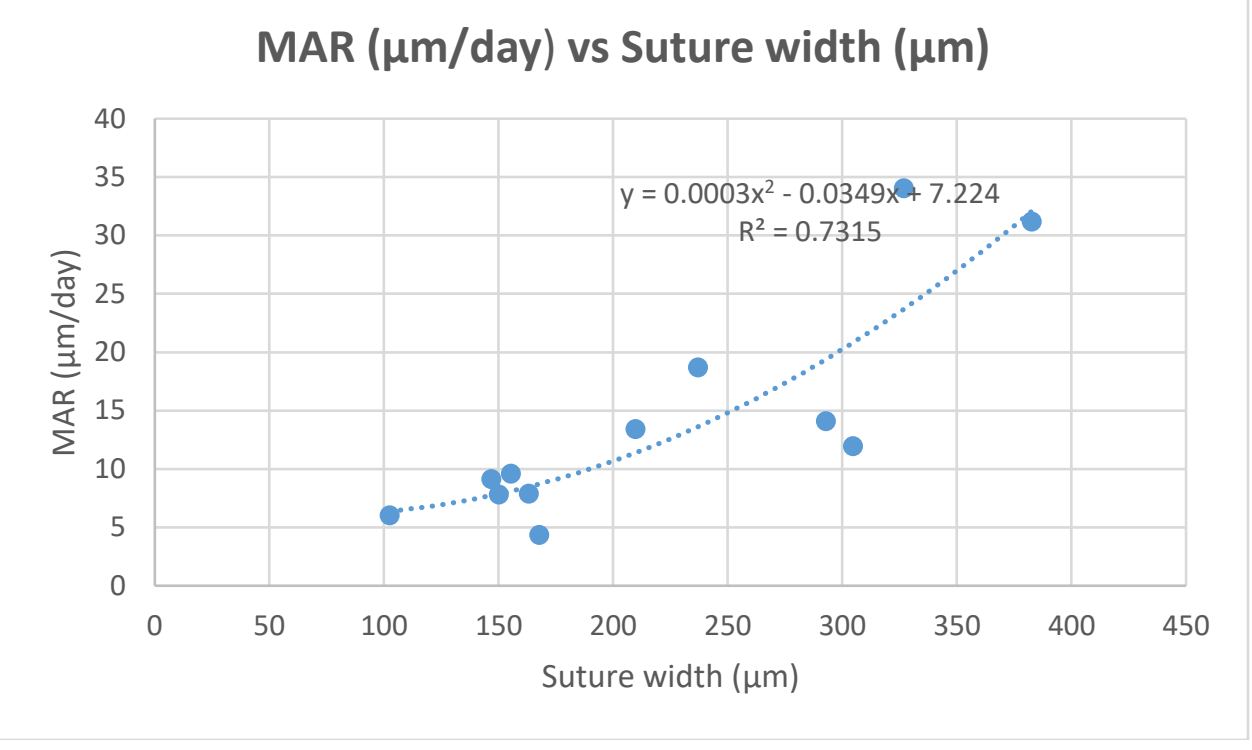


Figure 16: Graphs of A) suture width vs strain, B) MAR vs strain, C) MAR vs suture width, using data derived from Pig 3 only

A)

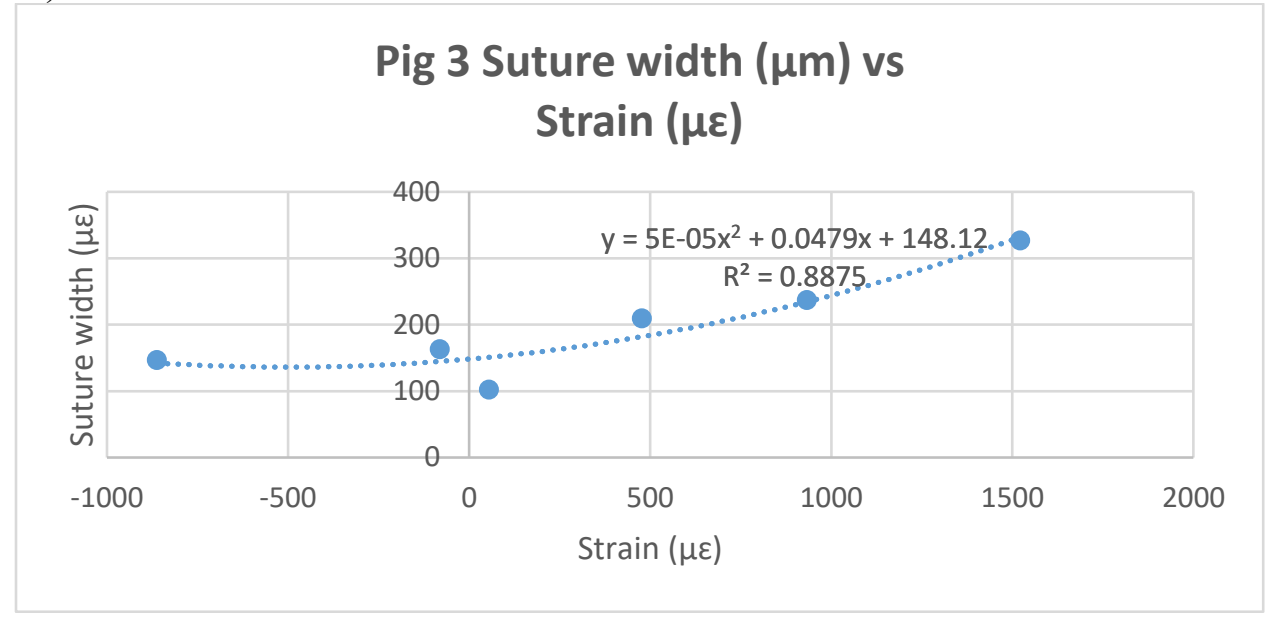

B)

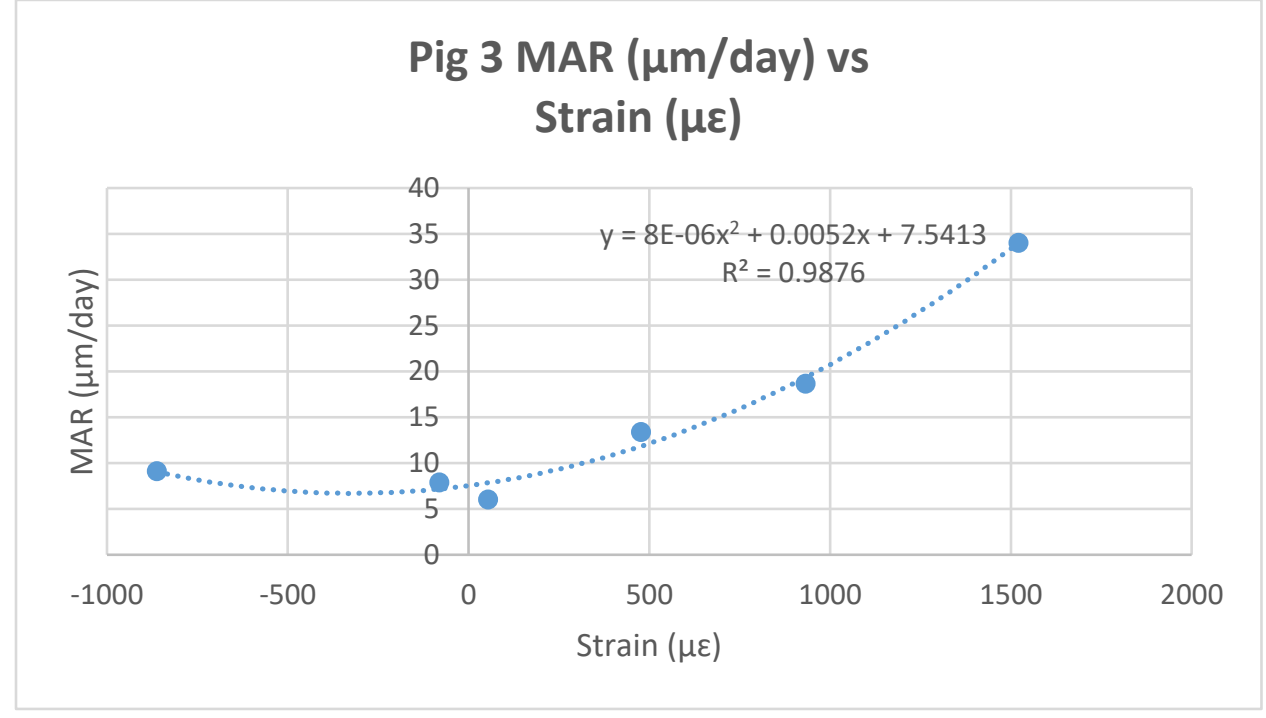


C)

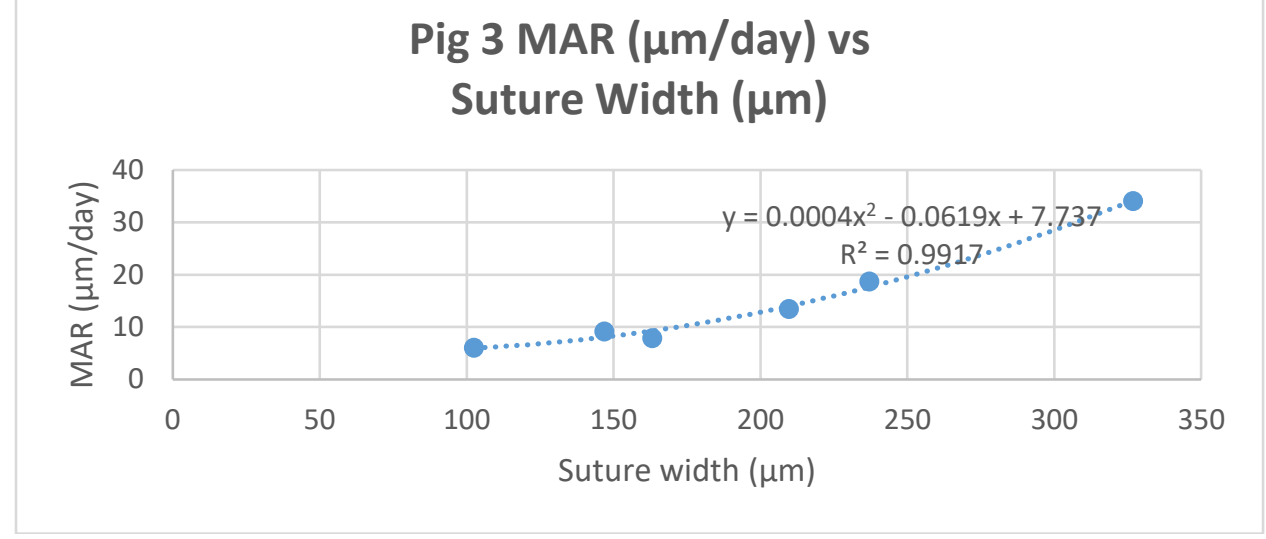


Figure 17: Graphs of A) suture width vs strain, B) MAR vs strain, C) MAR vs suture width, using data derived from Pig 4 only

A)

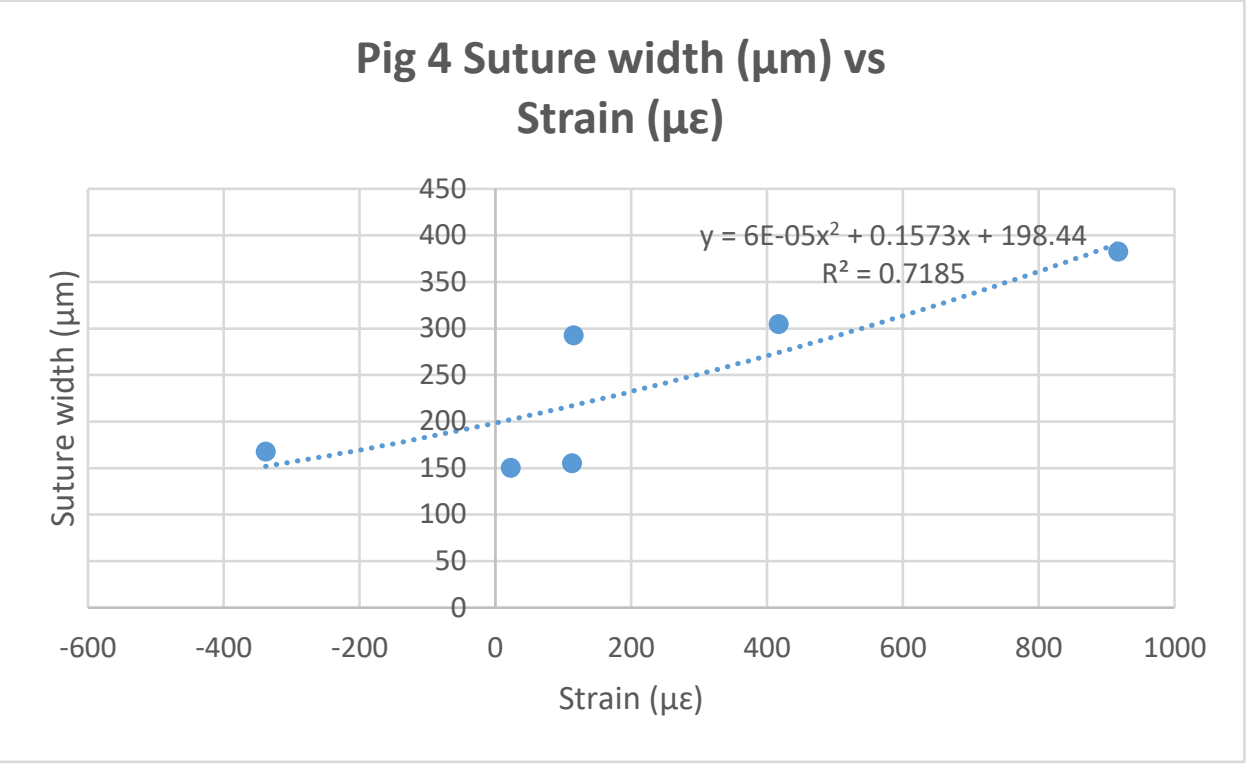

B)

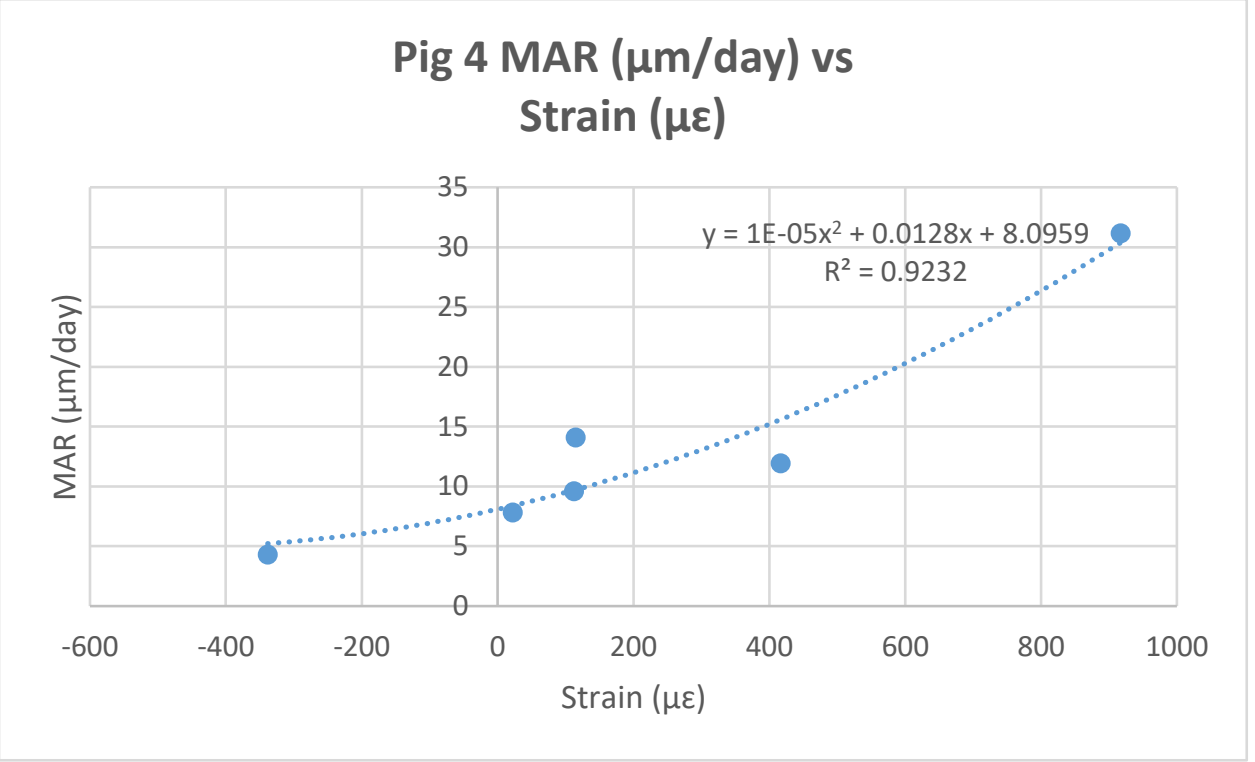


C)

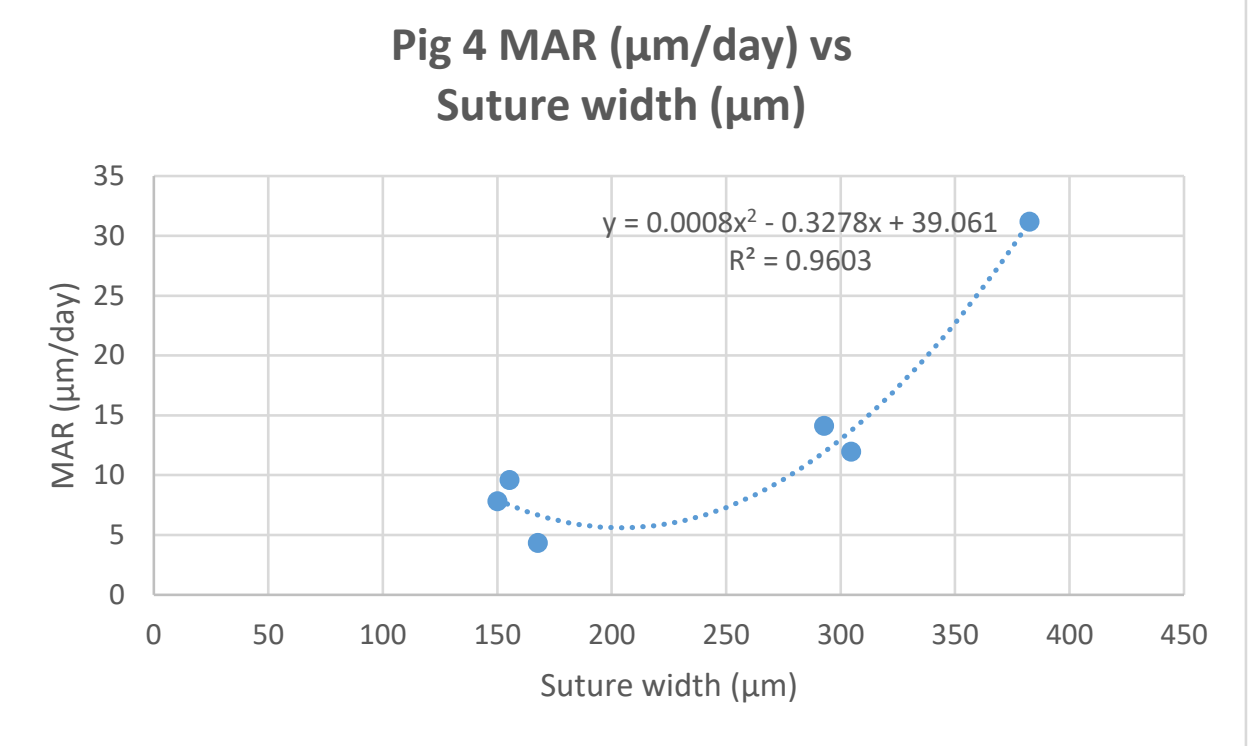


Figure 18: Comparison of in vivo and ex vivo strain magnitude

\section{Strain Magnitude In Vivo vs Ex Vivo}

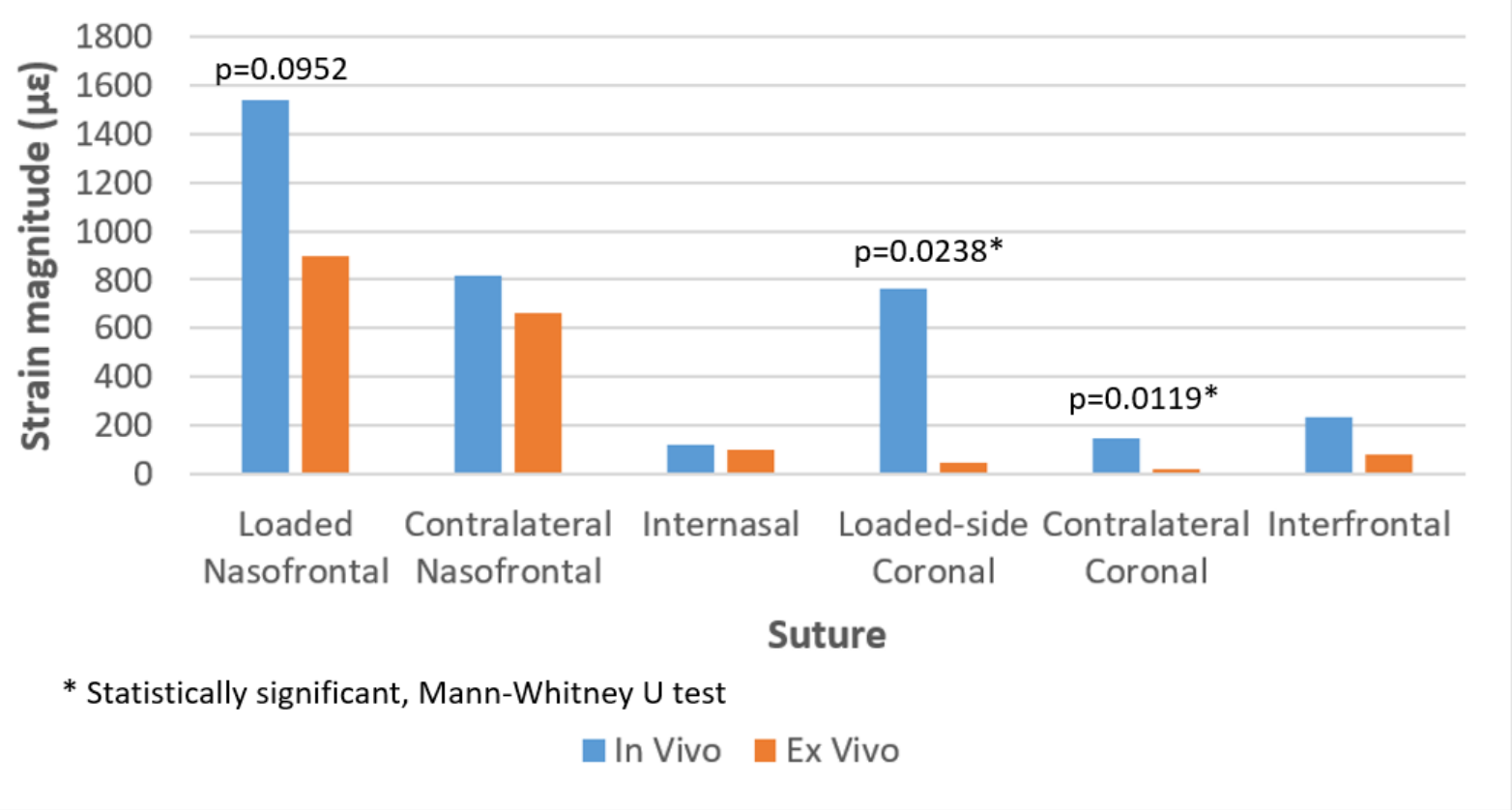

